THE EFFECTS OF LIGHTNING DISCHARGES ON

CONTROL \& COMMUNICATION CABLES AND ANTENNA SYSTEMS

A THESIS SUBMITTED TO

THE GRADUATE SCHOOL OF NATURAL AND APPLIED SCIENCES OF

MIDDLE EAST TECHNICAL UNIVERSITY

BY

ANIL CIVIL

IN PARTIAL FULLFILLMENT OF THE REQUIREMENTS

FOR

THE DEGREE OF MASTER OF SCIENCE

IN

ELECTRICAL AND ELECTRONICS ENGINEERING

DECEMBER 2014 

Approval of the thesis:

\section{THE EFFECTS OF LIGHTNING DISCHARGES ON CONTROL \& COMMUNICATION CABLES AND ANTENNA SYSTEMS}

submitted by ANIL CIVIL in partial fulfillment of the requirements for the degree of Master of Science in Electrical and Electronics Engineering Department, Middle East Technical University by,

Prof. Dr. Gülbin Dural Ünver

Dean, Graduate School of Natural and Applied Sciences

Prof. Dr. Gönül Turhan Sayan

Head of Department, Electrical and Electronics Engineering

Prof. Dr. Osman Sevaioğlu

Supervisor, Electrical and Electronics Engineering Dept., METU

Prof. Dr. Mirzahan Hizal

Co-supervisor, Electrical and Electronics Engineering Dept., METU

\section{Examining Committee Members:}

Prof. Dr. Ahmet Rumeli

Electrical and Electronics Engineering Dept., METU

Prof. Dr. Osman Sevaioğlu

Electrical and Electronics Engineering Dept., METU

Prof. Dr. Mirzahan Hizal

Electrical and Electronics Engineering Dept., METU

Prof. Dr. Muammer Ermiş

Electrical and Electronics Engineering Dept., METU

Mustafa Karagöz, M.Sc. in EEE

SST, ASELSAN

Date: $\quad \underline{03.12 .2014}$ 
I hereby declare that all information in this document has been obtained and presented in accordance with academic rules and ethical conduct. I also declare that, as required by these rules and conduct, I have fully cited and referenced all material and results that are not original to this work.

Name, Last name $\quad$ : $\quad$ Anıl Civil

Signature 


\title{
ABSTRACT \\ THE EFFECTS OF LIGHTNING DISCHARGES ON CONTROL \& COMMUNICATION CABLES AND ANTENNA SYSTEMS
}

\author{
Civil, An1l \\ M. S., Department of Electrical and Electronics Engineering \\ Supervisor: Prof. Dr. Osman Sevaioğlu \\ Co-supervisor: Prof. Dr. Mirzahan Hizal
}

December 2014, 63 pages

In this work, lightning discharges and their effects on control \& communication cables and antenna systems are investigated. The mechanism of lightning is described in detail and electric and magnetic fields created by lightning discharges are examined. An experimental test setup is designed and implemented in order to observe induced voltages on cables or antennas caused by lightning discharges. Test results are compared with each other and discussed in detail. Also, they are compared with theoretical findings. Effects of induced voltages on certain systems are studied. Moreover, some precautions to avoid the harmful effects of lightning are suggested.

Keywords: Lightning, lightning discharge, induced voltage, control cables, communication cables, antennas 


\title{
öz
}

\section{YILDIRIM DEŞARJLARININ KONTROL \& HABERLEŞME KABLOLARI VE ANTEN SISTEMLERİ ÜZERINE ETKİSI}

\author{
Civil, An1l \\ Yüksek Lisans, Elektrik Elektronik Mühendisliği Bölümü \\ Tez Yöneticisi: Prof. Dr. Osman Sevaioğlu \\ Ortak Tez Yöneticisi: Prof. Dr. Mirzahan Hızal
}

Aralık 2014, 63 sayfa

\begin{abstract}
Bu çalışmada, yıldırım deşarjları ve bu deşarjların kontrol ve haberleşme kabloları ve anten sistemleri üzerindeki etkisi araştırılmıştır. Yıldırım mekanizması detaylı bir şekilde anlatılmış ve yıldırım deşarjlarının oluşturduğu elektrik ve manyetik alanlar incelenmiştir. Yıldırım deşarjları sebebiyle kablolar ve antenler üzerinde endüklenen gerilimleri incelemek üzere bir test düzeneği tasarlanmış ve kurulmuştur. Test sonuçları ayrıntılarıyla incelenmiş ve birbirleriyle karşılaştırılmıştır. Ayrıca bu sonuçlar teorik bulgular ile karşılaştırılmıştır. Endüklenen gerilimlerin bazı sistemler üzerine etkileri anlatılmıştır. Ek olarak, yıldırımların oluşturduğu bu gerilimlerin zararlı etkilerinden kaçınmak için alınabilecek bazı tedbirler önerilmiştir.
\end{abstract}

Anahtar Kelimeler: Yıldırım, yıldırım deşarjları, endüklenen gerilimler, kontrol kabloları, haberleşme kabloları, antenler 
to my precious family... 


\section{ACKNOWLEDGEMENTS}

I would like to express my sincere thanks to my supervisor Prof. Dr. Osman Sevaioğlu and co-supervisor Prof. Dr. Mirzahan Hizal for his guidance, encouragement, suggestions and support throughout the thesis study.

I am also grateful to my thesis committee members Prof. Dr. Ahmet Rumeli, Prof. Dr. Muammer Ermiş and Mustafa Karagöz for their criticism and advices.

I wish to express my endless thanks to every member of my family, Neşe Civil, İsmet Civil, Onur Civil, Kübra Yolcu Civil and adorable Hira Civil for their unconditional love and support.

I would like to express my warmest thanks to Esra Erdem for her love, support and encouragement. It would be much harder to finish this work without her.

I am deeply grateful to Kemal Mert Gürbüz, Elçin Evran and Mert Tosun for their advices and wonderful friendships.

Special thanks to Emre Kantar, Yasin Çevik and Emre Boynuyoğun for their support and great friendships.

I would like to thank my friends Gökmen Cengiz, Can Görür, Barış Çiftçi, Murat Kayhan, Aycan Aydoğdu and Nadir Usluer for their support and encouragement. 
TABLE OF CONTENTS

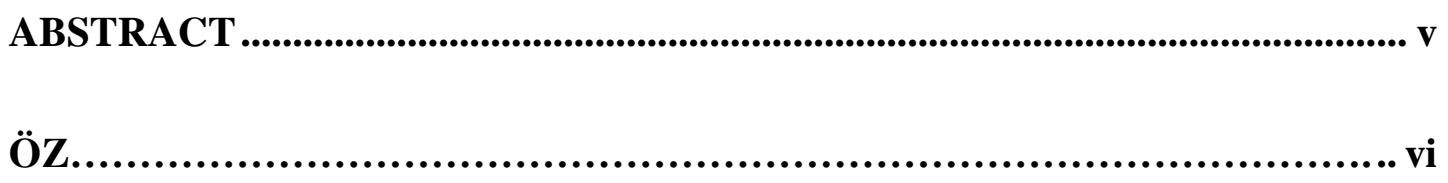

ACKNOWLEDGEMENTS..................................................................................... viii

TABLE OF CONTENTS.............................................................................................. ix

LIST OF TABLES …................................................................................................ $\mathrm{xi}$

LIST OF FIGURES ................................................................................................. xii

\section{CHAPTERS}

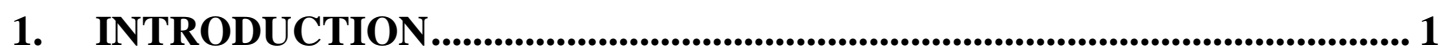

1.1. The Mechanism of Lightning .................................................................... 1

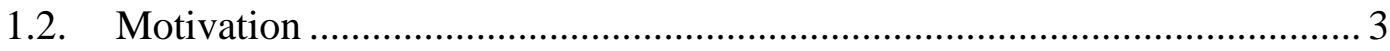

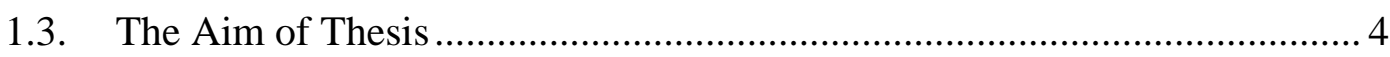

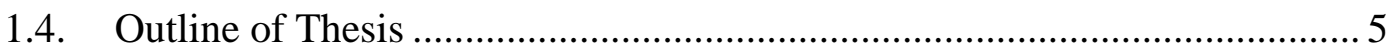

2. THE EFFECTS OF LIGHTNING DISCHARGES ON CONTROL AND COMMUNICATION CABLES........................................................................................ 7

2.1. Test Configuration.........................................................................

2.2. High Voltage Impulse Tests ................................................................. 10

2.2.1. When lightning strikes close to the cable............................................ 11

2.2.2. When lightning strikes directly the cable ............................................. 18 
2.2.3. Electric Field Measurements

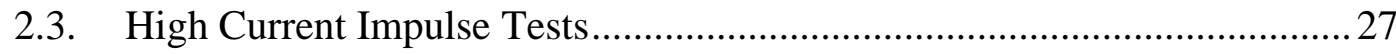

2.3.1. Indirect High Current Impulse Tests ................................................ 27

2.3.2. Direct High Current Impulse Tests .................................................... 32

\section{THE EFFECTS OF LIGHTNING DISCHARGES ON ANTENNA}

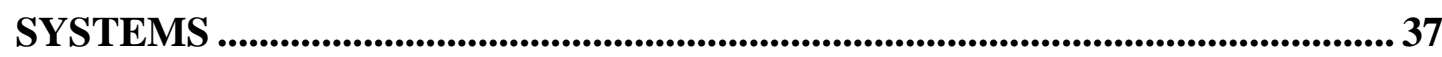

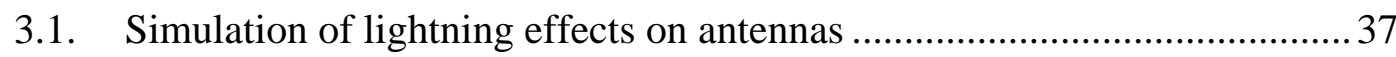

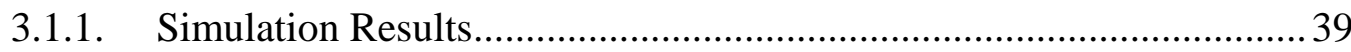

3.2. Lightning Impulse Voltage Tests ...................................................... 44

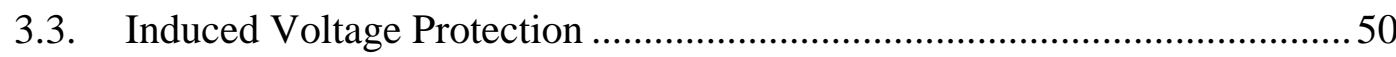

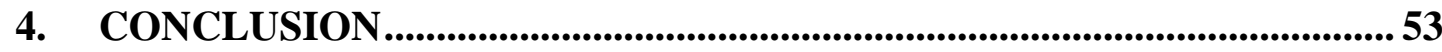

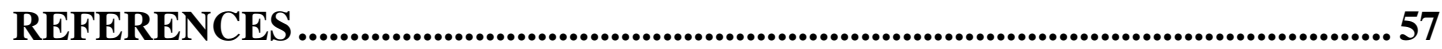

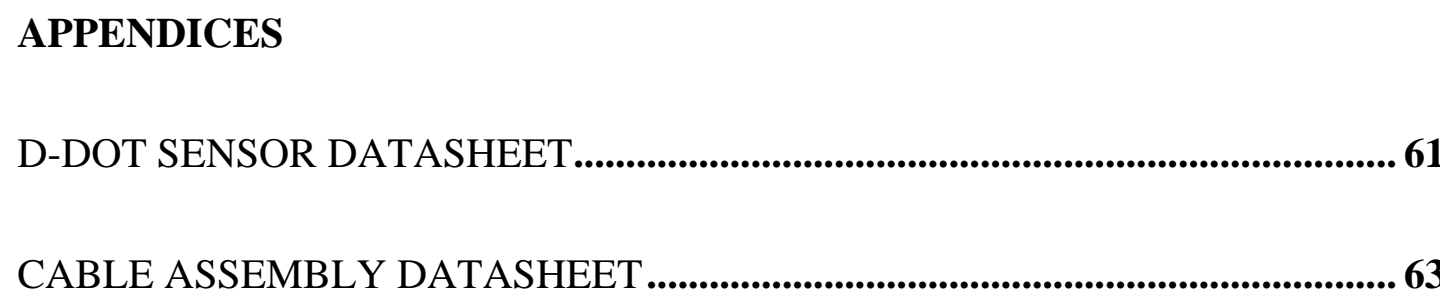




\section{LIST OF TABLES}

\section{TABLES}

Table 2-1 Induced voltage calculation coefficients .29

Table 2-2 Electromagnetic fields from near strike lightning 32

Table 2-3 Lightning indirect effects waveform characteristics. 32

Table 3-1 Total charges in the leader channel portions 39

Table 3-2 Total charges in the metal rod portions 40 


\section{LIST OF FIGURES}

\section{FIGURES}

Figure 1-1 Development of cloud-to-ground lightning flash (adapted from [3]) .........3

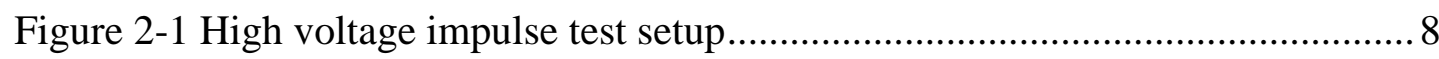

Figure 2-2 Structure of the high voltage impulse generator....................................

Figure 2-3 Structure of the current impulse generator .......................................... 10

Figure 2-4 Lightning impulse voltage waveform according to IEC 60060-1 (adapted

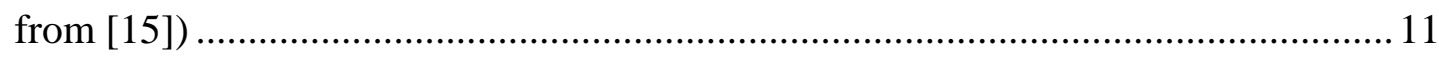

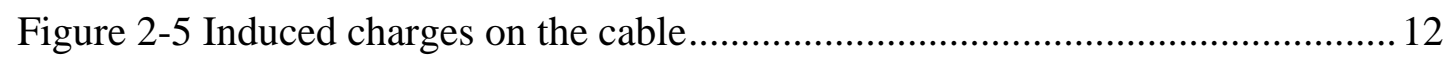

Figure 2-6 High voltage impulse test setup........................................................ 13

Figure 2-7 Transfer impedance parameters......................................................... 13

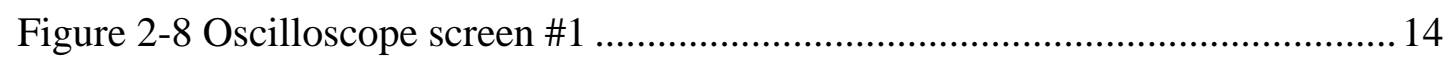

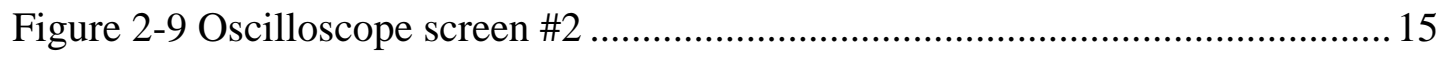

Figure 2-10 Oscilloscope screen \#3 …............................................................ 15

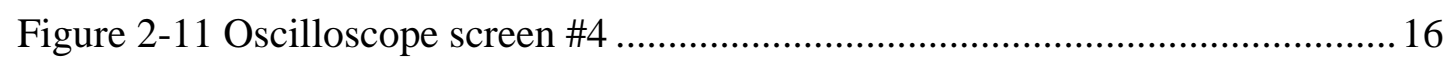

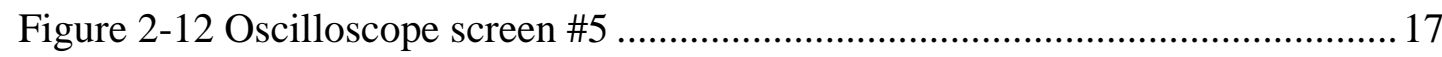

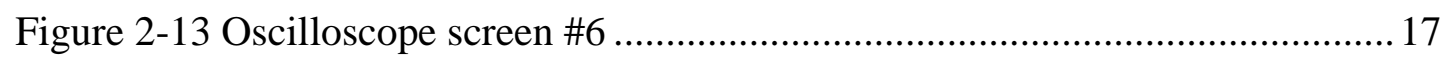

Figure 2-14 Test setup of direct high voltage impulse test .................................. 19

Figure 2-15 Test setup of direct high voltage impulse test ................................... 19 
Figure 2-16 Oscilloscope screen \#7

Figure 2-17 Oscilloscope screen \#8

Figure 2-18 D-dot sensor (adapted from [23])

Figure 2-19 D-dot sensor connection diagram (adapted from [22])

Figure 2-20 Equivalent circuit for D-dot sensor (adapted from [22]).

Figure 2-21 Noise on sensor cable

Figure 2-22 Output voltage of D-dot sensor 24

Figure 2-23 Measured electric fields 26

Figure 2-24 Lightning impulse current waveform according to IEC 60060-4-5 (adapted from [15])

Figure 2-25 Sensor used to measure time derivative of magnetic field 28

Figure 2-26 Current impulse noise measurement test setup 29

Figure 2-27 Current impulse noise. 30

Figure 2-28 Vertical magnetic field measurement test setup. 30

Figure 2-29 Vertical magnetic field measurement 31

Figure 2-30 Horizontal magnetic field measurement 31

Figure 2-31 High current impulse test setup

Figure 2-32 Impulse current wave 34

Figure 2-33 Oscilloscope screen \#9 35

Figure 2-34 Oscilloscope screen \#10 35 
Figure 2-35 Damaged cable 36

Figure 3-1 Simulation geometry 40

Figure 3-2 Voltage due to the charges in the metal rod 41

Figure 3-3 Electric field due to the charges in the metal rod 41

Figure 3-4 Induced voltage on $70 \mathrm{~cm}$ antenna which is $2.5 \mathrm{~m}$ far away from the metal $\operatorname{rod}$ 42

Figure 3-5 Induced voltage on $40 \mathrm{~cm}$ antenna which is $2.5 \mathrm{~m}$ far away from the metal $\operatorname{rod}$ 42

Figure 3-6 Induced voltage on $20 \mathrm{~cm}$ antenna which is $2.5 \mathrm{~m}$ far away from the metal $\operatorname{rod}$ 43

Figure 3-7 Induced voltage on $20 \mathrm{~cm}$ antenna which is $5 \mathrm{~m}$ far away from the metal $\operatorname{rod}$ 43

Figure 3-8 Induced voltage on $20 \mathrm{~cm}$ antenna which is $7.5 \mathrm{~m}$ far away from the metal $\operatorname{rod}$ 44

Figure 3-9 High voltage impulse test setup 45

Figure 3-10 High voltage impulse test setup 45

Figure 3-11 High voltage impulse test setup 46

Figure 3-12 Induced voltage on $20 \mathrm{~cm}$ antenna 47

Figure 3-13 Induced voltage on $40 \mathrm{~cm}$ antenna .48

Figure 3-14 Induced voltage on $70 \mathrm{~cm}$ antenna 48

Figure 3-15 Induced voltage on $20 \mathrm{~cm}$ antenna 49 
Figure 3-16 Induced voltage on $20 \mathrm{~cm}$ antenna

Figure 3-17 Induced voltage when there is no protection..................................... 51

Figure 3-18 Induced voltage with 3.3V zener diode ........................................... 51

Figure 3-19 Induced voltage with 5.6V zener diode ............................................5

Figure 3-20 Induced voltage with 5.6V varistor ............................................... 52

Figure 4-1 Lightning protection examples for control and communication cables ... 55 


\section{CHAPTER 1}

\section{INTRODUCTION}

\subsection{The Mechanism of Lightning}

Lightning is an electrostatic discharge between the electrically charged cloud and the earth surface. It is a natural phenomenon that can be very harmful. This dangerous incident occurs in the atmosphere 40-50 times in a second or nearly 1.4 billion times per year [1]. Therefore, it is an important phenomenon which must be investigated. It is not possible to examine lightning effects without analyzing the mechanism of lightning. Detailed information about each step of the mechanism of lightning is given below.

Strong winds are generated due to temperature variations in the atmosphere. Water droplets in the air are electrified by friction due to these strong winds. This electrification yields charge centers in the clouds. Positive charge centers are at the top and negative charge centers are at the bottom of the cloud [2]. Positive charges in the cloud are separated from the negative charges by strong winds. A positive charge center in a cloud may come close to a negative charge center in another cloud yielding cloud-to-cloud lightning which is beyond the scope of the thesis.

An ionized air channel is initiated from a negatively charged region in the thundercloud. This channel is called the leader channel. It is a conductive channel of partially ionized gas. Leader channels travel away from densely charged regions. Negatively charged leaders proceed towards the earth. These leaders usually split and form branches in a tree-like pattern [18]. Moreover, they travel in discrete steps. As the channel grows longer, its resistance increases. As a result, sufficient amount of negative charge cannot flow through the channel. Electric field decreases and ionization stops at this point. As time goes on, electrons accumulate at the tip, electric field increases, ionization starts again and the leader channel advances 
another step [14]. Photo ionization in the vicinity leads branching in the leader channel.

When a stepped leader approaches the ground, the presence of opposite charges on the ground enhances the strength of the electric field. The electric field is strongest on grounded objects whose tops are closest to the base of the thundercloud and who have sharp tips that results in electric field densification, such as tall buildings and trees. If the electric field is high enough, a positively charged ionic channel, called a positive or upward streamer, can develop from these points. As a downward leader connects to an initiated upward discharge, a low-resistance path is formed and a very strong discharge takes place. Once this path connects the ionized air between the positive surface charges and the negative charges in the cloud, a very high current of positive charges flows through the ionic channel towards the thundercloud. This is called the return stroke. This is the most visible part of the mechanism of lightning. This first stroke is followed by several secondary strokes. Once a negative charge center is neutralized, charge distribution in the cloud changes. Another negative charge center which is present in a nearby cloud moves towards the channel. This negative charge center is neutralized by another stroke. This huge flow of charge between the earth and the cloud heats the surrounding air, yielding an explosive expansion of the air which causes a shockwave and a loud noise which is called thunder. 


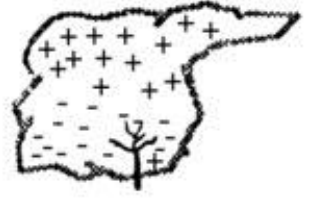

Stepped

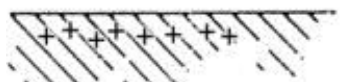

$\mathrm{t}=1.0 \mathrm{~ms}$

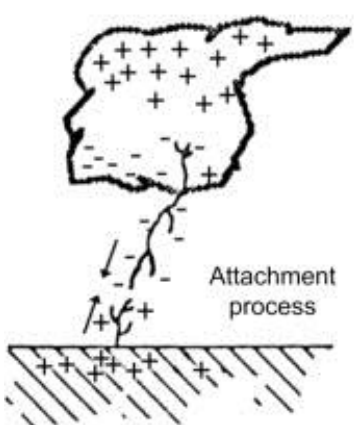

$20.00 \mathrm{~ms}$

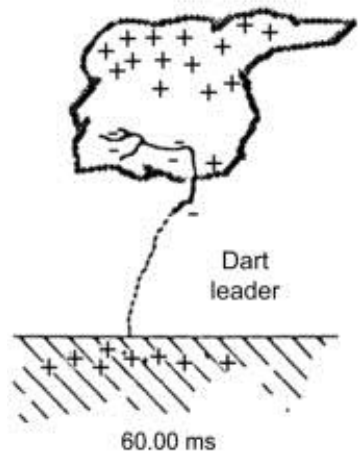

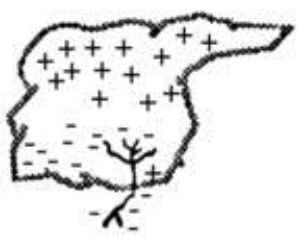

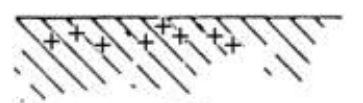

$1.2 \mathrm{~ms}$

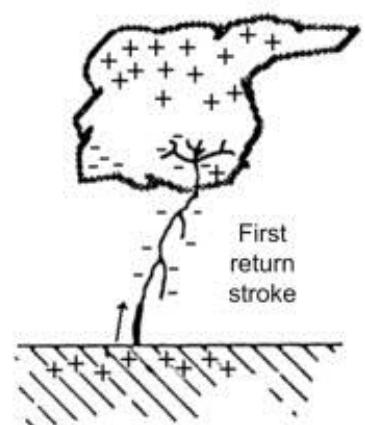

$20.10 \mathrm{~ms}$

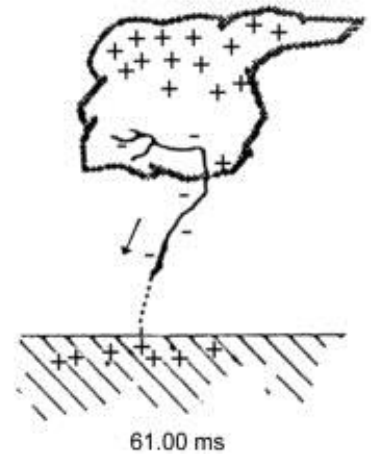

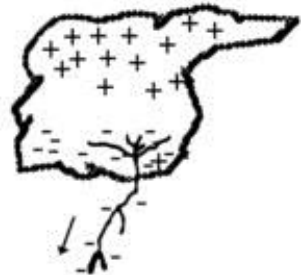
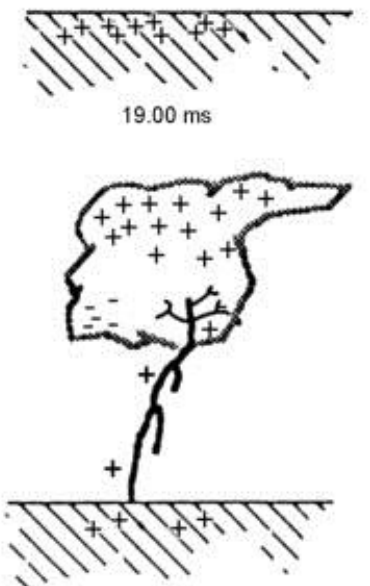

$20.20 \mathrm{~ms}$

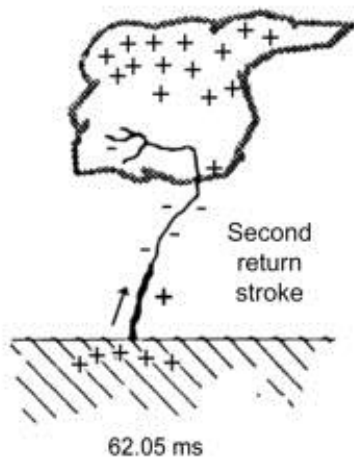

Figure 1-1 Development of cloud-to-ground lightning flash (adapted from [3])

\subsection{Motivation}

Lightning has some direct effects to the point it strikes. Due to its high voltage impulse characteristics, lightning causes electrical breakdowns on the material. The material is damaged thermally as well. It leads to burnt and darkened areas at the place it hits. In addition, as lightning current flows through impedances like cables, a potential difference is generated on it that causes the insulation material to breakdown. If lightning current flows through a tree or a building, animals or people around may be harmed due to this potential difference. 
Lightning has also indirect effects that are the main focus of this thesis. Lightning discharge causes rapidly changing electric and magnetic fields that result in electromagnetic pulse (EMP). EMP can cause permanent or temporary damages. It can harm integrated circuits and some electronic equipment on electronic devices like computers. Lightning impulse occurs in microseconds which mean electromagnetic waves that have a frequency in the order of $\mathrm{MHz}$ are generated. Consequently, these electromagnetic waves interrupt the antenna systems.

Power systems can also be affected by lightning strikes. There are a lot of examples of lightning strikes that results in power outages. The most notable power outage is the one in New York City in July, 1977. A lightning strike caused a nuclear power plant to shut down. A second lightning strike led two important transmission lines to knock out. These incidents resulted in 26 hours of power loss affecting nine million people [4]. This power loss yielded looting and vandalism. Studies show that this damage cost about $\$ 300$ million [5].

In this study, direct or indirect lightning hit experiments are conducted and outcomes are analyzed.

\subsection{The Aim of Thesis}

Lightning is an everyday phenomenon which has direct and indirect effects for electronic systems. A typical lightning can have millions of volts and amperes of $\leq 200 \mathrm{kA}$ [8], [14]. It is well known that as an object is hit by lightning it is damaged electrically and thermally. If this object is an electrical cable or an antenna, as in the experiments, the system which is connected to this cable or antenna is subjected to very large amount of voltages. In this case, there is not so much thing to protect the electrical system. Some experiments are conducted in order to analyze this case. However, it is not the main focus of this thesis. Indirect lightning strikes and their effects on electrical systems are the main interest of ours. Academic researches about indirect lightning effects are given and compared to the experimental results throughout the thesis. Induced voltage levels are discussed to verify whether they are harmful for electrical systems. 
In order to completely analyze lightning effects; one must deeply study the mechanism of lightning because lightning is a very complex phenomenon. Since, we put emphasis on the induced voltages caused by indirect lightning; the parts of the mechanism of lightning that result in induced voltages must be focused. The induced voltage caused by indirect lightning hit has mainly two components:

1) The charges in the clouds and mostly in the leader channel induce charges on the cables and antennas. As the charges in the leader channel are neutralized by the return stroke, these bound charges are released yielding travelling waves. Detailed information about this phenomenon is given in 2.2.1. In order to observe and test these electrostatically induced voltages, high voltage impulses are applied to the cables and antennas.

2) The rate of change of current in return stroke creates a magnetically induced voltage. High current impulses are applied to the cables in order to analyze magnetically induced voltage.

\subsection{Outline of Thesis}

This section gives brief information about the topics covered and the thesis chapters. Starting with this chapter, the mechanism of lightning is introduced and a problem definition is made. Motivation for choosing the topic is also explained. Importance of lightning effects on cables and antennas are discussed. In addition, the aim of this work is stated and the reason for choosing this topic is remarked.

Chapter 2 provides the theoretical analysis and test results about lightning discharge effects on control and communication cables. High voltage and high current impulses are applied directly and indirectly to the cables. Their results and possible effects to the electrical systems are discussed in this chapter. Theoretical analysis and test results are also compared.

Chapter 3 details indirect effects of lightning on antenna systems. High voltage impulses are applied indirectly to antennas and their effects are discussed in this chapter. Induced voltages due to charges on leader channel of lightning are 
examined. Their possible effects to the electrical system are studied. Some protection equipment is suggested to effectively clip off the induced voltage.

Finally, in Chapter 4, the thesis is concluded with a summary of the work done. The reasons to choose the topic of the thesis are detailed and the contributions of this study are explained. Moreover, the precautions for induced voltages caused by lightning discharges are illustrated. 


\section{CHAPTER 2}

\section{THE EFFECTS OF LIGHTNING DISCHARGES ON CONTROL AND COMMUNICATION CABLES}

Electrical systems are connected with cables. Therefore, induced voltages on these cables directly affect the systems. In order to analyze the induced voltages, lightning impulses are applied directly or indirectly to these cables. Moreover, theoretical analysis and test results are compared. Details are given in the following sections.

\subsection{Test Configuration}

High voltage and high current impulse experiments are conducted in order to investigate high electric fields, high magnetic fields and electromagnetic field effects generated by lightning discharges.

The voltage impulses used in the tests are generated by a multi-level voltage impulse generator (8 levels, $1000 \mathrm{kV}$, and $30 \mathrm{~kJ})$. This generator is charged with $(-80 \mathrm{x} 7) \mathrm{kV}$ throughout the experiments. A metal rod is placed to the experiment setup in order to stand for the leader channel. A wire fence is laid to the floor for grounding. Two metal boxes are used to represent an electronic system. These boxes have some electronic circuits having realistic impedance characteristics. One of the boxes (Box A) is placed close to the metal rod where the lightning discharge occurs. The other box (Box B), an oscilloscope and an uninterruptible power supply (UPS) are placed in a Faraday cage in order not to be affected from the induced voltages on power line cables. Our high voltage impulse generator is a generator that is charged by a parallel high voltage source. This generator is composed of some sphere gaps and some capacitors that discharges in serial form as it is triggered. This structure yields fast discharge currents and high frequency electromagnetic waves as it is triggered. As the tests conducted without the Faraday cage, it is observed that the 
electromagnetic waves that the generator produces interfere to the original waveform. Experimental setup and the structure of the high voltage impulse generator can be seen from Figure 2-1 and Figure 2-2.

In addition, box A \& B are connected with a cable. Our aim is to measure the voltage that is induced by the lightning discharge. The UPS is used to supply the oscilloscope's energy in order not to be affected from the noises coming from the mains.

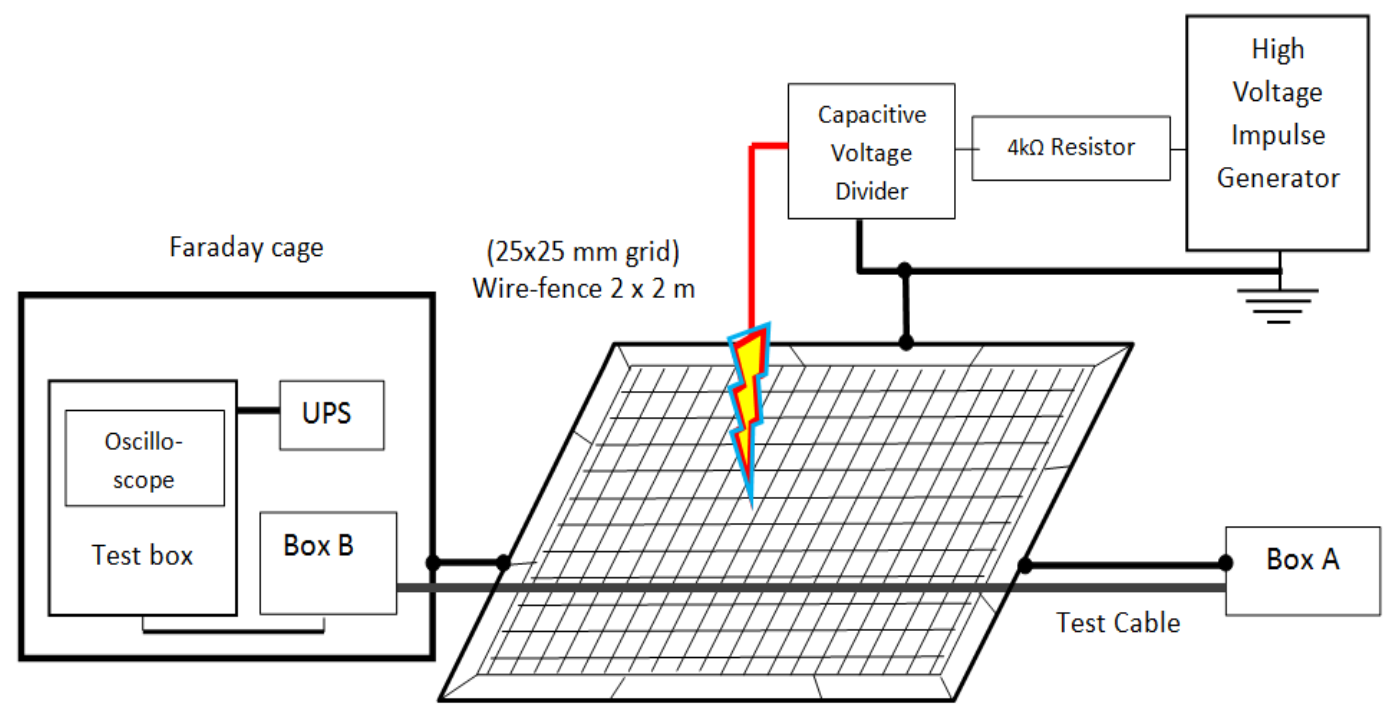

Figure 2-1 High voltage impulse test setup 


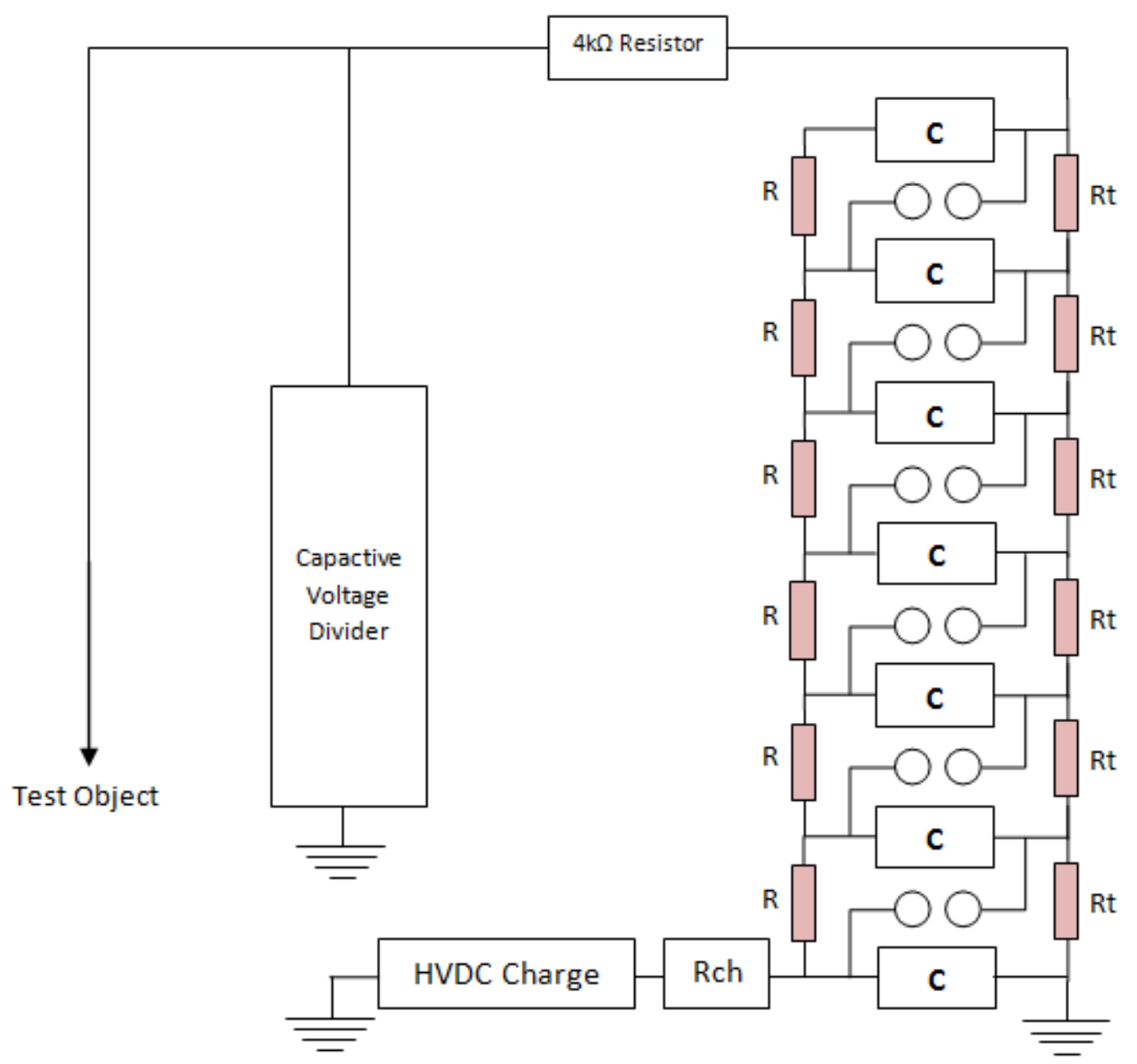

Figure 2-2 Structure of the high voltage impulse generator

Moreover, a current impulse generator is used to investigate the lightning impulse currents that flow through the cables. This generator's voltage is set to $0-30 \mathrm{kV}$ and it can give current impulses between $0-20 \mathrm{kA}$ that has the form of $8 / 20 \mu \mathrm{s}$ ( $8 \mu \mathrm{s}$ front, $20 \mu$ s tail duration). It is composed of parallel capacitors, a wave shaping inductance, a firing gap and a shunt resistor. The structure of the current impulse generator can be seen from Figure 2-3. 


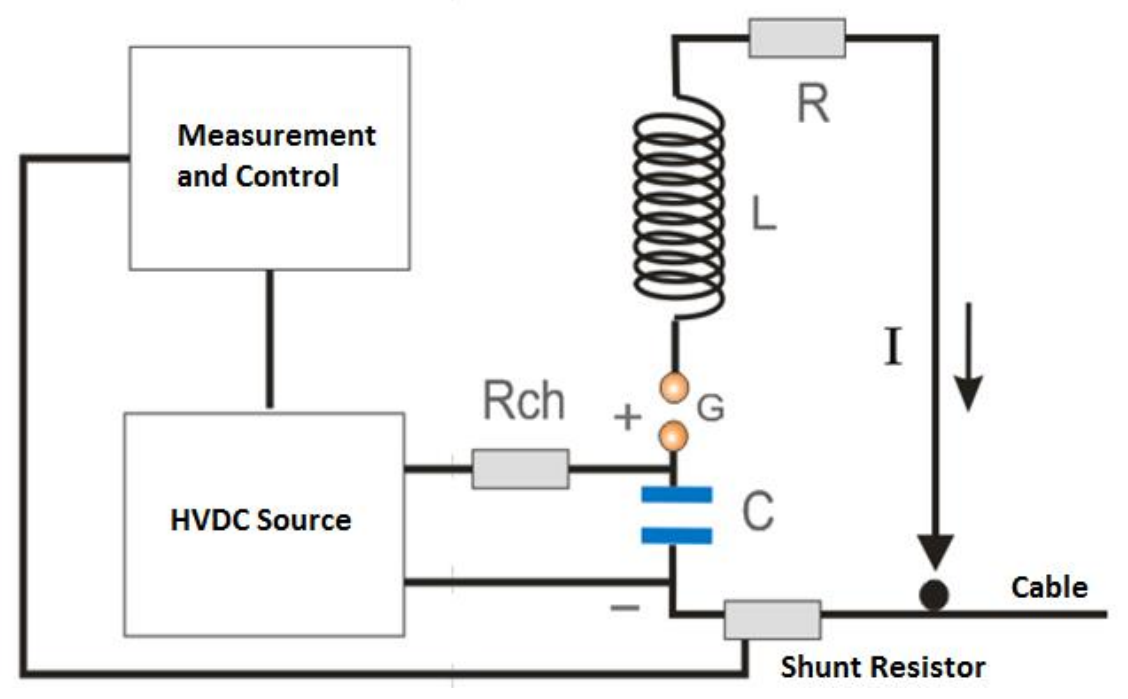

Figure 2-3 Structure of the current impulse generator

The cable which is used in the experiments is a cable assembly. The datasheet of the cable can be seen from Appendix B.

As lightning hits close to a cable, it will induce voltage on it. This mechanism is discussed in detail in 2.2.1. Since these cables are used to connect electrical units and systems, induced high voltages reach to these units and systems through the cables. These induced voltages can be high enough to damage units or systems. Semiconductor devices which are used in electronic circuits in units and systems may be harmed because these voltages can exceed the breakdown voltage of these semiconductors. Due to these reasons, the effect of indirect lightning strikes on control and communication cables is an important area of research.

\subsection{High Voltage Impulse Tests}

These tests aim to investigate the electric field generated by the charges carried by the leader channel. Another goal of these tests is to observe the excessive voltages due to the induced charges. These induced charges are generated by the charges in the leader channel as well. High voltage impulse waveform is set to the form of $1.2 / 50 \mu \mathrm{s}(1.2 \mu \mathrm{s}$ front, $50 \mu \mathrm{s}$ tail duration) which is defined by the standard IEC 60060-1 [19]. This waveform can be seen from Figure 2-4. 


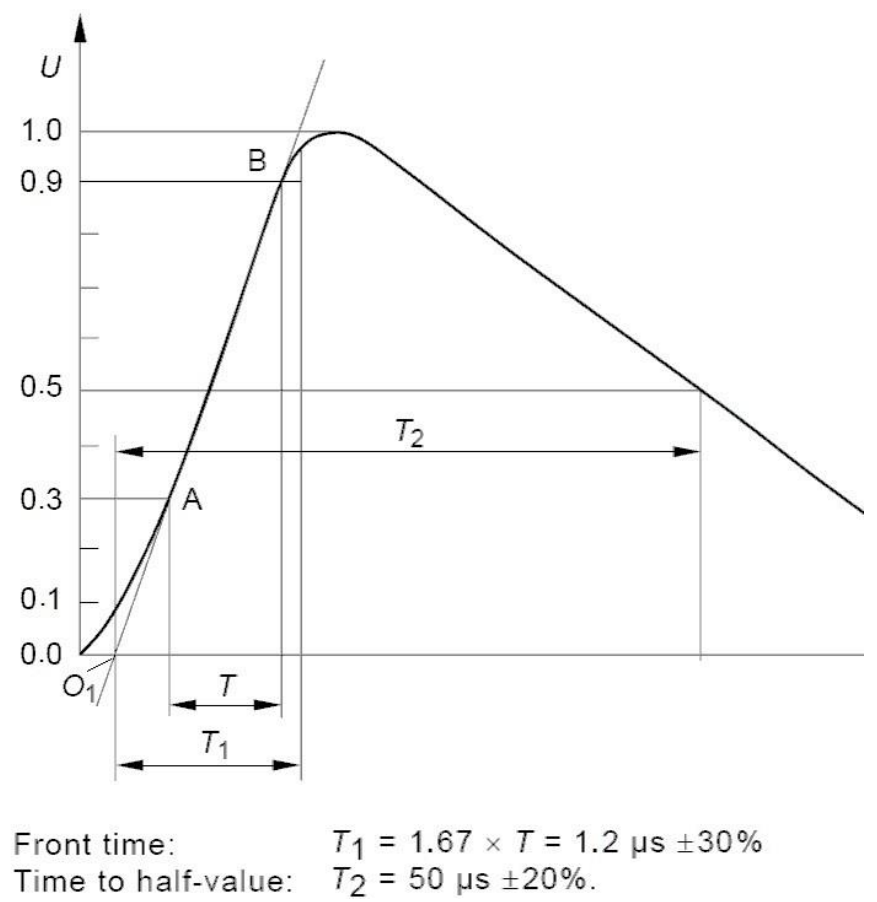

Figure 2-4 Lightning impulse voltage waveform according to IEC 60060-1 (adapted from [15])

Tests are divided into two categories. One is the case that lightning hits close to the cable. The other one is the case that lightning hits the cable.

\subsubsection{When lightning strikes close to the cable}

In this experiment, electric field caused by the charges in the leader channel (conductive rod) induces opposite signed charges on the earth surface and cable conductors. As the lightning discharge occurs, the induced charges on the earth surface neutralize the charges in the leader channel in nanoseconds. This yields the induced charges on the cable conductors to be free and moves in both directions. Figure 2-5 illustrates this mechanism.

The test setup can be seen from the Figure 2-6. 


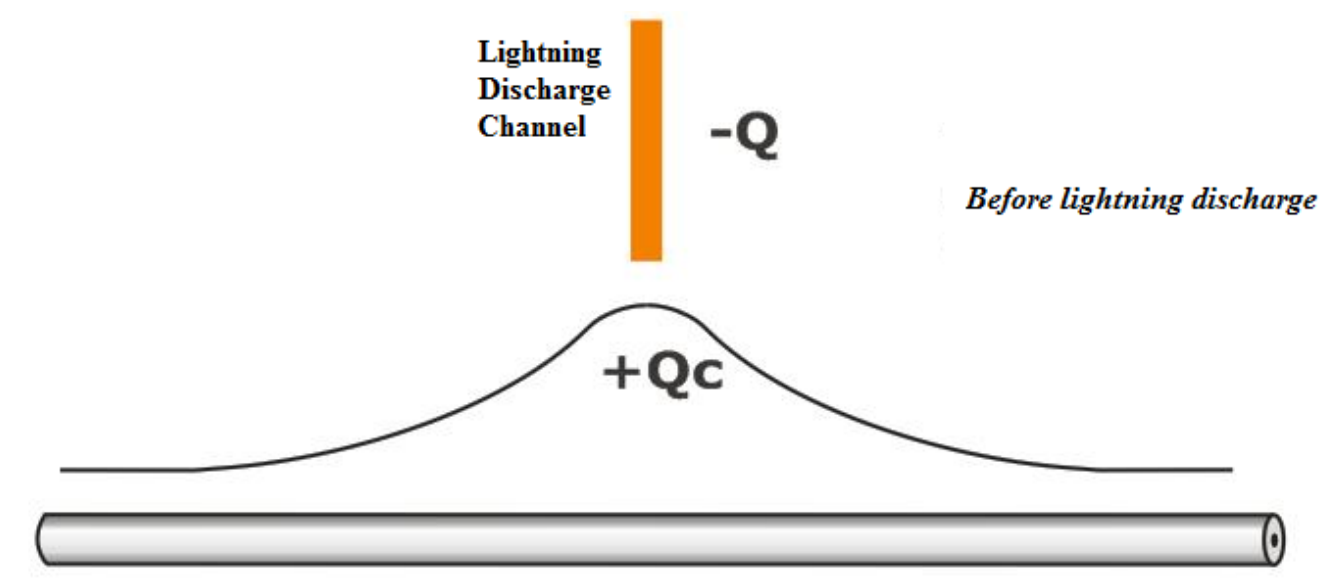

\section{Cable}

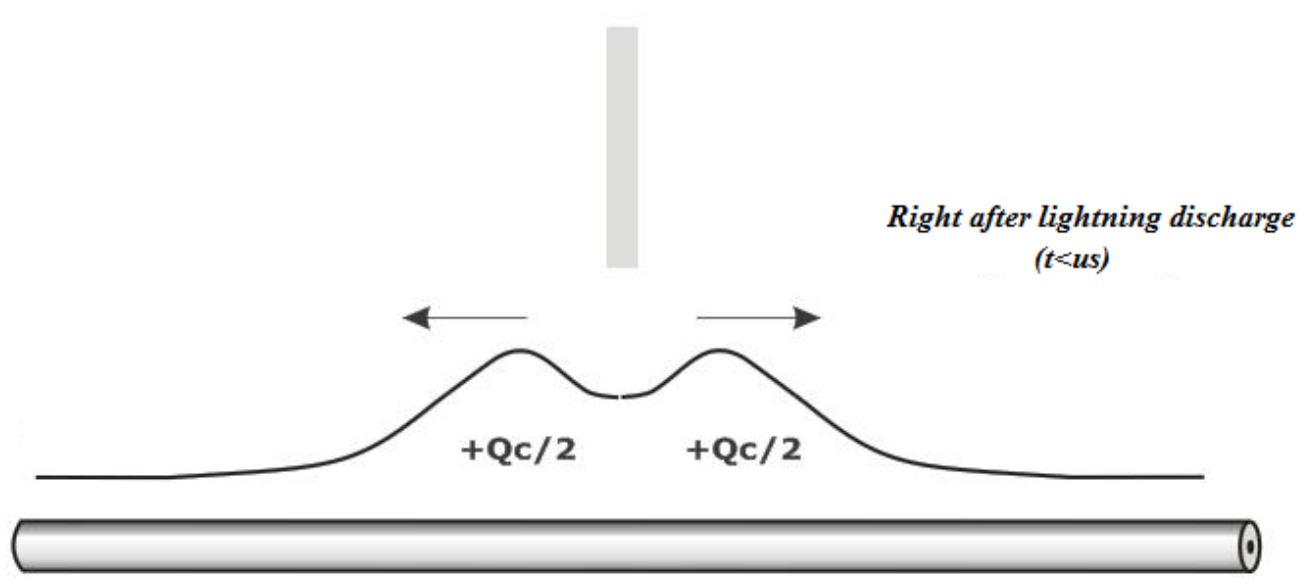

Cable

After lightning discharge

( $t>u s$ )

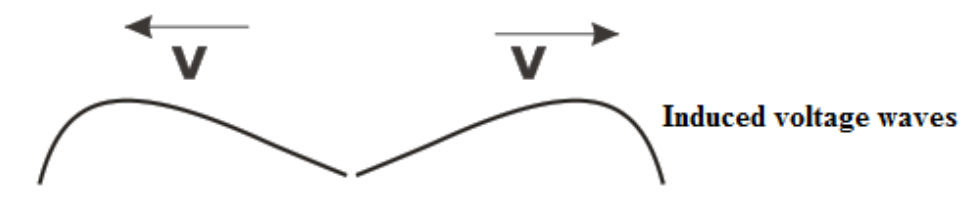

Cable

Figure 2-5 Induced charges on the cable 


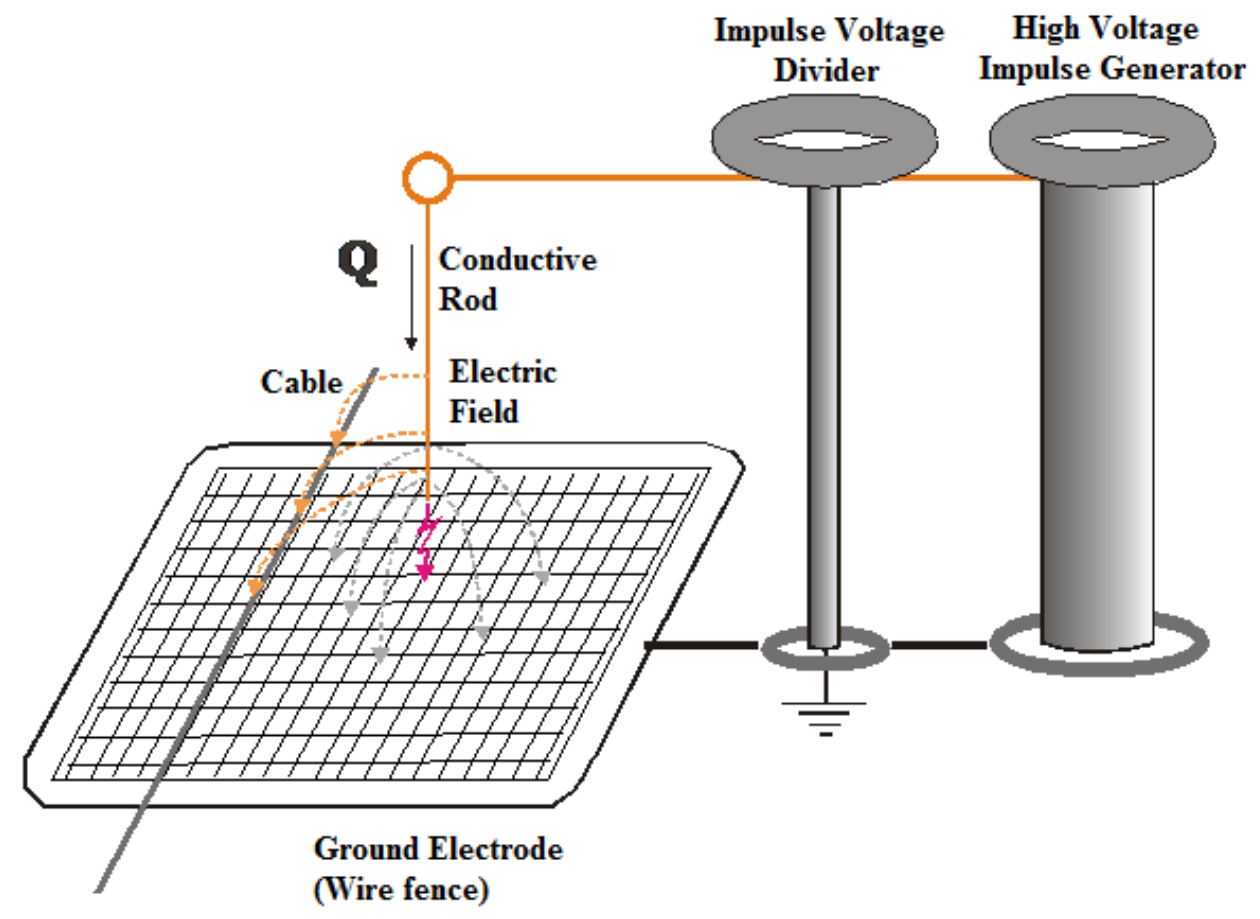

Figure 2-6 High voltage impulse test setup

The induced voltages are carried by cable shield for shielded cables, inner cable conductor for unshielded cables. For shielded cables, induced voltage (and current) waves also create voltage waves on inner cable conductors through the transfer impedance. Higher induced voltages should be expected for unshielded cables. Transfer impedance can be calculated as in Eq. (2.1).

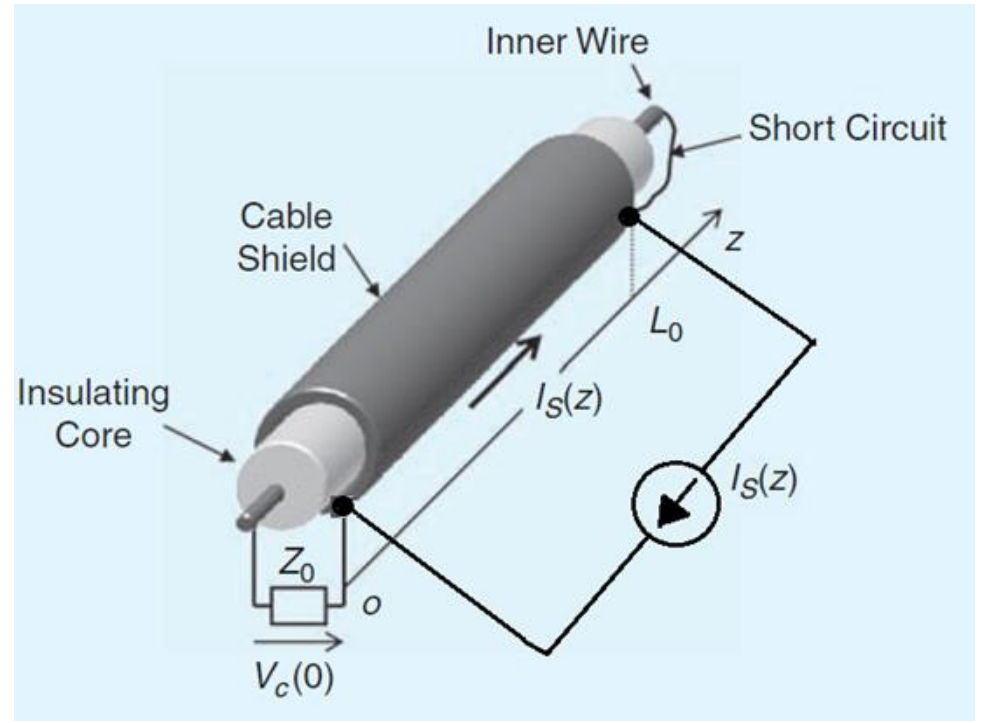

Figure 2-7 Transfer impedance parameters 


$$
Z_{t}=\frac{1}{L_{0}} \frac{V_{c}(0)}{I_{S}(Z)}
$$

where $V_{c}(0)$ is the voltage on the cable shield, $I_{s}(Z)$ is the current flows through the shield, and $\mathrm{L}_{0}$ is the length of the cable.

\subsubsection{High Voltage Impulse Test Results}

Oscilloscope is supplied from a utility power supply (UPS) and a voltage divider is used to measure the induced voltage. The division ratio of this voltage divider is 47 . That means the actual voltages are 47 times higher than the measured ones. Oscilloscope is supplied from a UPS throughout the experiments. Lightning hits a point $30 \mathrm{~cm}$ close to cable throughout the experiments.

1) Setup: The cable is connected to both grounded boxes. BNC signal end is not connected to the oscilloscope.

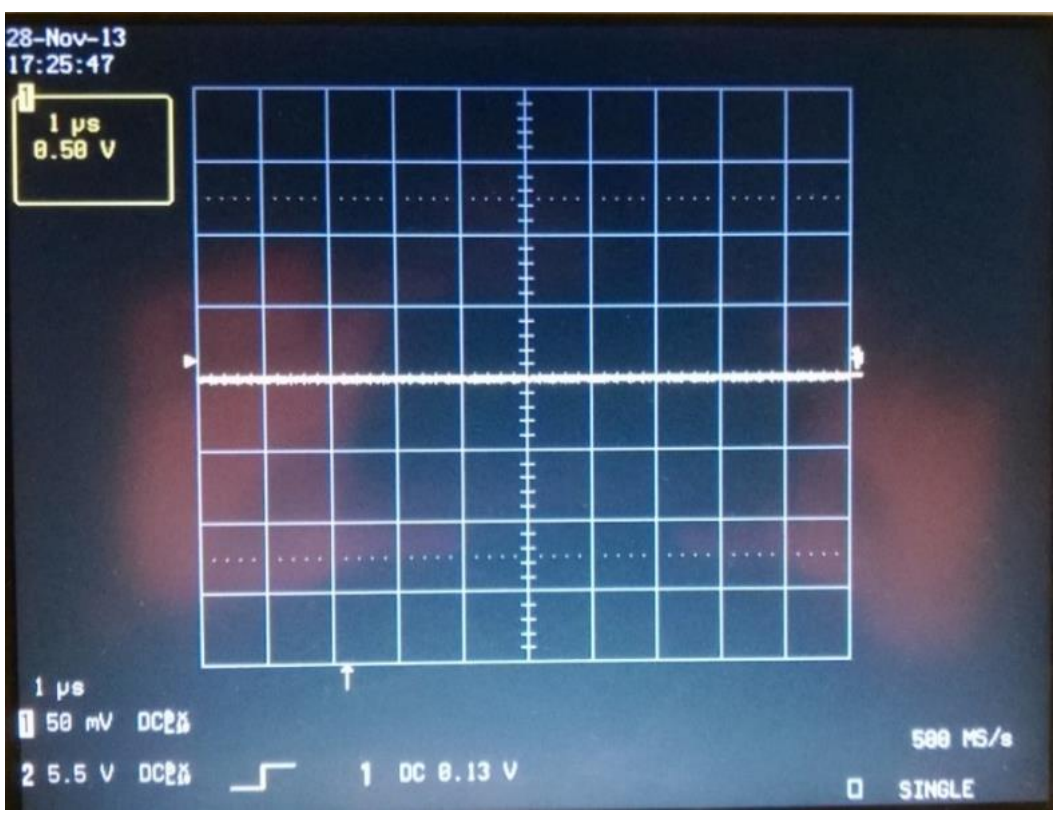

Figure 2-8 Oscilloscope screen \#1

This measurement was taken to confirm that the used Faraday cage is effective. 
2) Setup: The cable is connected to both grounded boxes. BNC signal end is connected to the oscilloscope. Probe is not connected to anywhere.

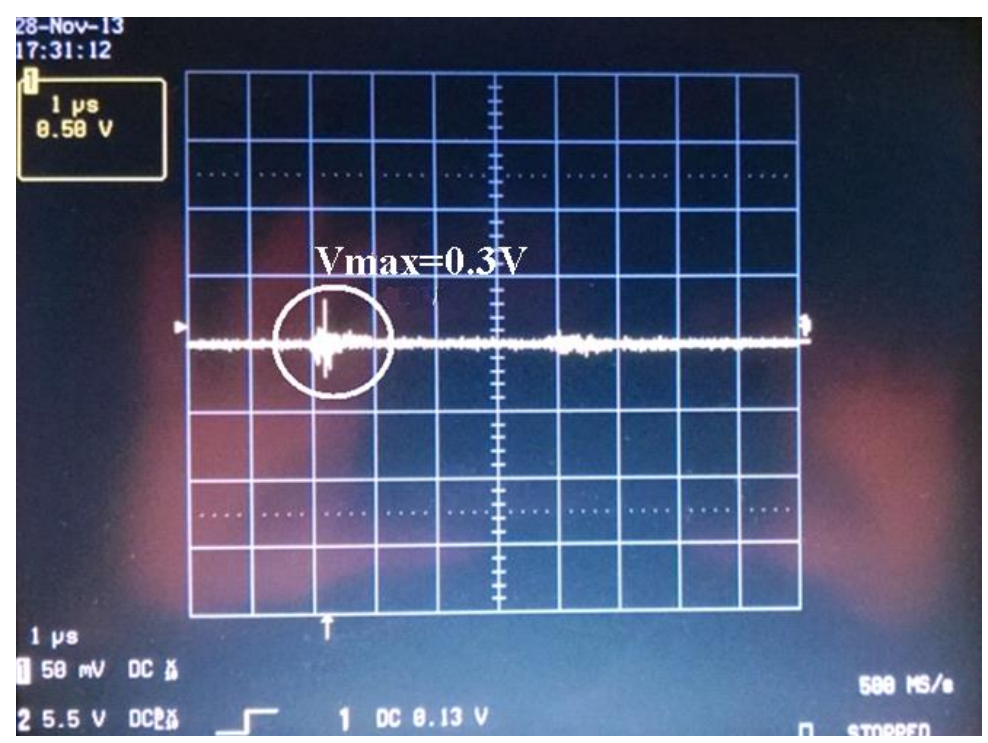

Figure 2-9 Oscilloscope screen \#2

This signal is caused by capacitive coupling of electromagnetic waves coming from high voltage impulse generator as the breakdown of air between sphere gaps.

3) Setup: The cable is connected to both grounded boxes. BNC signal end is connected to the oscilloscope. Probe is connected to a pin in the electronic circuits in box B having realistic impedance characteristics.

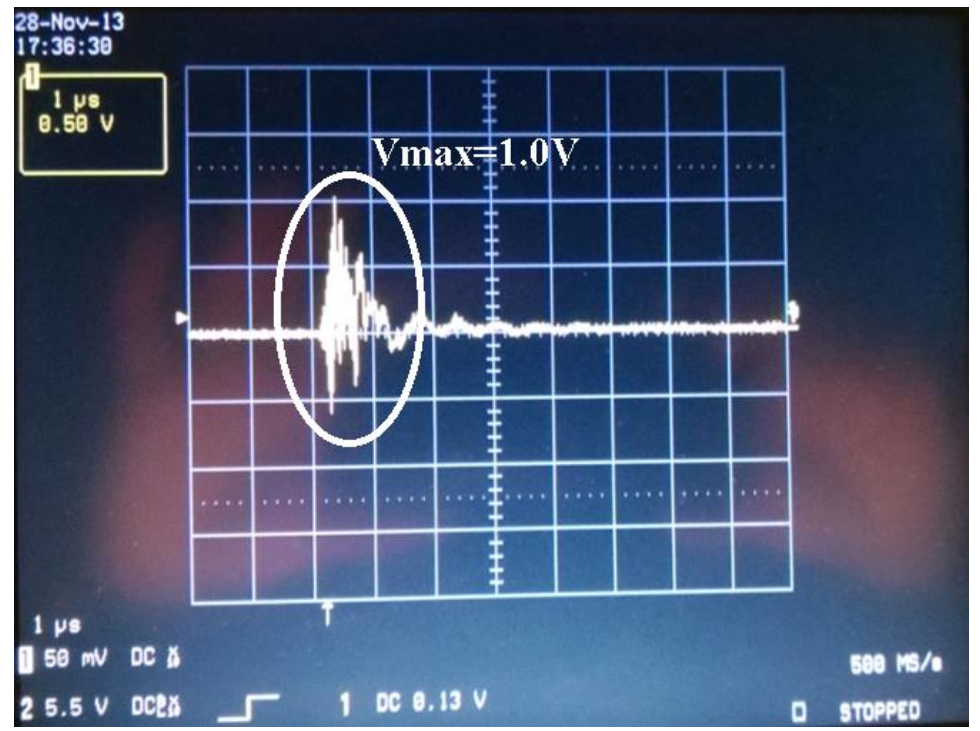

Figure 2-10 Oscilloscope screen \#3 
High voltage impulse generator is discharged by breakdown of air between the sphere gaps but the discharge between metal rod and wire fence did not occur. This signal is the electromagnetic pulse and the induced voltage caused by the impulse generator and the charges on cable conductor.

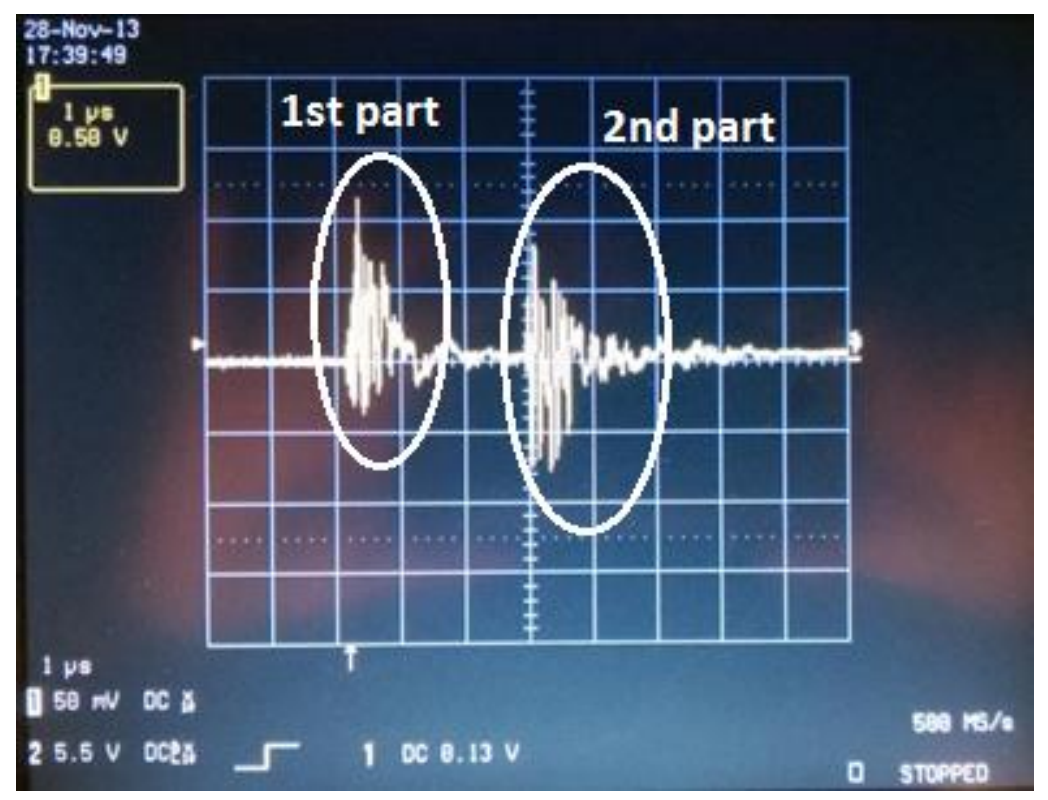

Figure 2-11 Oscilloscope screen \#4

This time, the breakdown between metal rod and wire fence occurred and a second signal is observed at the oscilloscope screen. The voltage can be divided into two parts. First part is the voltage due to the electromagnetic waves generated by the breakdown of the air between sphere gaps of the generator. This voltage will not be generated in natural lightning. Second part is generated due to the breakdown between metal rod and wire fence. This is the voltage coming from the cable conductor induced by the impulse current via magnetic field. The ionization in the discharge channel approximately takes $2.8 \mu$ s which can be seen from the Figure 2-11.

4) Setup: The cable is connected to grounded box B, but not connected to box A. BNC signal end is connected to the oscilloscope. Probe is connected to a pin in the electronic circuits in box $\mathrm{B}$ having realistic impedance characteristics. 


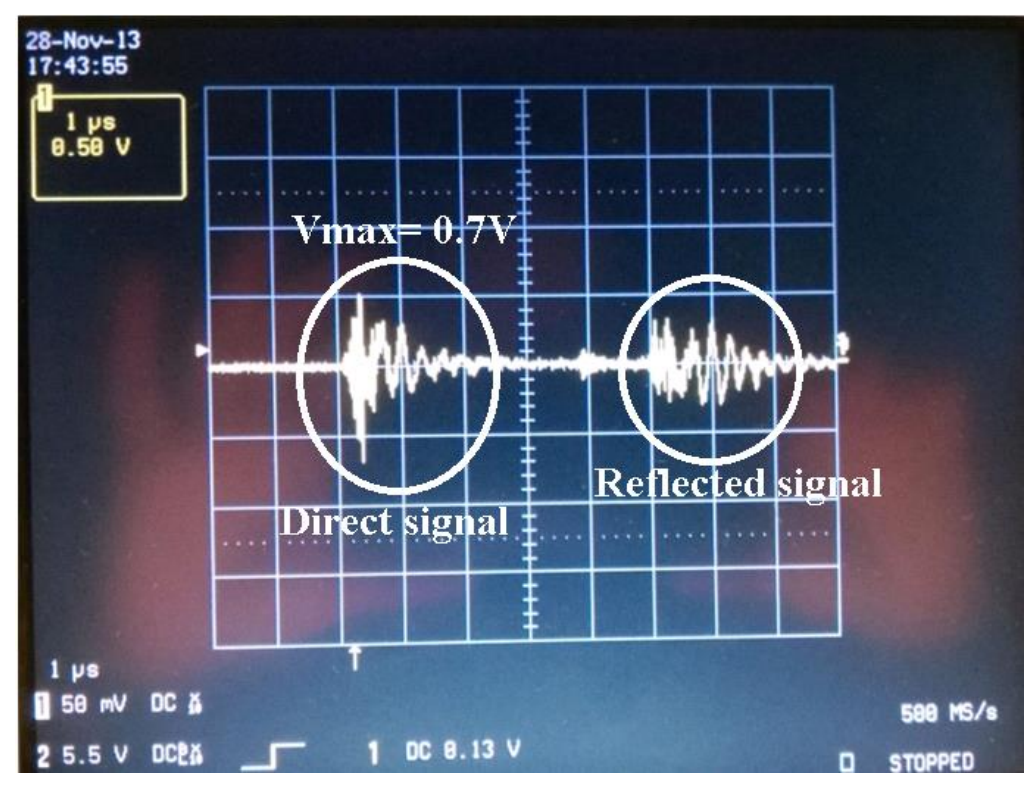

Figure 2-12 Oscilloscope screen \#5

Since the cable is not connected to box A, the signal reflected from the open cable end and measured in the circuits in box B. As can be seen from the Figure 2-12, the direct signal is measured first, the reflected signal is measured about $2.5 \mu \mathrm{s}$ later.

5) Setup: The cable is connected to both ungrounded boxes. BNC signal end is connected to the oscilloscope. Probe is connected to a pin in the electronic circuits in box B having realistic impedance characteristics.

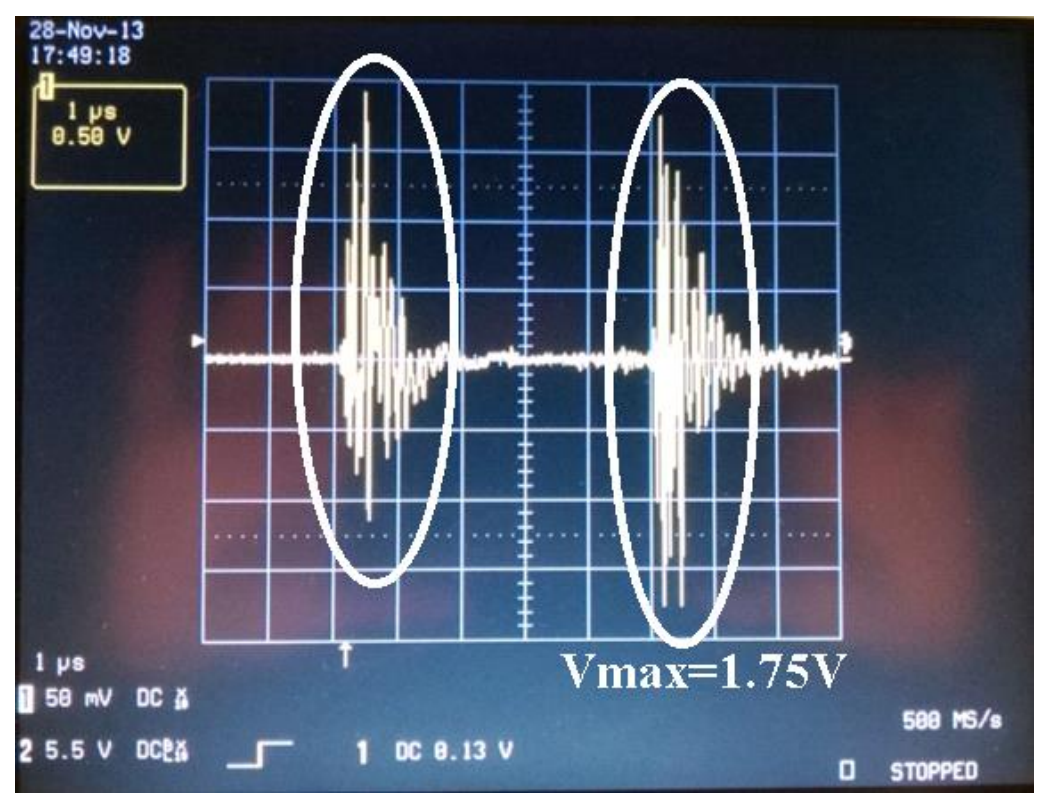

Figure 2-13 Oscilloscope screen \#6 
As the box A is not grounded, cable conductor and the box A itself acts as an antenna and high voltage is observed at the measurement end. This case can be seen from the Figure 2-13.

These experimental results can be extrapolated in order to calculate the voltage that 50m ( $\left.\mathrm{d}_{1}\right)$ away, 200kA ( $\left.\mathrm{I}_{1}\right), 1.2 / 50 \mu \mathrm{s}$ shaped lightning induces. The discharge current for the high voltage impulse generator used is $140 \mathrm{~A}\left(\mathrm{I}_{2}\right)$. Since it is charged to $-560 \mathrm{kV}(-70 \times 8$ levels $)$ and its current is limited by $4 \mathrm{k} \Omega$ resistor. The experiments are conducted as impulse voltages applied $30 \mathrm{~cm}\left(\mathrm{~d}_{2}\right)$ close to the cable. Induced voltage is linearly dependent to distance.

The highest induced voltage is for the sixth experimental configuration. Therefore, it is convenient to take this voltage value $(1.75 \mathrm{~V})$ into account $\left(\mathrm{V}_{\text {ind }}\right)$. Hence, the induced voltage for a $50 \mathrm{~m}$ away, $200 \mathrm{kA}, 1.2 / 50 \mu \mathrm{s}$ shaped lightning can be calculated as in Eq. (2.2) and Eq. (2.3). Remember that the voltage division ratio of capacitive voltage divider is 47 .

$$
\begin{gathered}
V=47 \times V_{\text {ind }} \times\left(\frac{I_{1}}{I_{2}}\right) \times\left(\frac{d_{2}}{d_{1}}\right) \\
V=47 \times 1,75 \times\left(\frac{200000}{140}\right) \times\left(\frac{0.3}{50}\right)=705 \mathrm{~V}
\end{gathered}
$$

This voltage is high enough to damage some electronic equipment. It may exceed the breakdown voltage of some semiconductor devices and cause them burn out.

\subsubsection{When lightning strikes directly the cable}

If a lightning directly strikes a cable, very high voltage is generated on it. In these experiments, metal rod that represents the leader channel is put close to the cable in order to have the lightning directly hit the cable. A metal needle is stuck to the cable to guarantee that the lightning hit the cable, nowhere else. The reason behind sticking the metal needle is to dense the electric field on the top of the needle and attract the lightning. Moreover, the needle ensures that the lightning impulse voltage get through to the cable conductor. Cables are damaged in these experiments due to very high voltages and energy. Test setup can be seen from Figure 2-14 and Figure 2-15. 


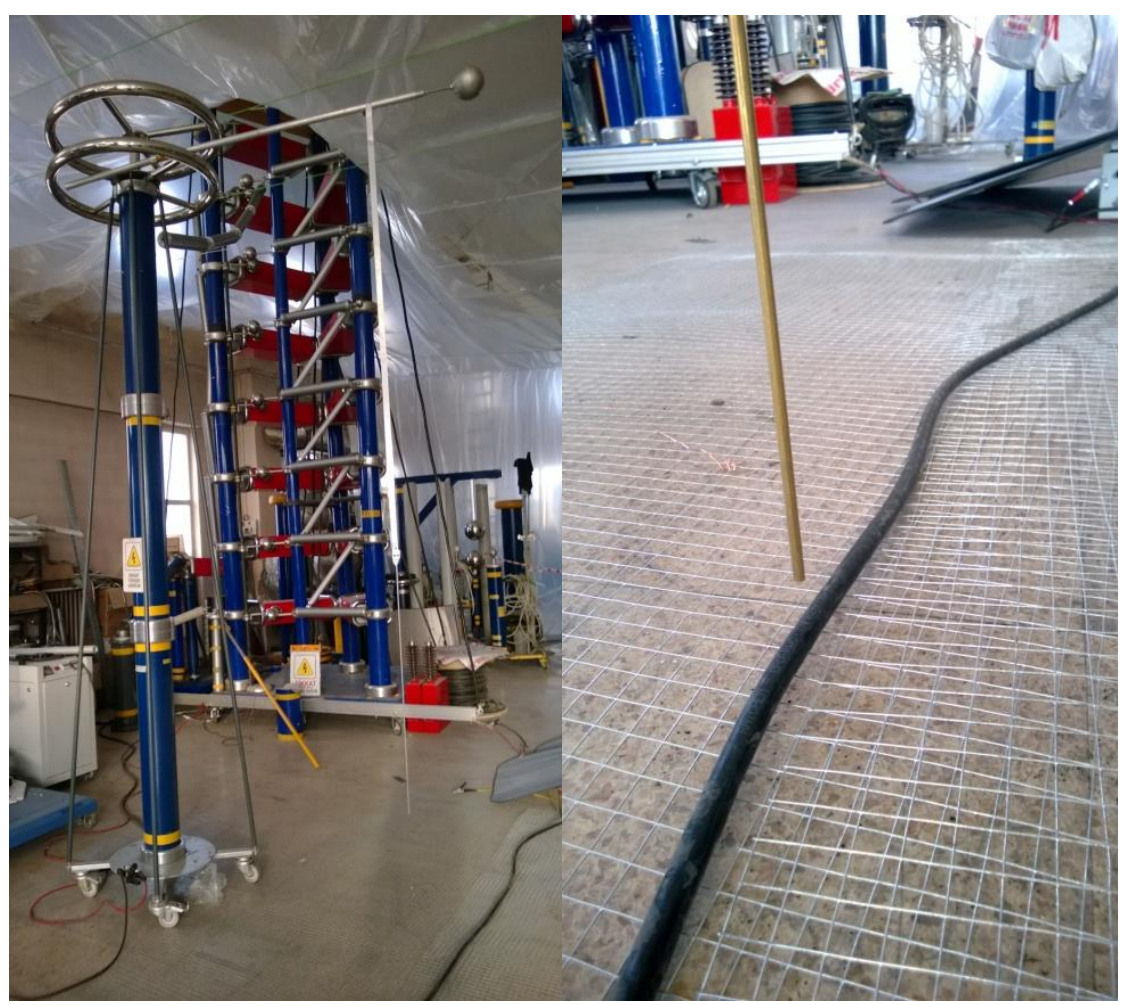

Figure 2-14 Test setup of direct high voltage impulse test

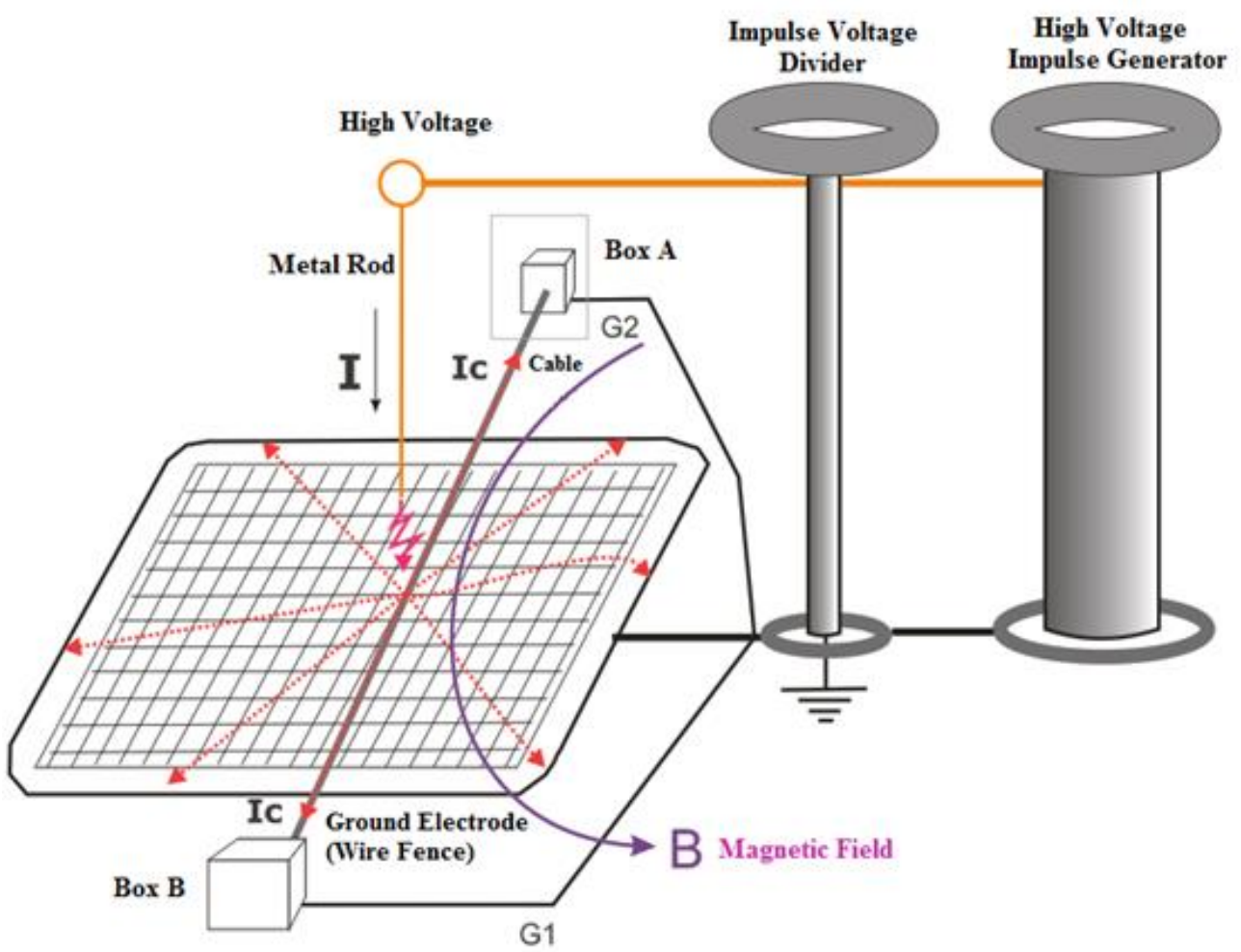

Figure 2-15 Test setup of direct high voltage impulse test 
In this case, since the voltage generated in the cable shield is very high, it jumps to the ground in a short time. Generated voltage on the inner cable conductor can jump to the ground as well and little part of this voltage can reach to the measurement end.

\subsubsection{High Voltage Impulse Test Results}

Oscilloscope is supplied form a utility power supply (UPS) and a capacitive voltage divider is used to measure the induced voltage. The division ratio of this voltage divider is 3385 . That means the actual voltages are 3385 times higher than the measured ones. Oscilloscope is supplied from a UPS throughout the experiments.

1) Setup: The cable is connected to both grounded boxes. BNC signal end is connected to the oscilloscope. Probe is connected to a pin in the electronic circuits in box A having realistic impedance characteristics.

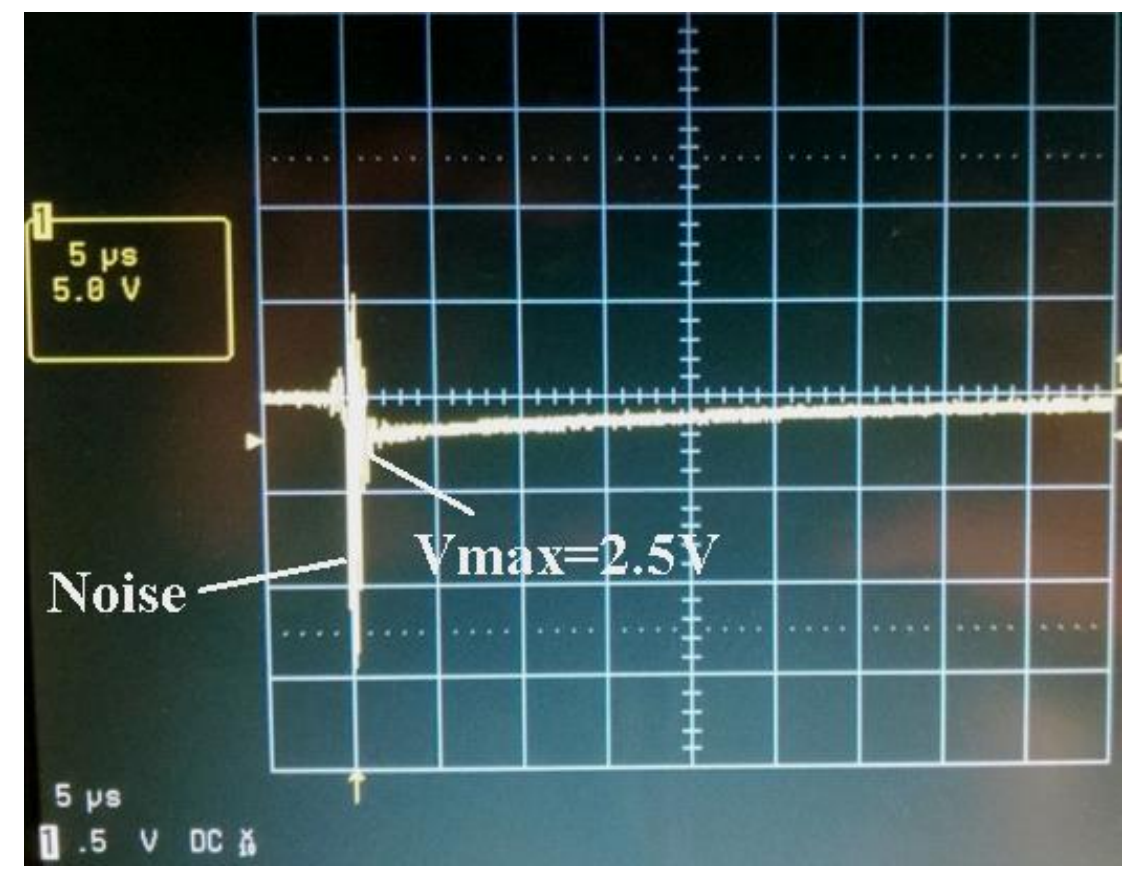

Figure 2-16 Oscilloscope screen \#7

Induced voltage for this configuration is measured as about $2.5 \mathrm{~V}$ as in Figure 2-16. That means induced voltage on the cable is 3385 times 2.5 which is $8,46 \mathrm{kV}$. This induced voltage travels through the cable and reaches the system. As a result, electronic equipment is damaged due to this high voltage. 
2) Setup: The cable is connected to both boxes. While box A is grounded, box B is not. BNC signal end is connected to the oscilloscope. Probe is connected to a pin in the electronic circuits in box A having realistic impedance characteristics.

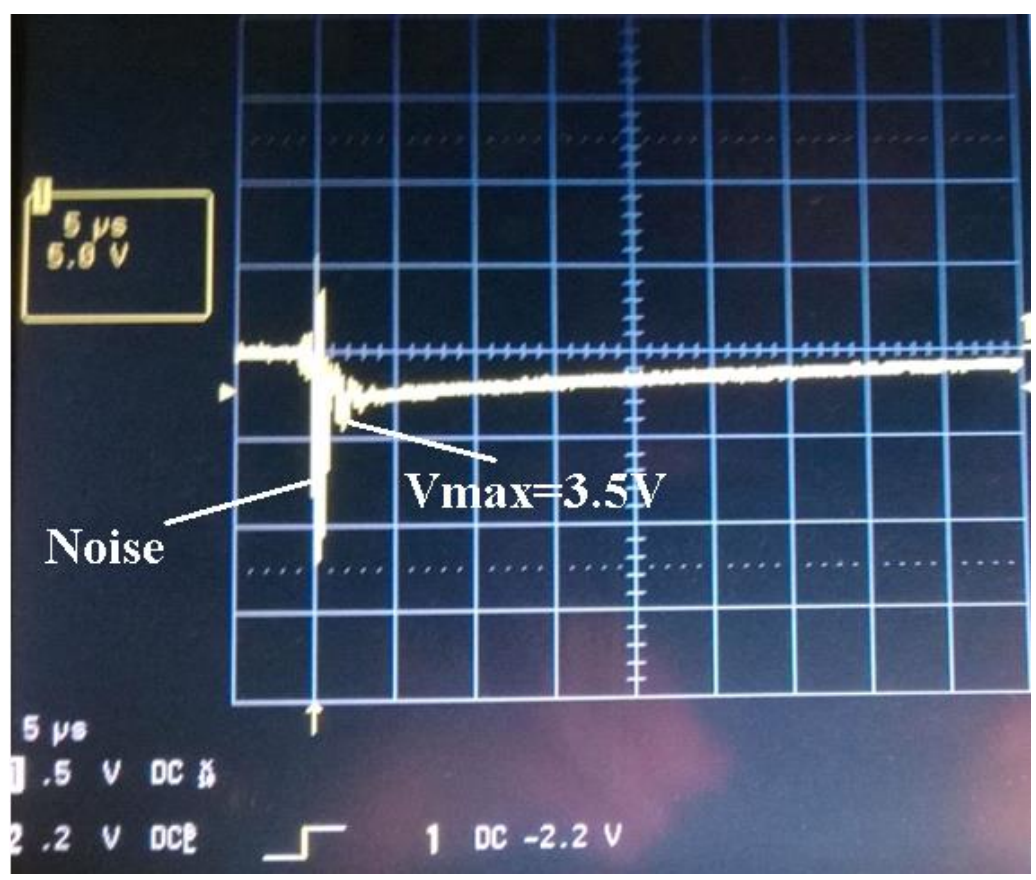

Figure 2-17 Oscilloscope screen \#8

Induced voltage for this configuration is measured as about $3.5 \mathrm{~V}$ as in Figure 2-17. That means induced voltage on the cable is 3385 times 3.5 which is $11,85 \mathrm{kV}$. This is even higher voltage value than the first configuration resulting in damaged electronic system.

\subsubsection{Electric Field Measurements}

Electric field nearby a lightning discharge can reach to $3.10^{-6} \mathrm{~V} / \mathrm{m}$ [21]. An experimental setup is designed in order to measure the electric field due to lightning discharges. A D-dot sensor, which is manufactured by Montena Inc, with the type number SFE3-5G is used in these experiments. This sensor can be seen from Figure 2-18. 


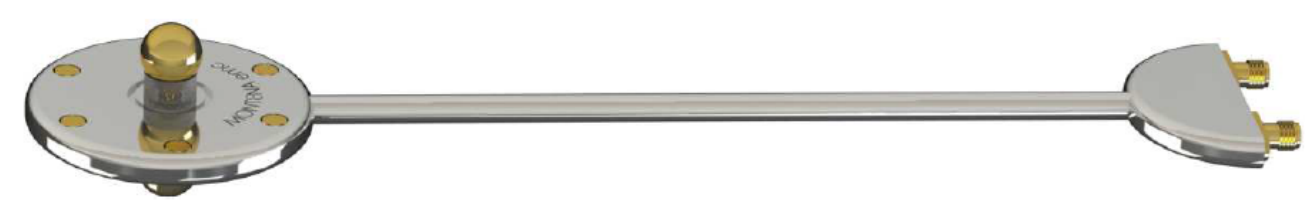

Figure 2-18 D-dot sensor (adapted from [23])

D-dot sensors are calibrated dipole antennas and designed to measure the derivative of electric field. Since it is a dipole antenna, the voltages that are measured by this sensor can be correlated to the ones measured in Chapter 3. This sensor does not measure static electric field. Time varying electric field that is generated by the EMP effect of lightning are measured by using D-dot probe. Unstable outputs of the D-dot sensor is stabilized by a balun and connected to $1 \mathrm{M} \Omega$ input of the oscilloscope via an integrator.

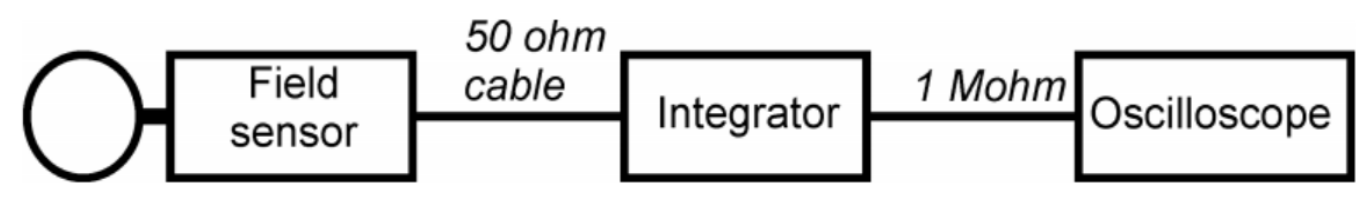

Figure 2-19 D-dot sensor connection diagram (adapted from [22])

Equivalent circuit for D-dot sensor can be seen from Figure 2-20.

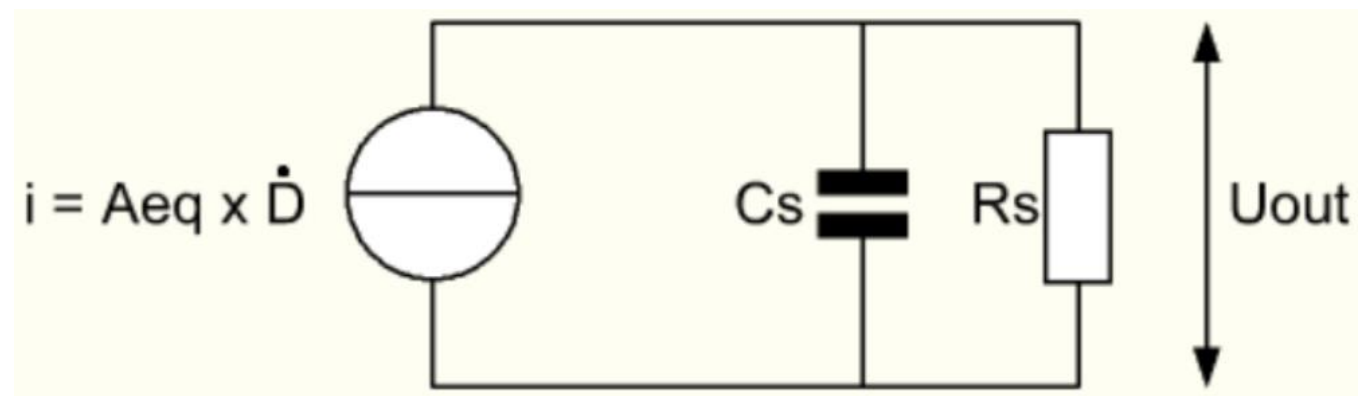

Figure 2-20 Equivalent circuit for D-dot sensor (adapted from [22])

Induced charges on the D-dot sensor flow through the impedance of the system. The current created by the D-dot sensor is proportional to the equivalent surface area of the sensor and the derivative of the displacement of charges. Output voltage of the D-dot sensor can be calculated from Eq. (2.4) [22]. 


$$
V_{\text {out }}(t)=R_{S} A_{e q} \frac{\partial D(t)}{\partial t}
$$

As an integrator is connected to D-dot sensor, the voltage measured by the oscilloscope is formulated by Eq. (2.5) [22].

$$
V_{\text {out }}(t)=\frac{R_{S} A_{e q} \varepsilon_{0} E(t)}{R_{i} C_{i}}
$$

where $\mathrm{R}_{\mathrm{s}}$ is the impedance seen by the sensor $(50 \Omega)$,

Aeq is the equivalent surface area,

$\mathrm{R}_{\mathrm{i}} \mathrm{C}_{\mathrm{i}}$ is time constant of the integrator,

$\varepsilon_{0}=8.854 \times 10^{-12} \mathrm{AsV}^{-1} \mathrm{~m}^{-1}$

$\mathrm{D}$ is the electric displacement.

Time constant of the integrator used in the experiments are given as $1 \mu \mathrm{s}$ and the equivalent surface of D-dot sensor is given as $2.10^{-3} \mathrm{~m}^{2}$ by the manufacturers. Therefore, $\mathrm{V}_{\text {out }}(\mathrm{t})$ and $\mathrm{E}(\mathrm{t})$ can be found as:

$$
V_{\text {out }}(t)=885,4 \times 10^{-9} E(t)
$$

Eq. (2.6) yields:

$$
E(t)=1,13 \times 10^{6} V_{\text {out }}(t)
$$

At first step, D-dot sensor is disconnected to the system in order to measure the noise on sensor cable due to firing of generator. This noise is ignored for measurements and can be seen from Figure 2-21. 


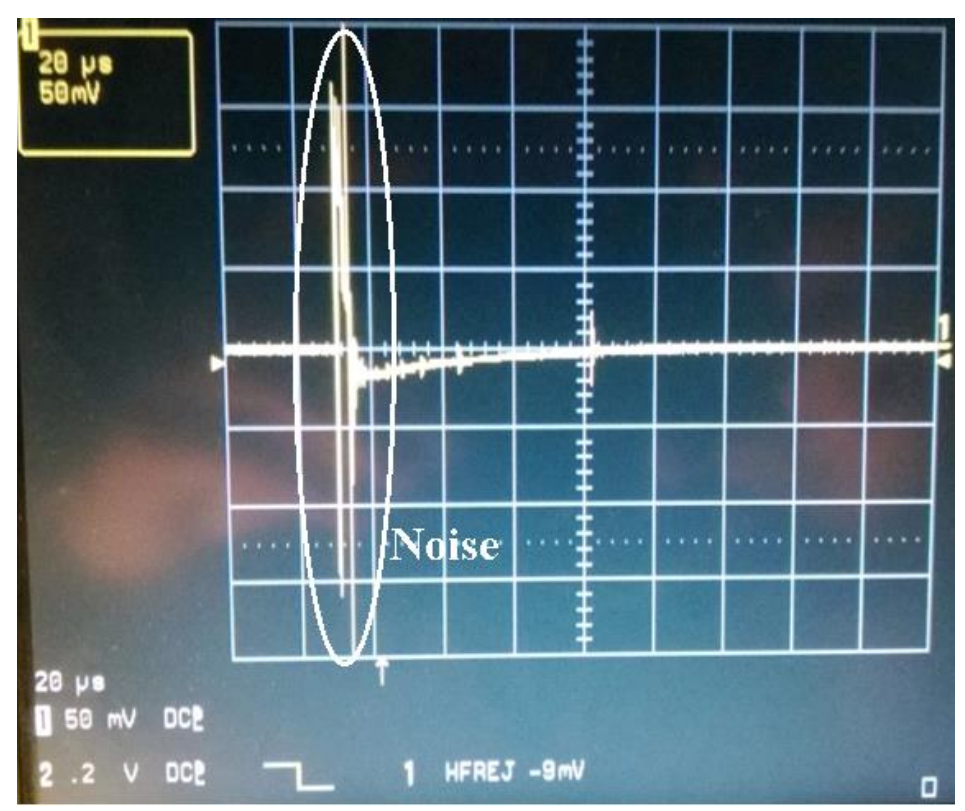

Figure 2-21 Noise on sensor cable

D-dot sensor cable is connected to the system and measurements are taken. The sensor is placed 1.5 meter $\left(\mathrm{d}_{2}\right)$ away from metal rod that represents leader channel. Measured waveform can be seen from Figure 2-22.

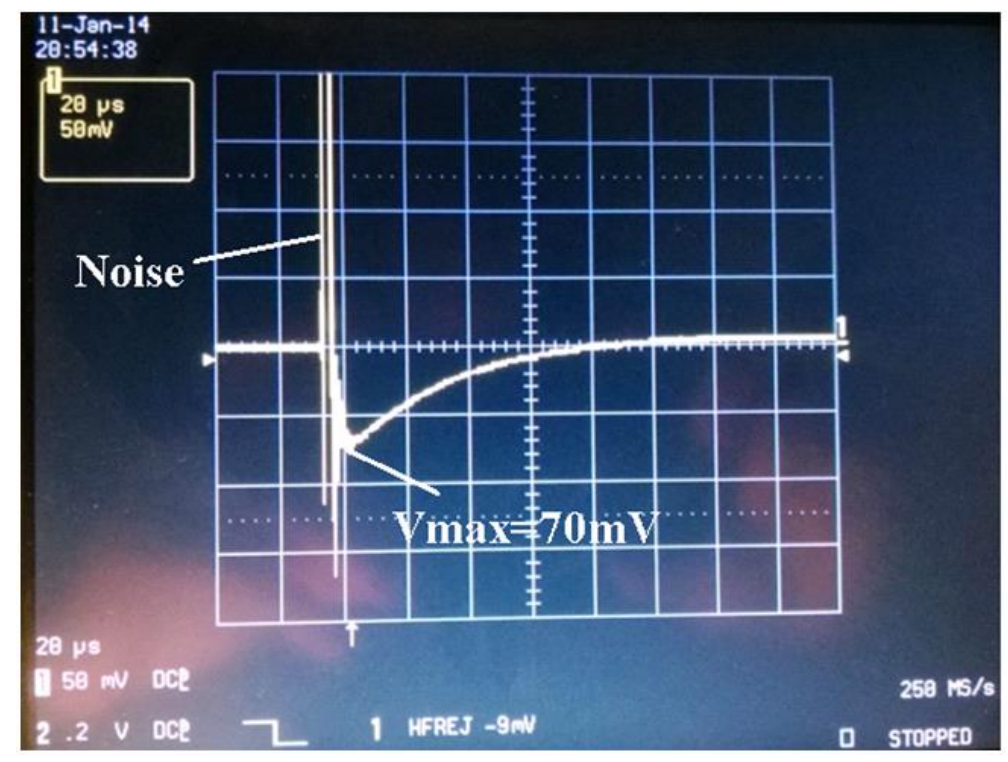

Figure 2-22 Output voltage of D-dot sensor

Since high voltage impulse generator is negatively charged, electric field is also negative. Maximum value of output voltage of $\mathrm{D}$-dot sensor is $-70 \mathrm{mV}$. Electric field can be calculated using Eq. (2.7) as $79.1 \mathrm{KV} / \mathrm{m}$. 
The relation between electric field, discharge intensity and measurement distance can be analyzed. Value of average electric field created by discharge is given in Eq. (2.8).

$$
E_{a v}=\frac{V}{d}
$$

where $\mathrm{V}$ is the voltage and $\mathrm{d}$ is the distance.

Electric charge and current subjected to lightning discharge is given in Eq. (2.9) and Eq. (2.10) respectively.

$$
\begin{aligned}
& Q=V \cdot C_{d i s} \\
& I_{d i s}=\frac{\Delta Q}{\Delta t}
\end{aligned}
$$

where $\mathrm{C}_{\mathrm{dis}}$ is the capacitance between the ground and discharge channel \& conductors. $I_{\text {dis }}$ is the discharge current. This current is $140 \mathrm{~A}\left(\mathrm{I}_{2}\right)$ for the high voltage generator used. Since it is charged to $-560 \mathrm{kV}(-70 \times 8$ levels $)$ and its current is limited by $4 \mathrm{k} \Omega$ resistor. $\Delta \mathrm{t}$ is constant and very close to $50 \mu \mathrm{s}$ since the impulse voltage is $1.2 / 50 \mu$ s shaped. Consequently, there is a linear relation between current and electric charge flowing. Moreover, electric field caused by electric charges is inversely proportional to square of distance.

Therefore, electric field created $50 \mathrm{~m}\left(\mathrm{~d}_{1}\right)$ away by a $200 \mathrm{kA}\left(\mathrm{I}_{1}\right), 1.2 / 50 \mu$ s shaped lightning can be calculated. Remember that $\mathrm{d}_{2}$ is 1.5 meter.

$$
\begin{aligned}
& E=E_{\text {measured }} \times\left(\frac{I_{1}}{I_{2}}\right) \times\left(\frac{d_{2}}{d_{1}}\right)^{2} \\
& E=79.1 \times\left(\frac{200000}{140}\right) \times\left(\frac{1.5}{50}\right)^{2}=101.7 \mathrm{kV} / \mathrm{m}
\end{aligned}
$$

Electric field which is calculated in Eq. (2.12) is created by lightning discharge, not by the static charges in metal rod. This is the electric field at the point that is $50 \mathrm{~m}$ far away from lightning. 
Electric field in various distances and lightning magnitudes can be calculated in a similar way. Hence, since there is a linear relation between electric field and induced voltage on cables around as in Eq. (2.8), there will be a similar magnification for induced voltages as well in a real lightning discharge phenomenon.

\subsubsection{Comparison of Test Results with Academic Background}

The experiments show that electric field created 50m away by a 200kA lightning is $101.7 \mathrm{kV} / \mathrm{m}$ ( or $1,017 \times 10^{5} \mathrm{~V} / \mathrm{m}$ ). Previous studies prove that this is a convenient result. Electric fields of 200kA lightning are measured with different measurement types between 1969 and 1981 by various scientists. As can be seen from Figure 2-23, typical values of electric fields are close or equal to $1 \times 10^{5} \mathrm{~V} / \mathrm{m}$ which are so close to experimental results [6].

\begin{tabular}{lccc}
\hline Investigation & $\begin{array}{c}\text { Typical } \\
(\mathrm{V} / \mathrm{m})\end{array}$ & $\begin{array}{c}\text { High Values } \\
\text { Occasionally Observed }\end{array}$ & $\begin{array}{c}\text { Measurement } \\
\text { Type }\end{array}$ \\
\hline $\begin{array}{c}\text { Winn et al. } \\
(1974)\end{array}$ & $5-8 \times 10^{4}$ & $2 \times 10^{5}$ & Rockets \\
Winn et al. (1981) & - & $1.4 \times 10^{5}$ & Balloons \\
$\begin{array}{c}\text { Rust, Kasemir } \\
\text { (private comm.) }\end{array}$ & $1.5 \times 10^{5}$ & $3.0 \times 10^{5}$ & Aircraft \\
$\begin{array}{c}\text { Kasemir and } \\
\text { Perkins (1978) }\end{array}$ & $1 \times 10^{5}$ & $2.8 \times 10^{5}$ & Aircraft \\
$\begin{array}{c}\text { Imyanitov } \\
\text { et al. (1972) }\end{array}$ & $1 \times 10^{5}$ & $2.5 \times 10^{5}$ & Aircraft \\
$\begin{array}{c}\text { Evans (1969) } \\
\text { Fitzgerald (1976) }\end{array}$ & $2-4 \times 10^{5}$ & $2 \times 10^{5}$ & Parachuted \\
\hline
\end{tabular}

Figure 2-23 Measured electric fields

There are a lot of studies to formulate the electric field caused by lightning. Since the mechanism of lightning is very complex, the formulation of electric field generated by lightning discharge is complex as well which can be solved by using computer programs [16], [17]. 


\subsection{High Current Impulse Tests}

In these tests, magnetic fields effects and some destructive effects of lightning impulse current are investigated. Direct or indirect strikes are analyzed throughout the experiments. Magnitude of lightning impulse current used in experiments is $10 \mathrm{kA}$. This waveform is set to the form of $8 / 20 \mu$ s ( $8 \mu$ s front, $20 \mu$ s tail duration) which is defined by the standard IEC 60060-4-5 [20]. The waveform can be seen from Figure 2-24.

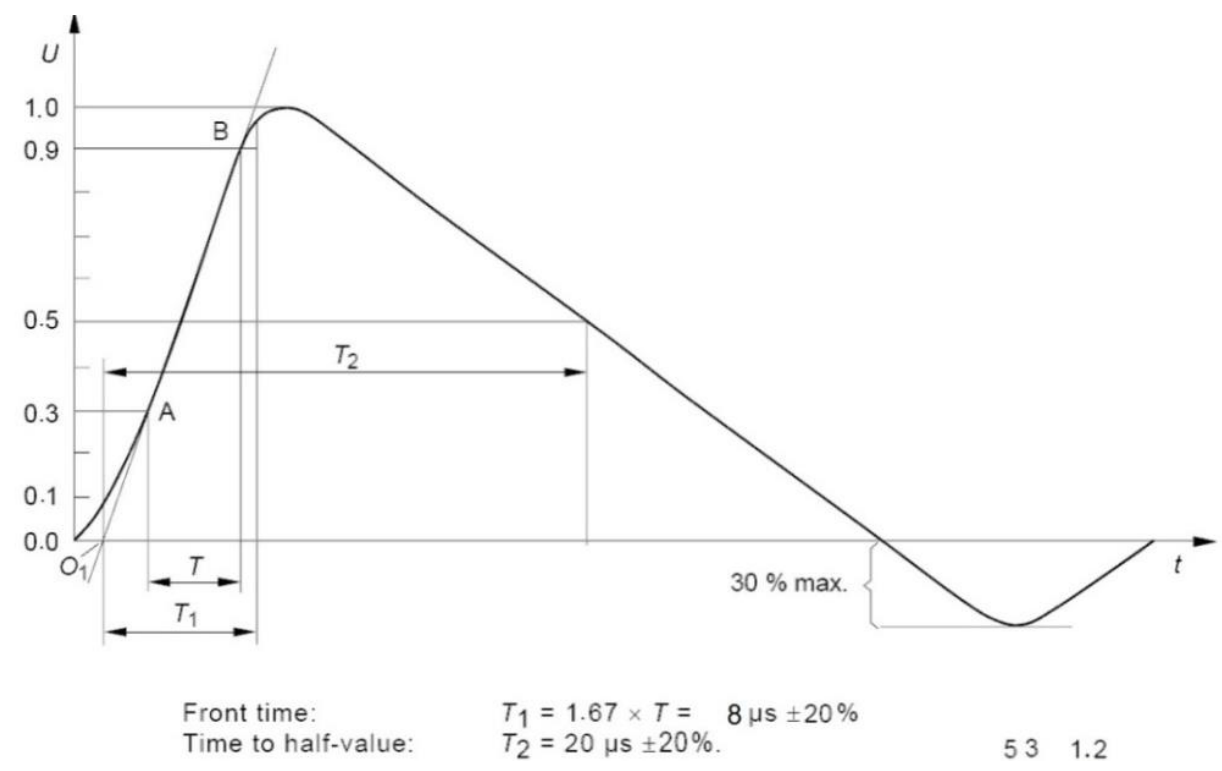

Figure 2-24 Lightning impulse current waveform according to IEC 60060-4-5 (adapted from [15])

Some magnetic field measurements are taken and correlations between real lightning discharges are examined.

\subsubsection{Indirect High Current Impulse Tests}

Induced voltages caused by induced charges due to lightning discharges are measured in these experiments. Time derivative of magnetic field are also measured during experiments. In order to measure that, a sensor is designed and implemented. This sensor is an air core coil whose radius is $7.75 \mathrm{~mm}$ and it has 13 turns. This sensor can be seen from Figure 2-25. 


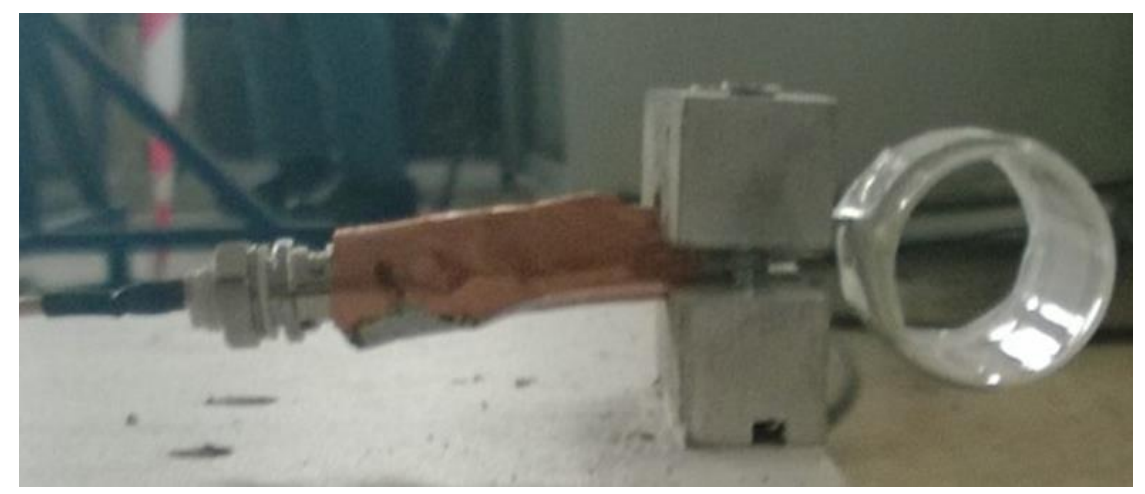

Figure 2-25 Sensor used to measure time derivative of magnetic field

Induced voltage of the coil and derivative of magnetic field can be calculated as in Eq. (2.13) and Eq. (2.14) respectively.

$$
\begin{aligned}
& V_{\text {coil }}=-\frac{\mu_{0} n A}{2 \pi r} \frac{d i}{d t} \\
& \frac{d H}{d t}=\frac{1}{2 \pi r} \frac{d i}{d t}
\end{aligned}
$$

where $\mu_{0}$ is the vacuum permeability, $\mathrm{n}$ is the number of turns, $\mathrm{A}$ is the area, and $\mathrm{r}$ is the radius of the coil.

Therefore, $\mathrm{dH} / \mathrm{dt}$ can be rewritten as in Eq. (2.15)

$$
\frac{d H}{d t}=-\frac{V_{c o i l}}{\mu_{0} n A}
$$

Hence,

$$
\frac{d H}{d t}=-V_{\text {coil }} \times 0.324 \times 10^{9} \mathrm{~A} / \mathrm{m} / \mathrm{s}
$$

Induced voltage due to magnetic field is proportional to the derivative of magnetic field. Therefore, if derivative of magnetic field is calculated using measured induced voltage, induced voltages can be calculated as distance and lightning current differs at the same value of derivative of magnetic field. 
Maximum induced voltage is measured as $400 \mathrm{mV}$ in the experiments as can be seen from Figure 2-30. This voltage is measured when the sensor is $1 \mathrm{~m}$ away from lightning discharge. As derivative of magnetic field is calculated from Eq. (2.16)

using measured induced voltage value, $\frac{d h}{d t}$ value can be found as $0.13 \times 10^{9} \mathrm{~A} / \mathrm{m} / \mathrm{s}$. Table 2-1 gives coefficients related to lightning current and distance that will be used to calculate induced voltages.

Table 2-1 Induced voltage calculation coefficients

\begin{tabular}{|c|c|c|c|c|}
\hline $\begin{array}{r}\text { Lightning } \\
\text { Current }\end{array}$ & 20kA & $50 \mathrm{kA}$ & $100 \mathrm{kA}$ & $200 \mathrm{kA}$ \\
\hline $50 \mathrm{~m}$ & 0.34 & 0.85 & 1.7 & 3.4 \\
\hline $10 \mathrm{~m}$ & 1.7 & 4.25 & 8.5 & 17 \\
\hline $5 \mathrm{~m}$ & 3.4 & 8.5 & 17 & 34 \\
\hline $1 \mathrm{~m}$ & 17 & 42.5 & 85 & 170 \\
\hline
\end{tabular}

\subsubsection{Indirect Current Impulse Test Results}

1) Sensor cable is disconnected to the sensor and shorted to its shield in order to observe noise caused by current impulse. That noise can be seen from Figure 2-27.

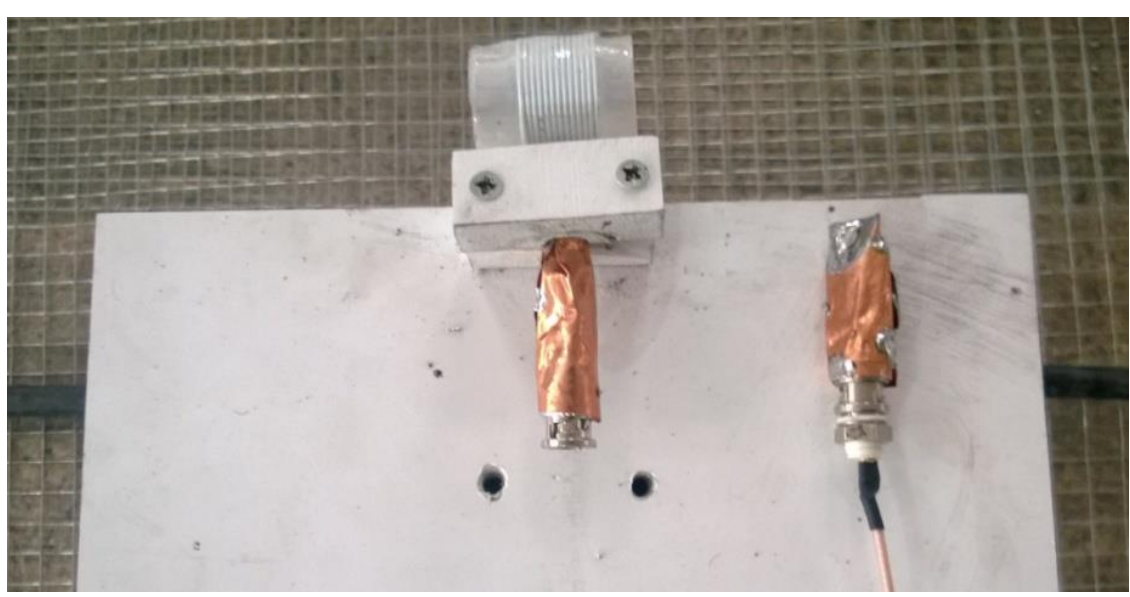

Figure 2-26 Current impulse noise measurement test setup 


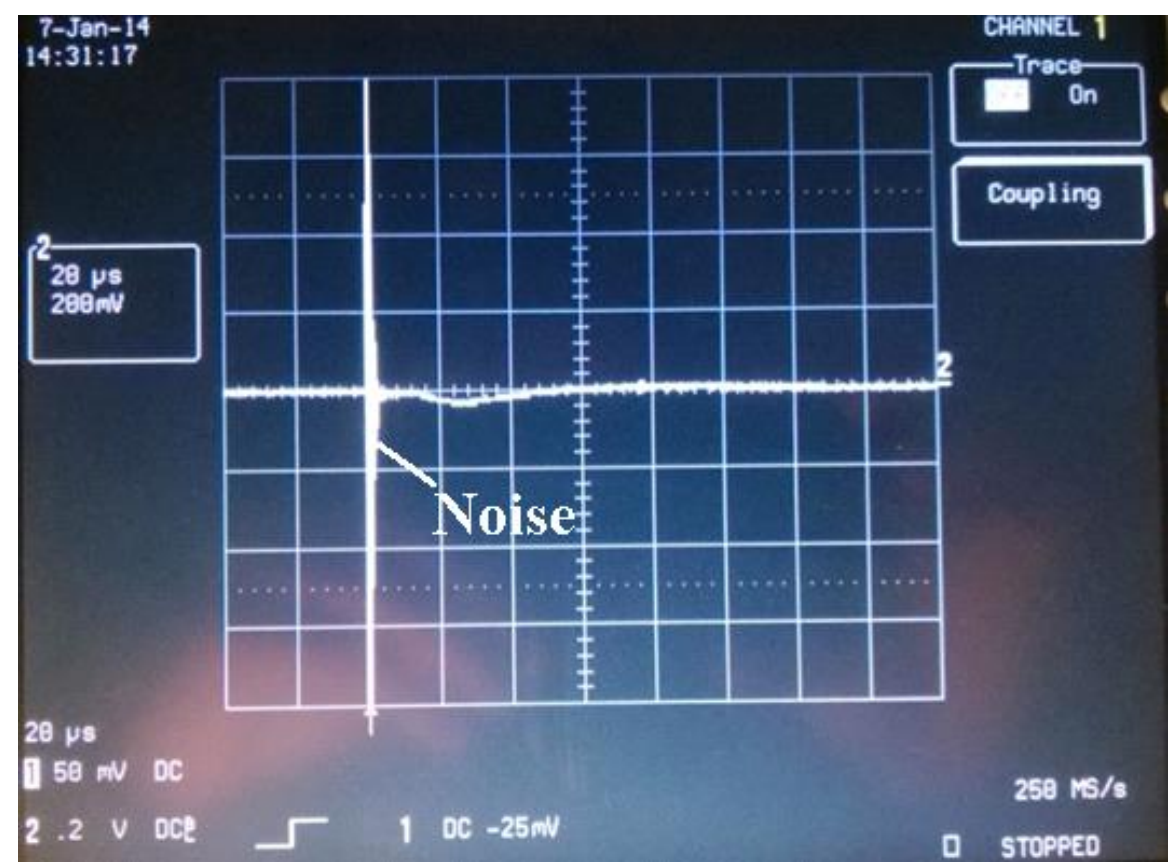

Figure 2-27 Current impulse noise

2) Sensor is placed vertically and current impulse is applied nearby.

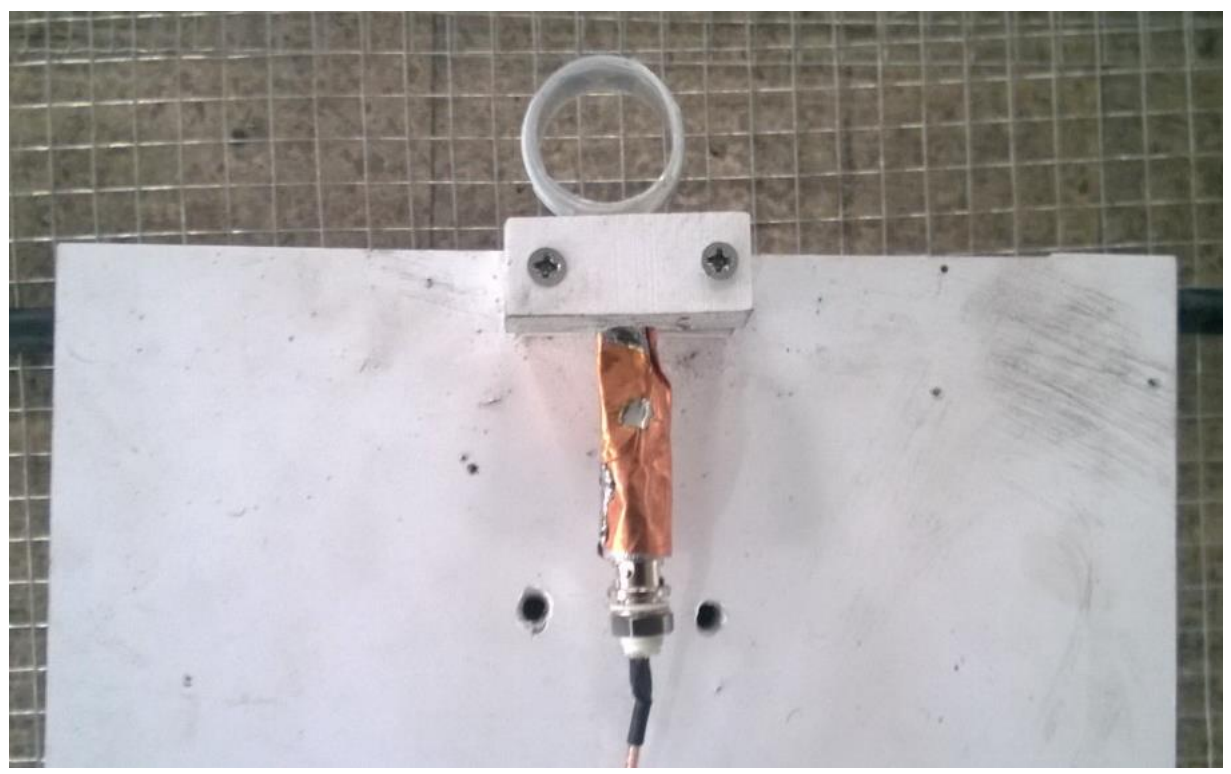

Figure 2-28 Vertical magnetic field measurement test setup 


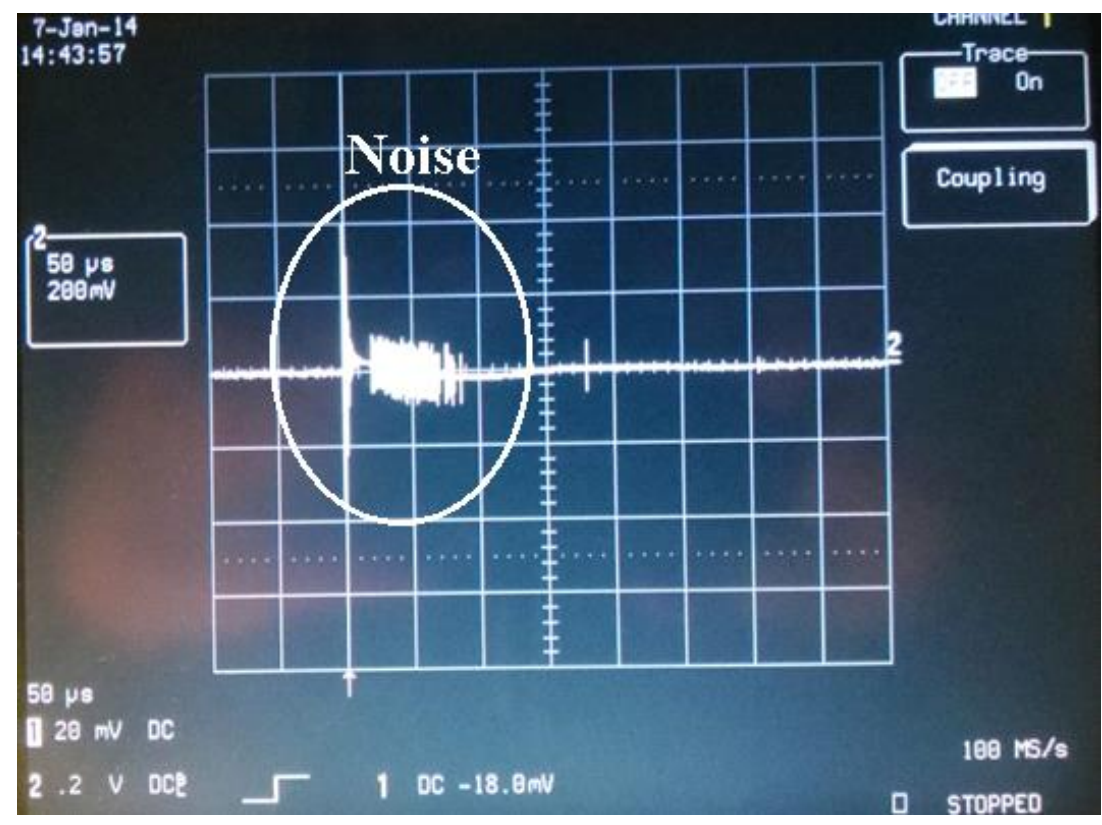

Figure 2-29 Vertical magnetic field measurement

Since lightning current flows vertically, magnetic field due to this current is horizontal. Horizontal magnetic field does not induce voltage on vertically placed sensor. Some high frequency voltages are observed at Figure 2-29. These are noises coming from current impulse generator.

3) Sensor is placed horizontally and current impulse is applied nearby.

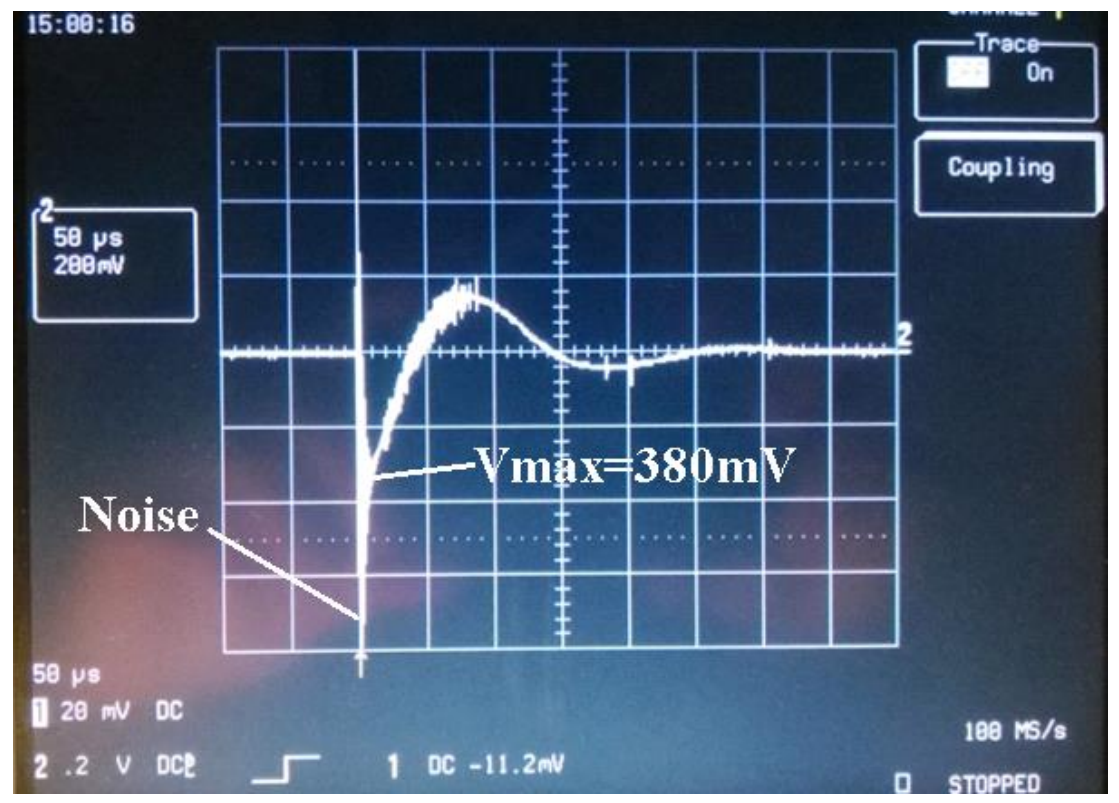

Figure 2-30 Horizontal magnetic field measurement 
Horizontal magnetic field is created due to lightning current that flows vertically.

Electromagnetic effects of a lightning are described as in Table 2-2 in MIL-STD464C standard. These descriptions are for lightning having 200kA peak current level and striking $10 \mathrm{~m}$ nearby.

Table 2-2 Electromagnetic fields from near strike lightning

\begin{tabular}{|c|c|}
\hline Magnetic field rate of change at 10 meters & $2.2 \times 10^{9} \mathrm{~A} / \mathrm{m} / \mathrm{s}$ \\
\hline Electric field rate of change at 10 meters & $6.8 \times 10^{11} \mathrm{~V} / \mathrm{m} / \mathrm{s}$ \\
\hline
\end{tabular}

Lightning indirect effects waveform characteristics described in MIL-STD-464C can be seen from Table 2-3.

Table 2-3 Lightning indirect effects waveform characteristics

\begin{tabular}{|c|c|c|c|c|c|c|c|c|}
\hline $\begin{array}{l}\text { Current } \\
\text { compo- } \\
\text { nent }\end{array}$ & $\begin{array}{c}\text { Peak } \\
\text { current } \\
\text { (kA) }\end{array}$ & $\begin{array}{c}\text { Action } \\
\text { Integral } \\
\left(A^{2} s\right)\end{array}$ & $\begin{array}{l}\text { Decay } \\
\text { to } 50 \% \\
\text { ( } \mu \mathrm{s})\end{array}$ & $\begin{array}{c}\text { Time to } \\
10 \% \\
(\mu \mathrm{s})\end{array}$ & $\begin{array}{c}\text { Time to } \\
90 \% \\
(\mu s)\end{array}$ & $\begin{array}{l}\text { Time to } \\
\text { Peak } \\
\text { ( } \mu \mathrm{s})\end{array}$ & $\begin{array}{l}\text { Rate of } \\
\text { rise }\end{array}$ & $\begin{array}{c}\text { Peak rate } \\
\text { of rise } \\
t=0+ \\
\text { (A/s) }\end{array}$ \\
\hline A & 200 & $2.0 \times 10^{6}$ & 69 & 0.15 & 3.0 & 6.4 & $\begin{array}{l}1.0 \times 10^{11} \\
@ 0.5 \mu \mathrm{s}\end{array}$ & $1.4 \times 10^{11}$ \\
\hline B & \multicolumn{8}{|c|}{ Produces average current of $2 \mathrm{kA}$ over a 5 millisecond period } \\
\hline $\mathrm{C}$ & \multicolumn{8}{|c|}{ Defined as rectangular waveform for analysis purposes of $400 \mathrm{~A}$ for 500 milliseconds } \\
\hline D & 100 & $0.25 \times 10^{6}$ & 34.5 & 0.08 & 1.5 & 3.18 & $\begin{array}{l}1.0 \times 10^{11} \\
@ 0.25 \mu \mathrm{s}\end{array}$ & $1.4 \times 10^{11}$ \\
\hline $\mathrm{D} / 2$ & 50 & $6.25 \times 10^{4}$ & 34.5 & 0.08 & 1.5 & 3.18 & $\begin{array}{l}0.5 \times 10^{11} \\
@ 0.25 \mu \mathrm{s}\end{array}$ & $0.7 \times 10^{11}$ \\
\hline $\mathrm{H}$ & 10 & $\mathrm{~N} / \mathrm{A}$ & 4.0 & 0.0053 & 0.11 & 0.24 & $\mathrm{~N} / \mathrm{A}$ & $2.0 \times 10^{11}$ \\
\hline
\end{tabular}

As peak rate of current rise $\left(\frac{d i}{d t}\right)$ of A component is taken as $1.4 \times 10^{11}$ as in

Table 2-3 and distance ( $\mathrm{r}$ ) is selected as $10 \mathrm{~m}$, derivative of magnetic field ( $\left.\frac{d H}{d t}\right)$ can be calculated as $2.2 \times 10^{9} \mathrm{~A} / \mathrm{m} / \mathrm{s}$ as in Table $2-2$.

\subsubsection{Direct High Current Impulse Tests}

These experiments are conducted in order to observe the effects of electromagnetic waves caused by lightning that hits the system directly. High current impulses are 
applied directly to the cables and current waves are measured in these tests. The impulse current applied to the cables has a $10 \mathrm{kA}$ peak value. Test setup can be seen from Figure 2-31. The structure of current impulse generator can be seen from Figure 2-3.

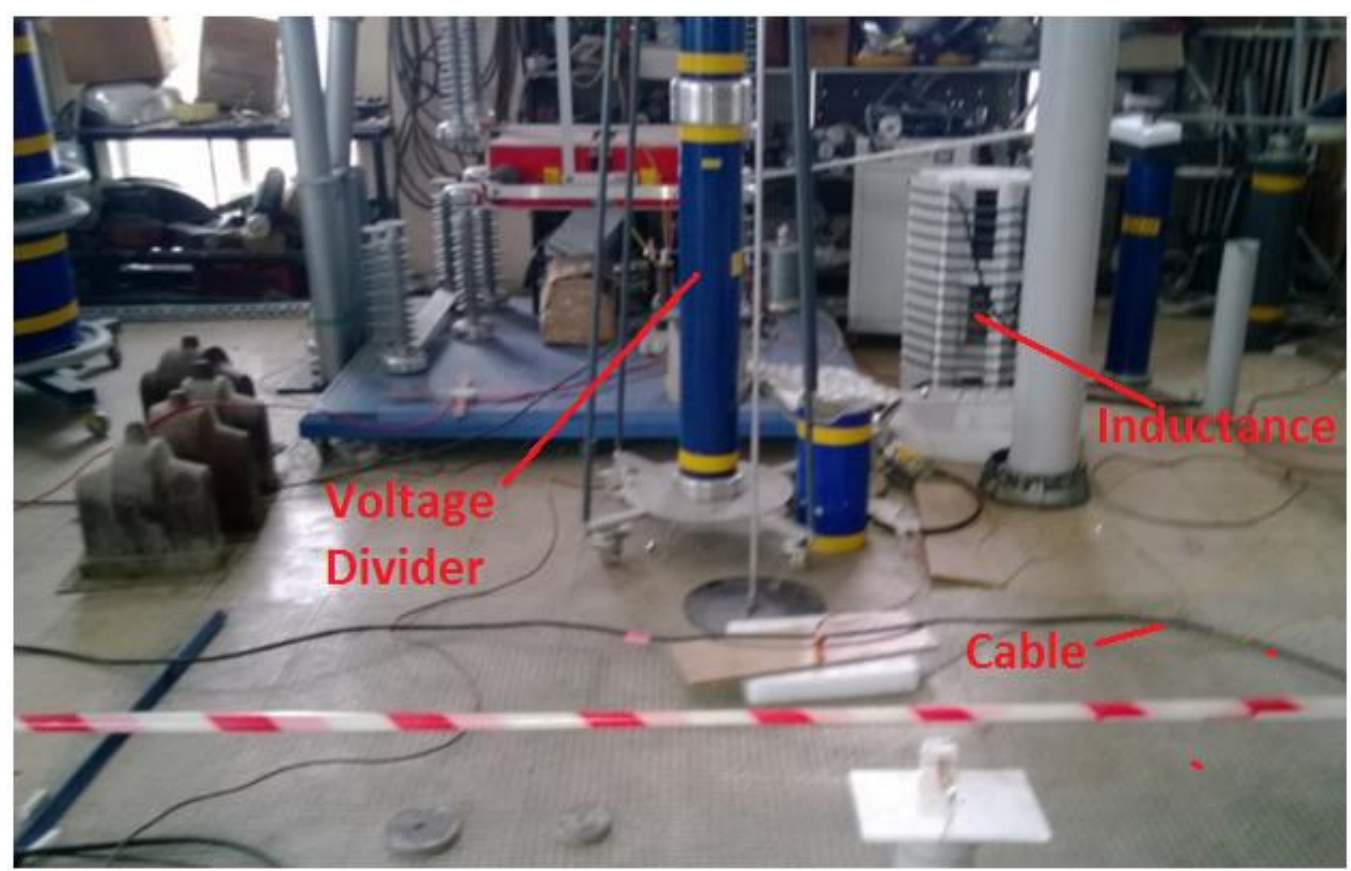

Figure 2-31 High current impulse test setup

High current impulse generator is charged to $-20 \mathrm{kV}$ and current wave is measured from the $0.82 \mathrm{~m} \Omega$ shunt resistor. Measured impulse current wave can be seen from Figure 2-32. 


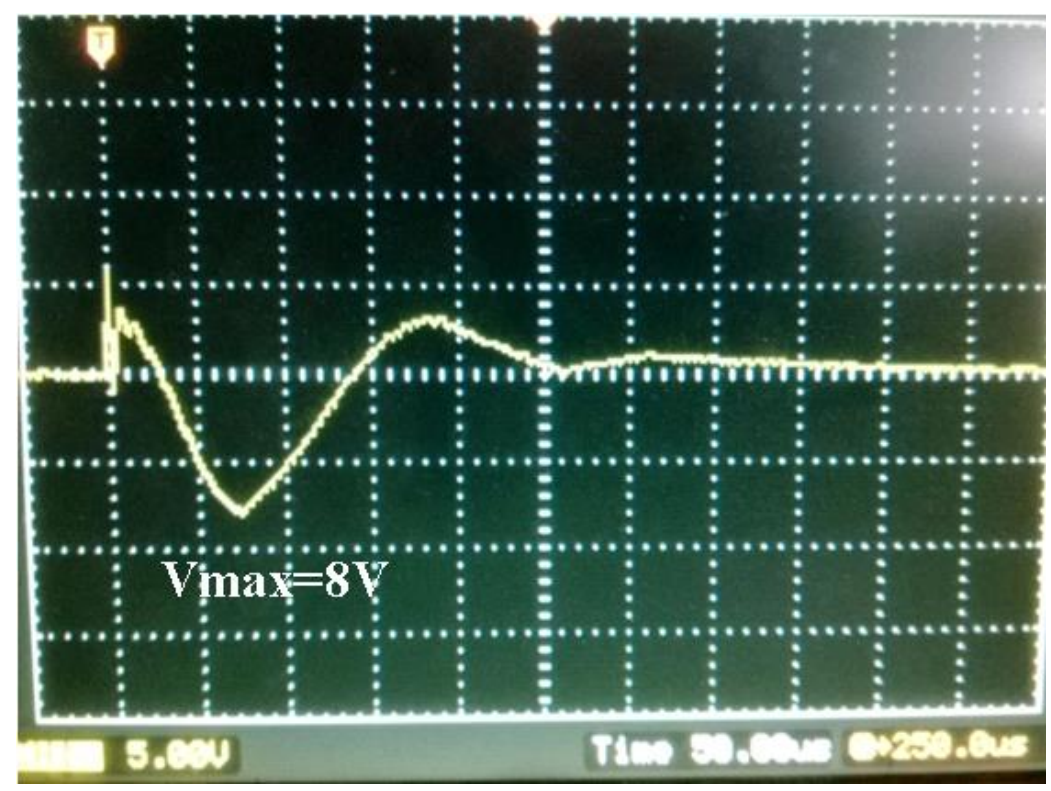

Figure 2-32 Impulse current wave

The peak value of the measured wave is observed to be $8 \mathrm{~V}$. Therefore peak current can be calculated as in Eq. (2.17).

$$
I_{\text {peak }}=\frac{8 \mathrm{~V}}{0.82 \times 10^{-3} \Omega}=9,76 \mathrm{kA}
$$

\subsubsection{High Current Impulse Test Results}

A capacitive voltage divider is used to measure the voltages on cables. Division ratio of this voltage divider is 47 . That means the actual voltages are 47 times higher than the measured ones.

1) Setup: The cable is connected to both grounded boxes. Box A is in the Faraday cage, Box B is outside the Faraday cage. 


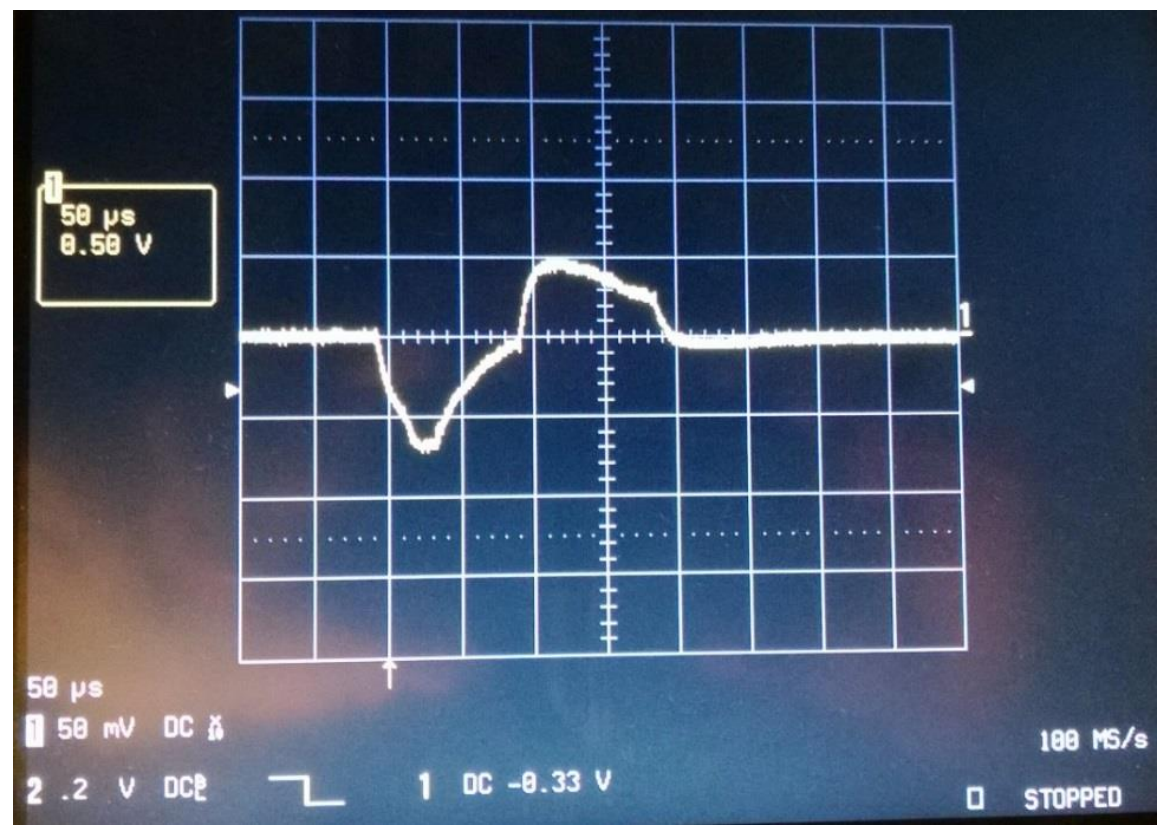

Figure 2-33 Oscilloscope screen \#9

2) Setup: Box A grounded while Box B does not. Box A is in the Faraday cage, Box B is outside the Faraday cage.

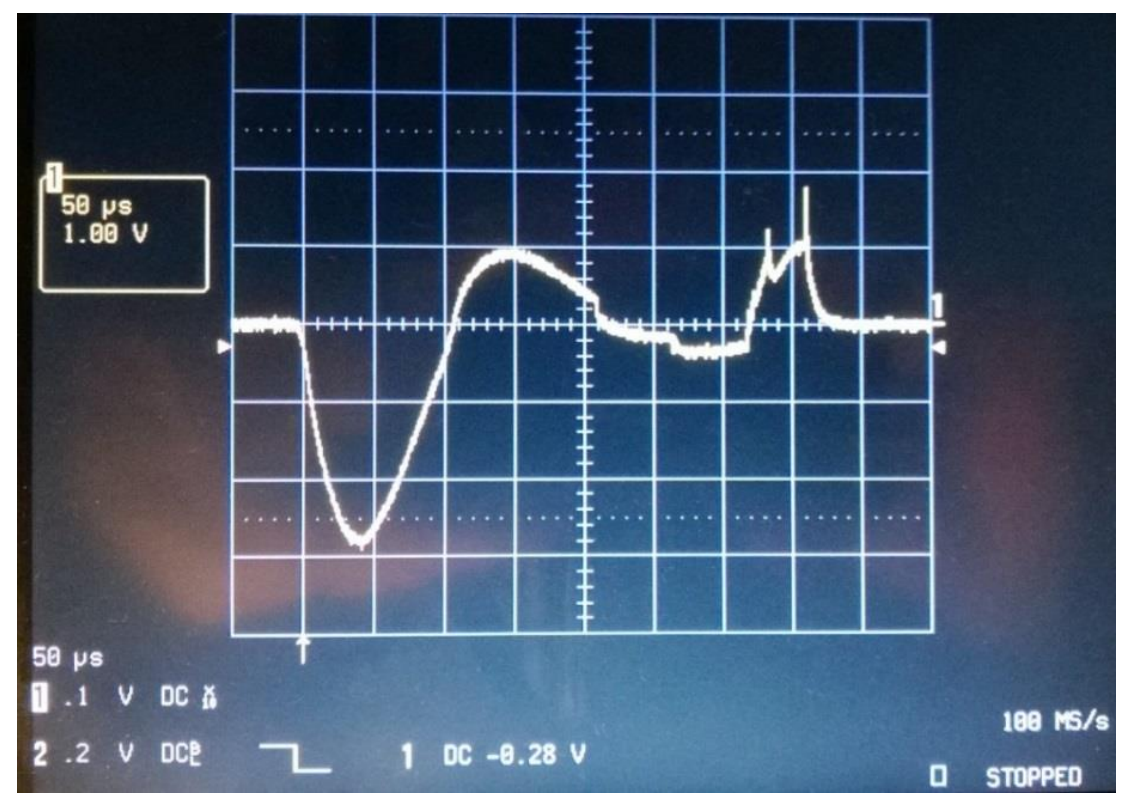

Figure 2-34 Oscilloscope screen \#10

Measured voltage is $32,25 \mathrm{~V}$ for the first test setup while it is $124.7 \mathrm{~V}$ for the second test setup. As a result, it is observed that not grounding the system outside almost triples the measured voltages. 
Maximum measured voltage for $10 \mathrm{kA}, 8 / 20 \mu$ s shaped direct high current impulse is 124.7V. Remember that the voltage division ratio of capacitive voltage divider is 47 .

$$
V=47 \times 124,7 \times\left(\frac{200000}{10000}\right)=117.2 \mathrm{kV}
$$

Calculated voltage in Eq. (2.18) is a very high voltage for an electronic system. If this high voltage travels through the cables and reach the electronic system, it will definitely cause damage.

High current impulses harm the cables used. This damage can be seen from Figure 2-35.

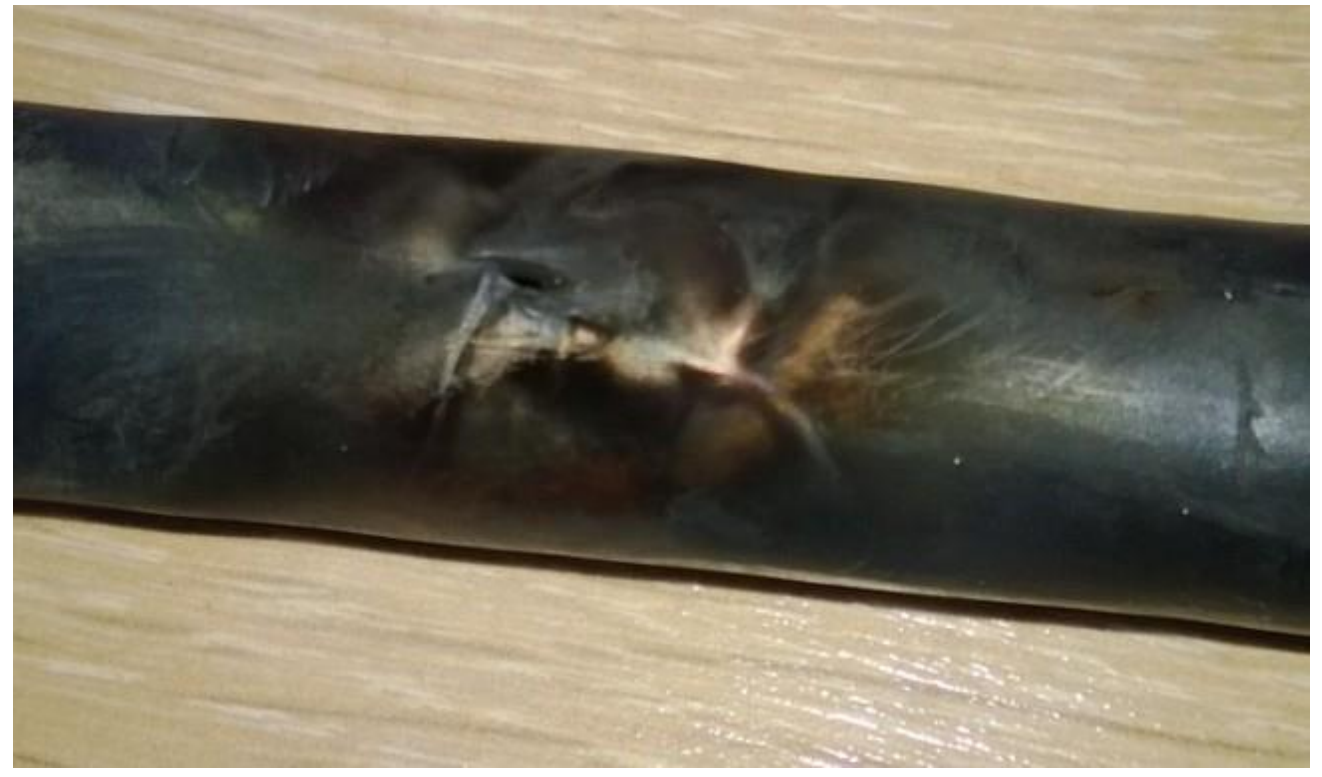

Figure 2-35 Damaged cable 


\section{CHAPTER 3}

\section{THE EFFECTS OF LIGHTNING DISCHARGES ON ANTENNA SYSTEMS}

An antenna is an electrical instrument that converts electromagnetic waves into electrical power, and vice versa [7]. A typical antenna consists of metallic conductors. Therefore, antennas are sensitive to lightning. Lightning discharge creates electromagnetic waves and these waves induce voltage on antennas. Since antennas are connected to electrical units on a system, there is a risk for an electrical unit to be damaged due to high induced voltages.

If one investigates the mechanism of lightning which is described in $1.1, \mathrm{~s} /$ he will see that electrical charges in thunderclouds reach to the tip of leader channel and whole leader channel is filled by electrical charges in exponentially increasing fashion from the top to the bottom [13]. In other words, more electrical charges are present at the bottom tip of the leader channel. These charges create an electric field around the channel yielding induced voltages on antennas around them. As return stroke is initiated, large amount of current flows between the clouds and the ground. This current creates magnetic field that also induce voltages on antennas. However, induced voltage due to this current is beyond the scope of this thesis. Induced voltages due to the charges in the leader channel just before the return stroke are the main focus of the thesis.

In order to analyze induced voltages on an antenna some simulations and experiments are designed. Their details are given in the following sections.

\subsection{Simulation of lightning effects on antennas}

Before carrying out the experiments, some simulations of these experiments are made by using the program Ansys Maxwell 15.0. It is electromagnetic field simulation software which uses finite element analysis to solve static, frequency- 
domain, and time-varying electromagnetic and electric fields. A geometry which is similar to the one in Figure 3-9 is drawn using the simulation program. The antenna is simulated as a cylinder with $0.3 \mathrm{~cm}$ radius that is placed to $2.5 \mathrm{~m}, 5 \mathrm{~m}$ and $7.5 \mathrm{~m}$ far away to leader channel (metal rod for the experiments). Another cylinder with $1 \mathrm{~cm}$ radius and $3 \mathrm{~m}$ length is placed to stand for leader channel. This cylinder is divided into four because the charges in the leader channel are not distributed equally. In fact, they are increasing exponentially towards the bottom tip of the leader channel. Therefore, each cylinder has a different charge. These charges are calculated as in Eq. (3.6) and Eq. (3.7).

Let's analyze the real lightning first. The lightning leader channel can be regarded as a charged conductor, whose charge density at a height $\mathrm{h}$ is given as Eq. (3.1) [13].

$$
Q_{h}=Q_{o} e^{-\beta h}\left(\mathrm{C} / \mathrm{cm}^{3}\right)
$$

Assume that thundercloud is at the height of $2500 \mathrm{~m}$ with a leader channel extending downwards to $50 \mathrm{~m}$ above the ground. Since the charge density is exponentially increases downwards, fewer charges present on higher portions of the leader channel when compared to lower portions. Assume that all of the charges are distributed to lower $300 \mathrm{~m}$ part of the leader channel. The total charge $\mathrm{q}_{0}$ on the leader channel is given as in Eq. (3.2).

$$
q_{0}=Q_{0} \int_{h_{1}}^{h_{2}} e^{-\beta h} d h
$$

where $\mathrm{h}_{1}=50 \mathrm{~m}\left(\right.$ or $\left.5.10^{3} \mathrm{~cm}\right), \mathrm{h}_{2}=350 \mathrm{~m}\left(\right.$ or $\left.35.10^{3} \mathrm{~cm}\right)$ and $\beta=10^{-5}$

$$
q_{0}=Q_{0} \int_{5.10^{3}}^{35.10^{3}} e^{-\beta h} d h
$$

From which,

$$
q_{0}=-\frac{Q_{0}}{\beta}\left[\frac{1}{e^{0.35}}-\frac{1}{e^{0.05}}\right]
$$

Let us assume that total charge in the leader, $\mathrm{q}_{0}$, is equal to 1 coulomb because approximately $50 \%$ of lightning has a charge of 1 coulomb [14]. Then, $\mathrm{Q}_{0}$ is calculated as in Eq. (3.5). 


$$
Q_{0}=4,0566 \cdot 10^{-5} \mathrm{C} / \mathrm{m}
$$

Therefore, total charge between $50-125 \mathrm{~m}$ portion of the leader channel is calculated as in Eq. (3.6).

$$
q_{50-125}=Q_{0} \int_{5.10^{3}}^{125.10^{2}} e^{-\beta h} d h
$$

Therefore,

$$
q_{50-125}=0.2787 C
$$

The total charges in $125-200 \mathrm{~m}, 200-275 \mathrm{~m}$ and $275-350 \mathrm{~m}$ can be calculated in a similar way. Remember that, leader channel is extending downwards to $50 \mathrm{~m}$ above the ground.

Table 3-1 Total charges in the leader channel portions

\begin{tabular}{|c|c|}
\hline Height $(\mathrm{m})$ & Total charge $(\mathrm{C})$ \\
\hline $50-125$ & 0.2787 \\
\hline $125-200$ & 0.2588 \\
\hline $200-275$ & 0.2401 \\
\hline $275-350$ & 0.2223 \\
\hline
\end{tabular}

\subsubsection{Simulation Results}

The geometry which is used in the simulation is given in Figure 3-1. In addition to the cylinders with pink color, there is a ground plane laid on XY plane. This ground plane is assigned to zero voltage. Reference of all voltages in simulation is this ground plane. The length of antenna is $70 \mathrm{~cm}$ and it is $2.5 \mathrm{~m}$ far away from the metal rod for the geometry in Figure 3-1. 


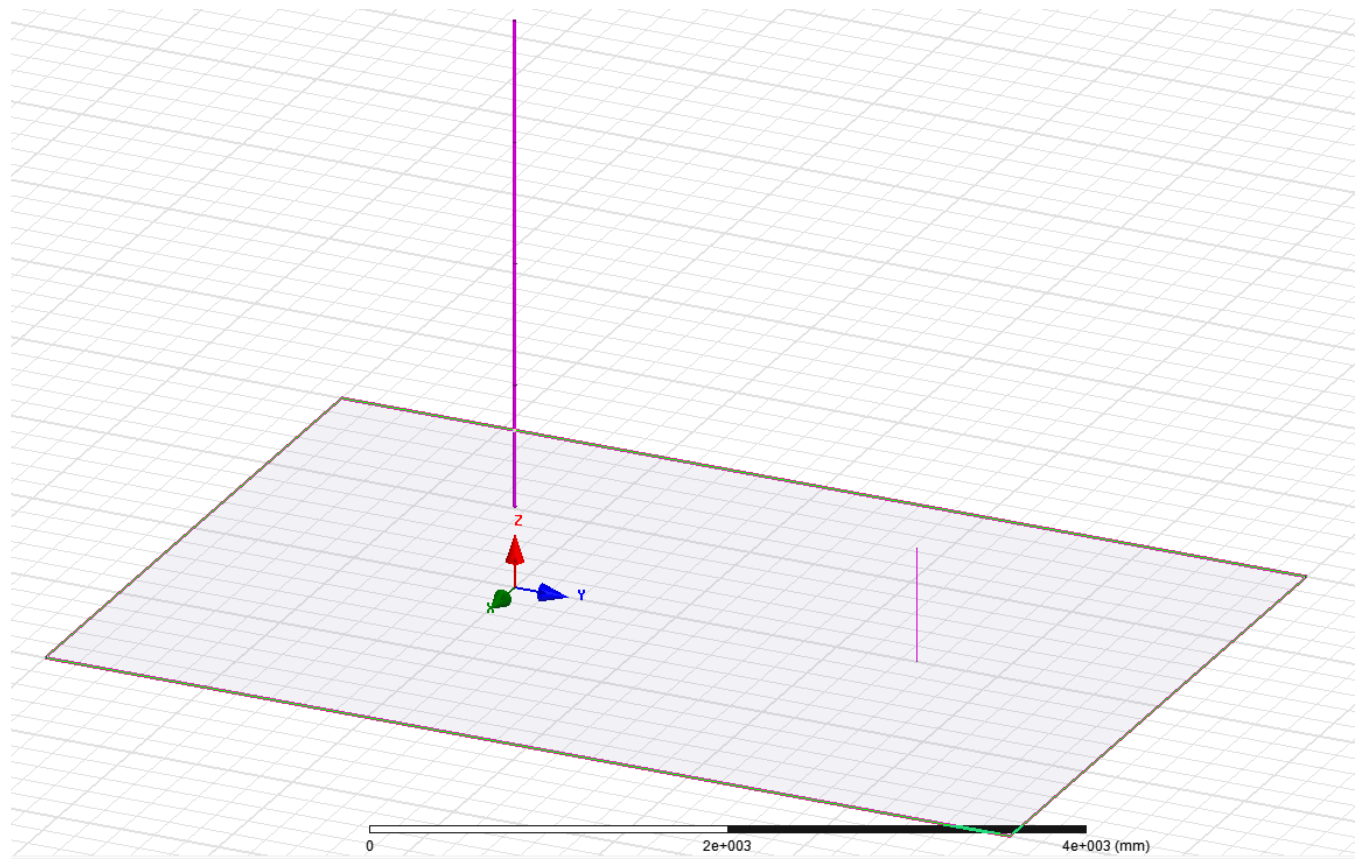

Figure 3-1 Simulation geometry

A lightning that has a total charge of 1 coulomb also has a current of approximately 20kA. The high voltage impulse generator which is used in experimental setup to measure the induced voltage on an antenna is charged with $360 \mathrm{kV}(6 \mathrm{x} 60 \mathrm{kV})$. This generator discharges to the ground via $4 \mathrm{k} \Omega$ resistor (experimental setup can be seen from Figure 3-9). Therefore, this discharge has a current of $90 \mathrm{~A}$ which is 0.0045 times less then real lightning current. Since the geometry of experimental setup is used in simulation, the total charges must be extrapolated to experimental values. The values that are used in simulation can be seen from Table 3-2.

Table 3-2 Total charges in the metal rod portions

\begin{tabular}{|c|c|}
\hline Height $(\mathrm{cm})$ & Total charge $(\mathrm{C})$ \\
\hline $50-125$ & $1.254 \times 10^{-3}$ \\
\hline $125-200$ & $1.165 \times 10^{-3}$ \\
\hline $200-275$ & $1.0804 \times 10^{-3}$ \\
\hline $275-350$ & $1.0003 \times 10^{-3}$ \\
\hline
\end{tabular}

Voltage and electric field due to the charges in metal rod can be seen from Figure 3-2 and Figure 3-3. Note that, there is an exponentially increasing trend towards to the bottom tip of the metal rod. 


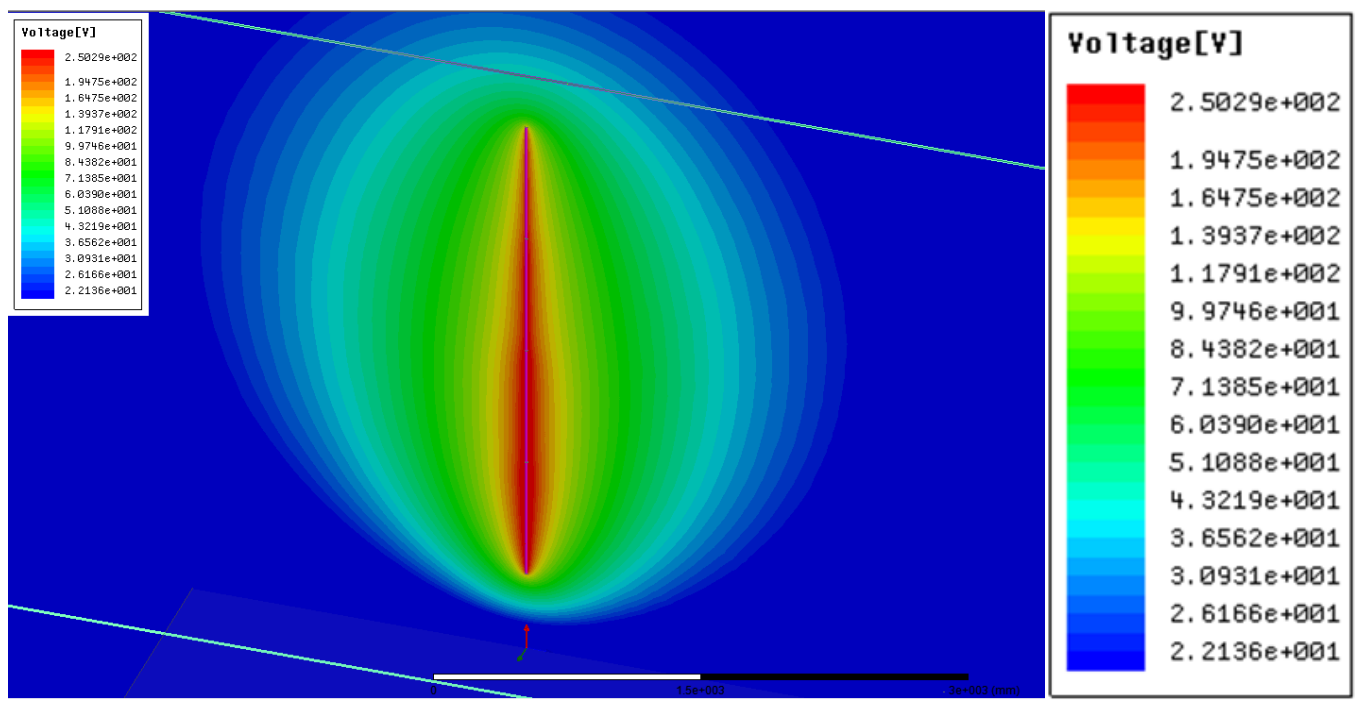

Figure 3-2 Voltage due to the charges in the metal rod

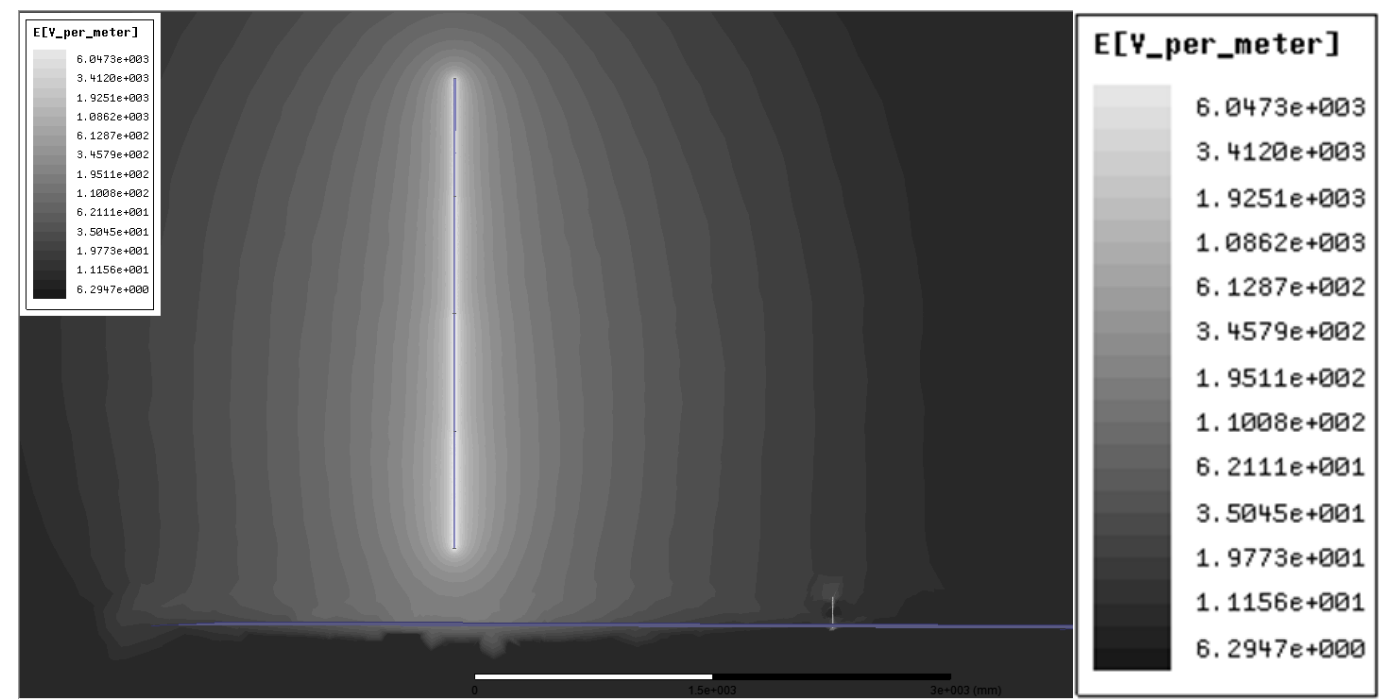

Figure 3-3 Electric field due to the charges in the metal rod

The charges in the metal rod induce voltage on the antenna. Induced voltage on $70 \mathrm{~cm}$ antenna which is $2.5 \mathrm{~m}$ far away from the metal rod can be seen from Figure 3-4. Antenna is zoomed in to observe how much voltage is induced on it. Induced voltage on the antenna is simulated to be $3.19 \mathrm{~V}$. Since the antenna is a conductive metal rod, induced voltage is the same everywhere on it. 


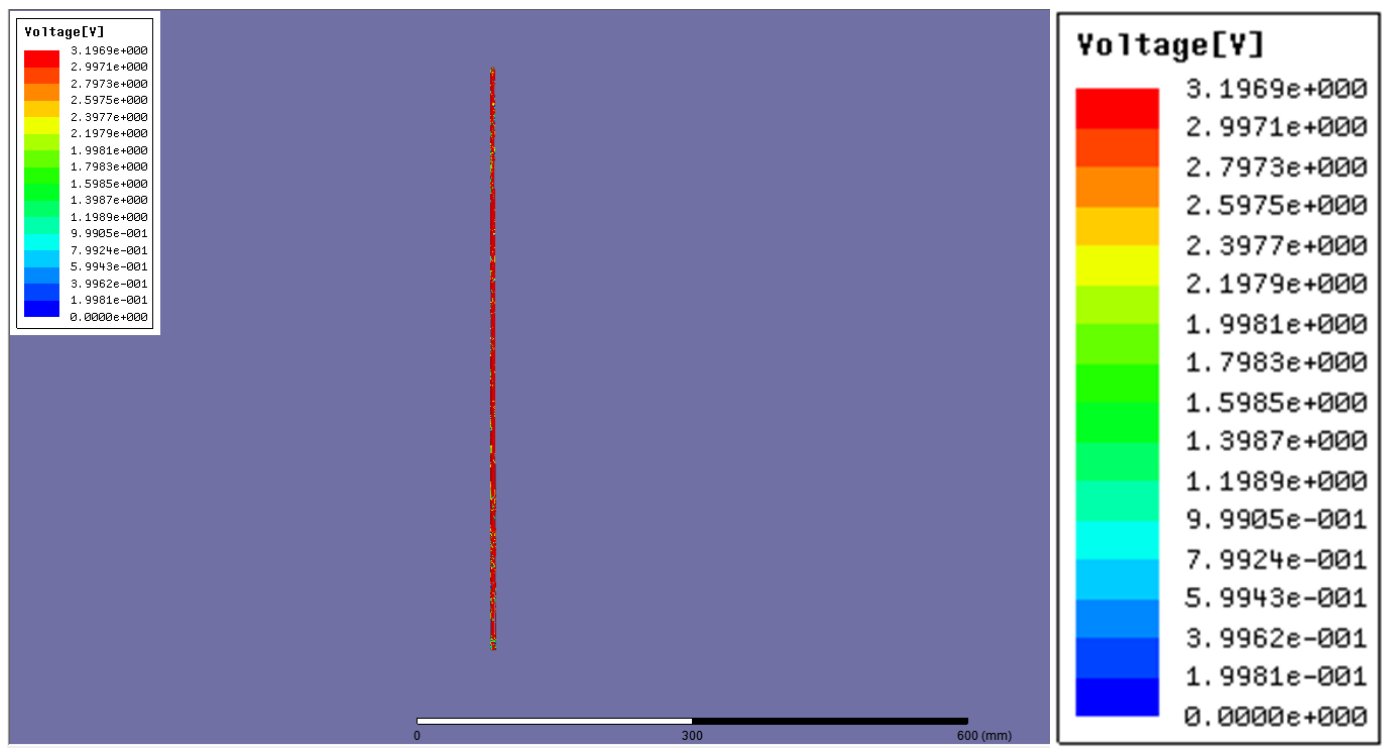

Figure 3-4 Induced voltage on $70 \mathrm{~cm}$ antenna which is $2.5 \mathrm{~m}$ far away from the metal $\operatorname{rod}$

Induced voltage on $40 \mathrm{~cm}$ antenna which is $2.5 \mathrm{~m}$ far away from the metal rod can be seen from Figure 3-5. Induced voltage on the antenna is simulated to be $1.91 \mathrm{~V}$.
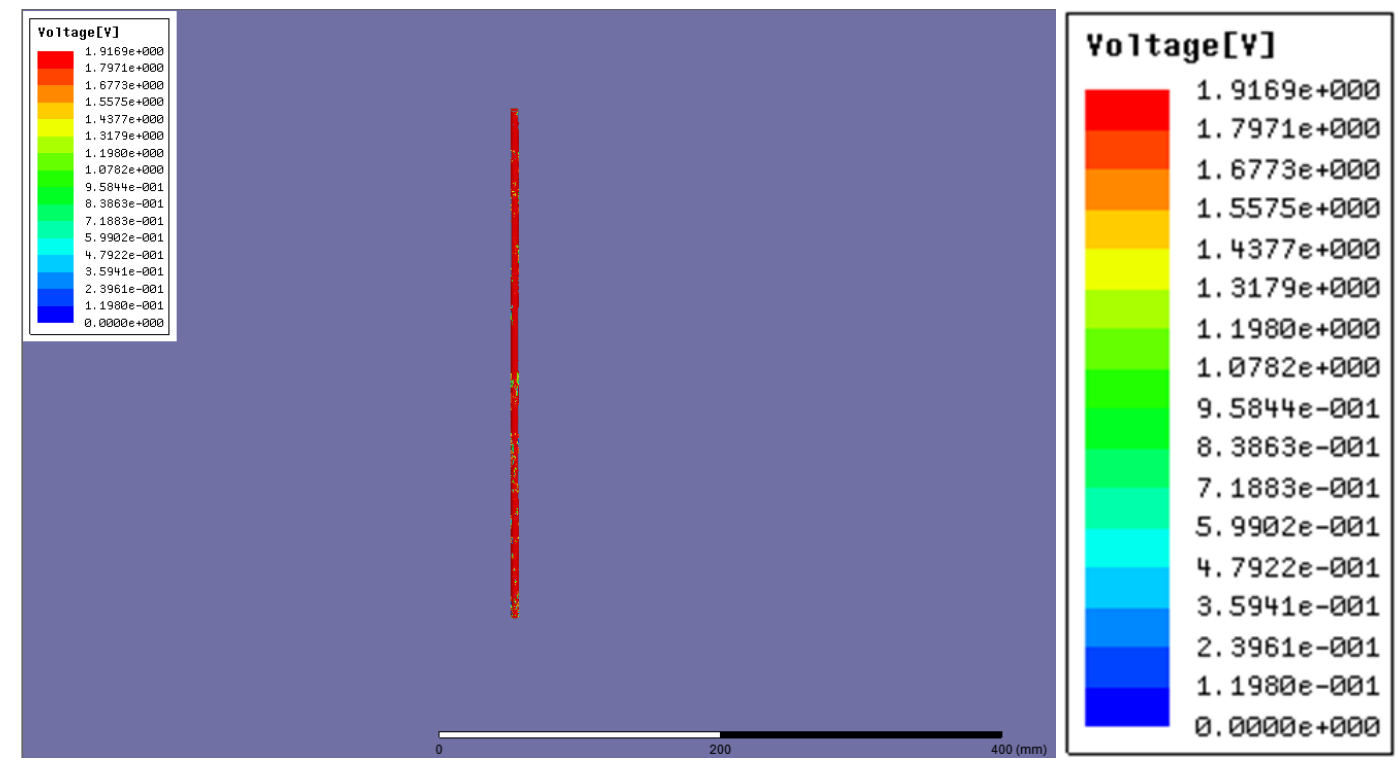

Figure 3-5 Induced voltage on $40 \mathrm{~cm}$ antenna which is $2.5 \mathrm{~m}$ far away from the metal $\operatorname{rod}$

Induced voltage on $20 \mathrm{~cm}$ antenna which is $2.5 \mathrm{~m}$ far away from the metal rod can be seen from Figure 3-6. Induced voltage on the antenna is simulated to be $0.97 \mathrm{~V}$. 


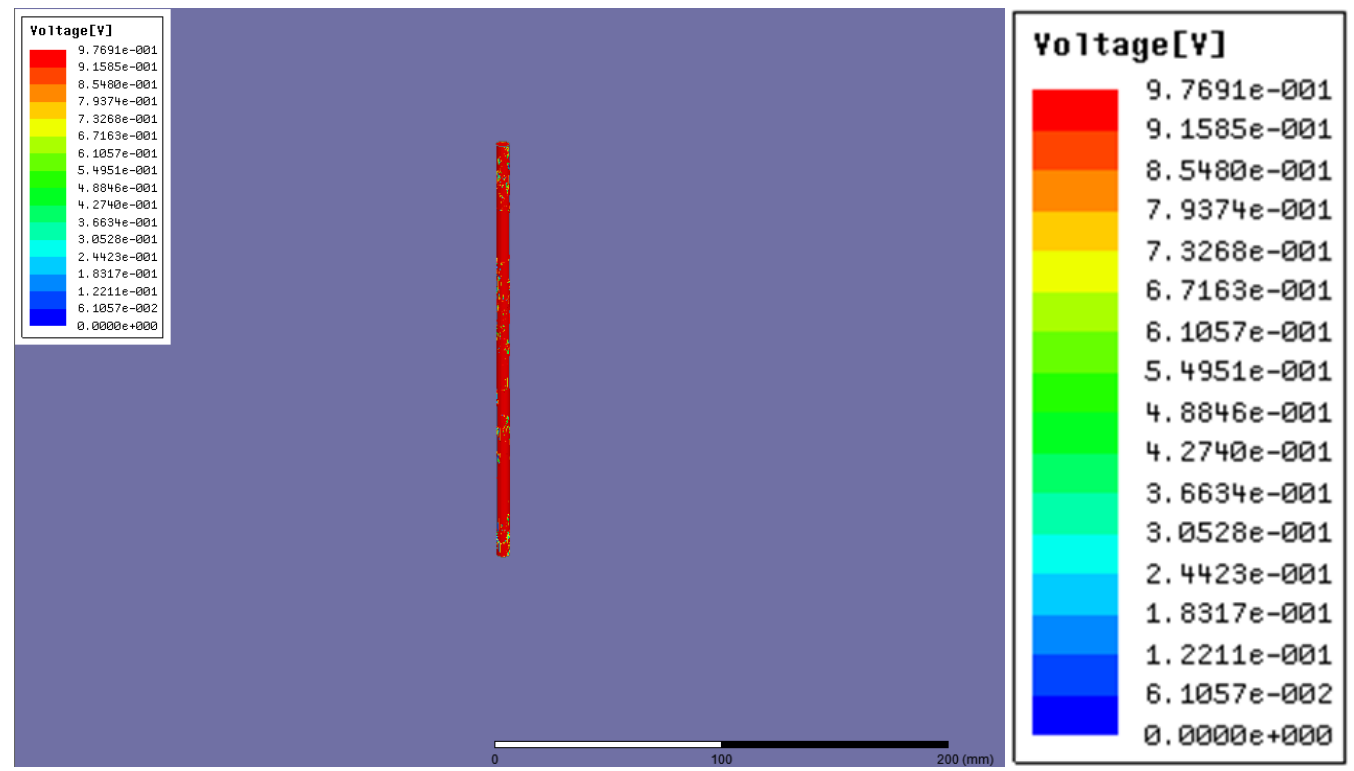

Figure 3-6 Induced voltage on $20 \mathrm{~cm}$ antenna which is $2.5 \mathrm{~m}$ far away from the metal rod

Note that, there is a linear relationship between the induced voltage and the length of antenna. This is because the capacitance between antenna and the ground changes linearly as antenna gets longer.

Induced voltage on $20 \mathrm{~cm}$ antenna which is $5 \mathrm{~m}$ far away from the metal rod can be seen from Figure 3-7. Induced voltage on the antenna is simulated to be $0.43 \mathrm{~V}$.
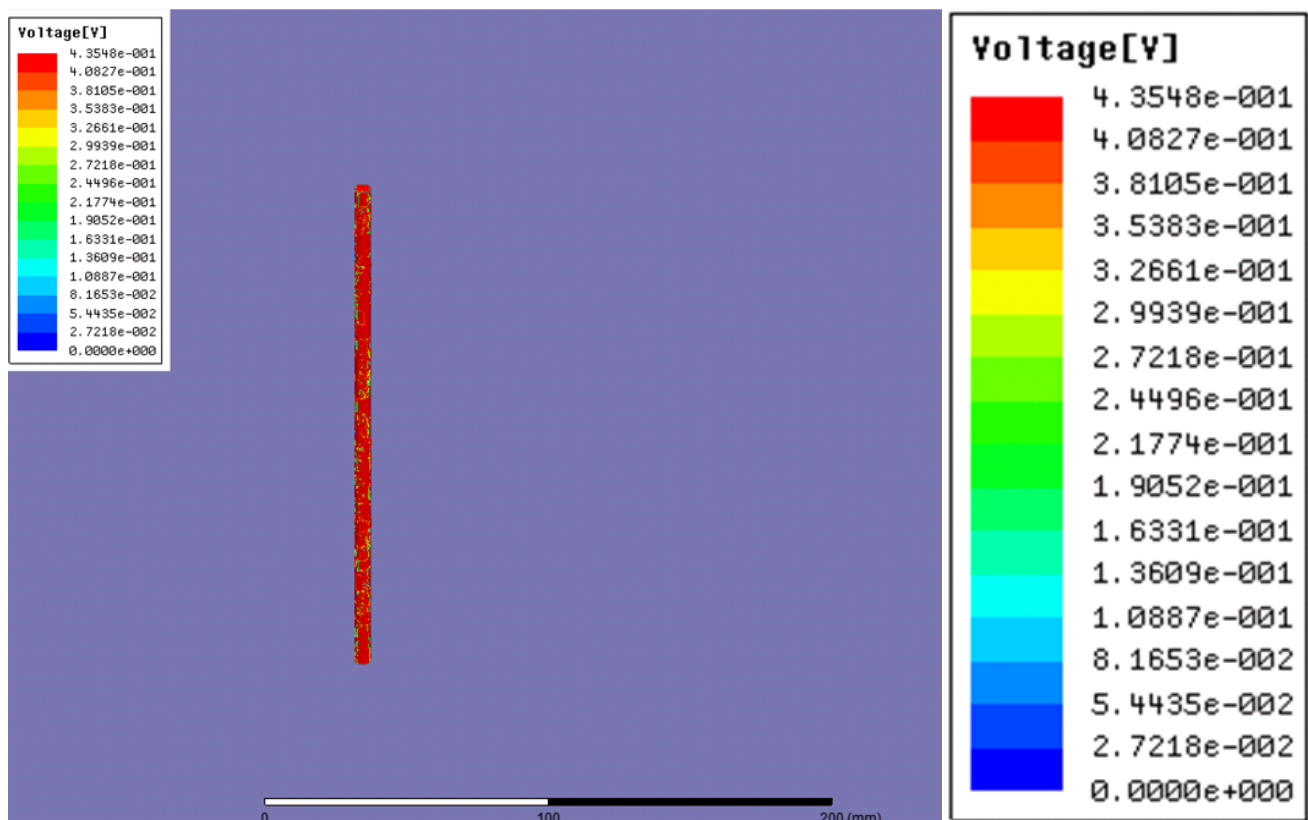

Figure 3-7 Induced voltage on $20 \mathrm{~cm}$ antenna which is $5 \mathrm{~m}$ far away from the metal rod 
Induced voltage on $20 \mathrm{~cm}$ antenna which is $7.5 \mathrm{~m}$ far away from the metal rod can be seen from Figure 3-8. Induced voltage on the antenna is simulated to be $0.13 \mathrm{~V}$.

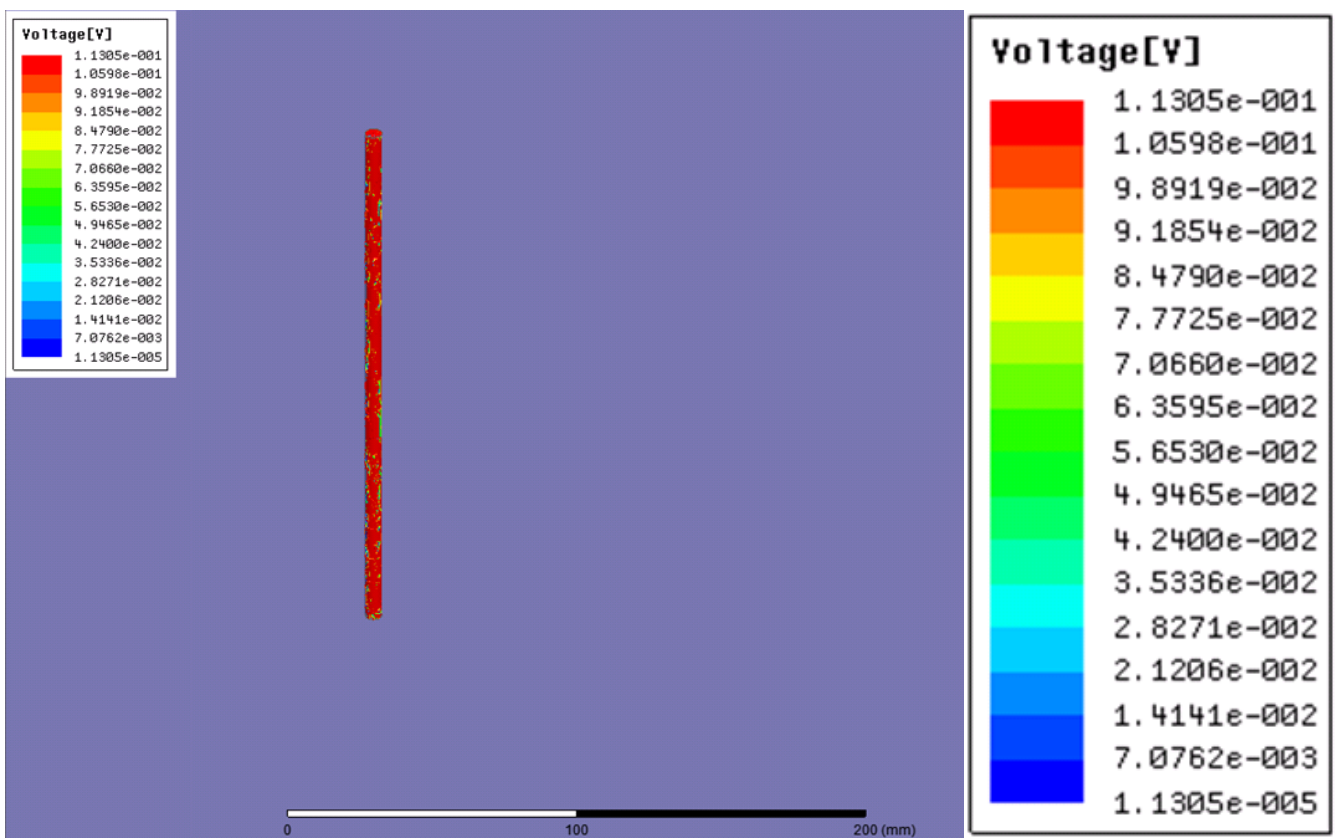

Figure 3-8 Induced voltage on $20 \mathrm{~cm}$ antenna which is $7.5 \mathrm{~m}$ far away from the metal $\operatorname{rod}$

\subsection{Lightning Impulse Voltage Tests}

The voltage impulses used in the tests are generated by a multi-level voltage impulse generator (8 levels, $1000 \mathrm{kV}$, and $30 \mathrm{~kJ}$ ), same as in 2.1. This time, generator is charged with (-60x6) $\mathrm{kV}$ throughout the experiments. A metal rod is placed to the top of the capacitive voltage divider in order to stand for the leader channel. A metal plate is laid to the floor for grounding. Test setup can be seen from Figure 3-9, Figure 3-10, and Figure 3-11. 

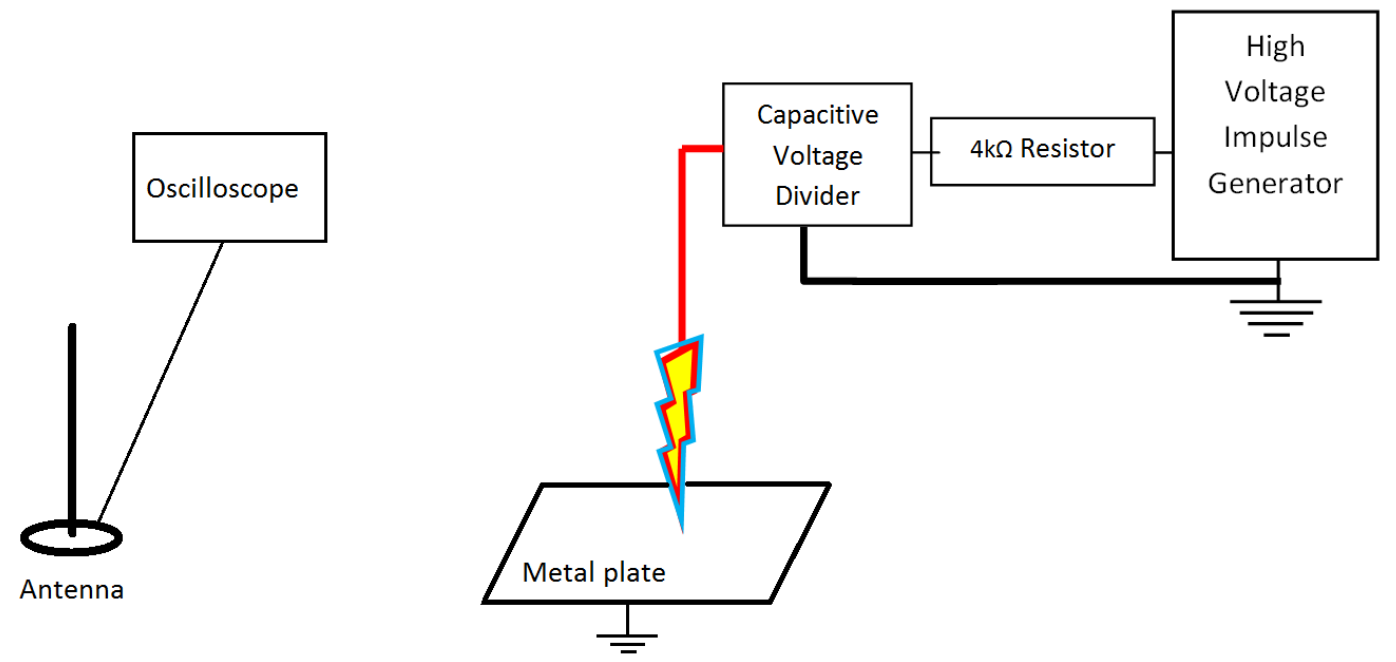

Figure 3-9 High voltage impulse test setup

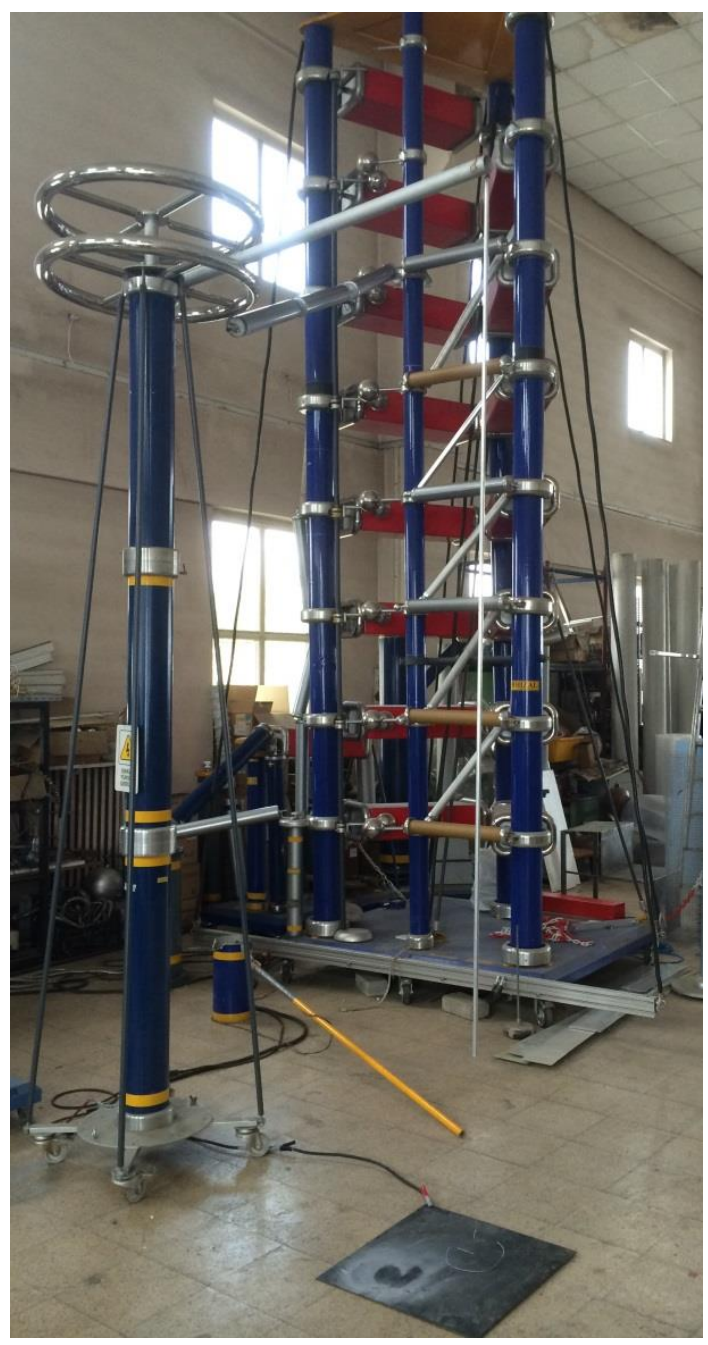

Figure 3-10 High voltage impulse test setup 


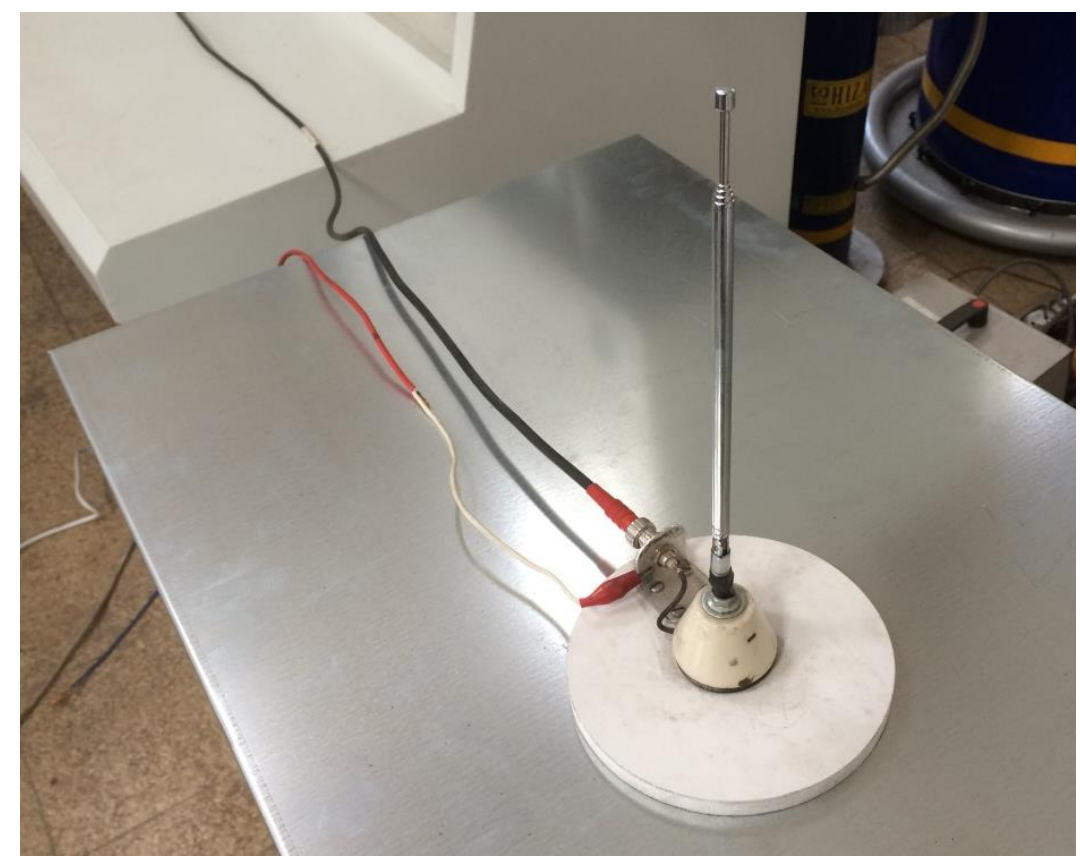

Figure 3-11 High voltage impulse test setup

Antenna is placed 2.5, 5, and $7.5 \mathrm{~m}$ near lightning discharge throughout the experiments in order to observe the effect of distance. In addition, antenna length is set to 20,40 and $70 \mathrm{~cm}$ to examine the effect of antenna length on induced voltage.

\section{1) Setup: Antenna is $2.5 \mathrm{~m}$ far from discharge channel}

Induced voltage can be seen from Figure $3-12$ as antenna length is $20 \mathrm{~cm}$. This voltage wave can be analyzed in 3 parts. First part is a voltage wave with high frequency that is observed at the beginning. This is the induced voltage due to the electromagnetic waves caused by the breakdown of air between spark gaps of the generator. There is no such thing in natural mechanism of lightning, so this voltage with high frequency can be ignored. There is a second high frequency voltage at the end which is the third part of the wave. This part is present due to the electromagnetic waves caused by the breakdown of the air between the tip of metal rod and grounded metal plate. This is the return stroke in natural mechanism of lightning which is present in real lightning. However, this part of the induced voltage is beyond the scope of the thesis. There is a voltage wave between these high frequency parts. This part is the main focus of the thesis because this voltage is induced by the electric field due to the charges in metal rod (leader channel in natural lightning). This voltage wave has the $1.2 / 50 \mu$ s impulse shape only with a 2901 times 
less magnitude. 2901 is the division ratio of the capacitive voltage divider. Induced voltage is $0.85 \mathrm{~V}$ (which is simulated to be $0.97 \mathrm{~V}$ using Ansys Maxwell) just before the breakdown of the air between metal rod and grounded metal plate.

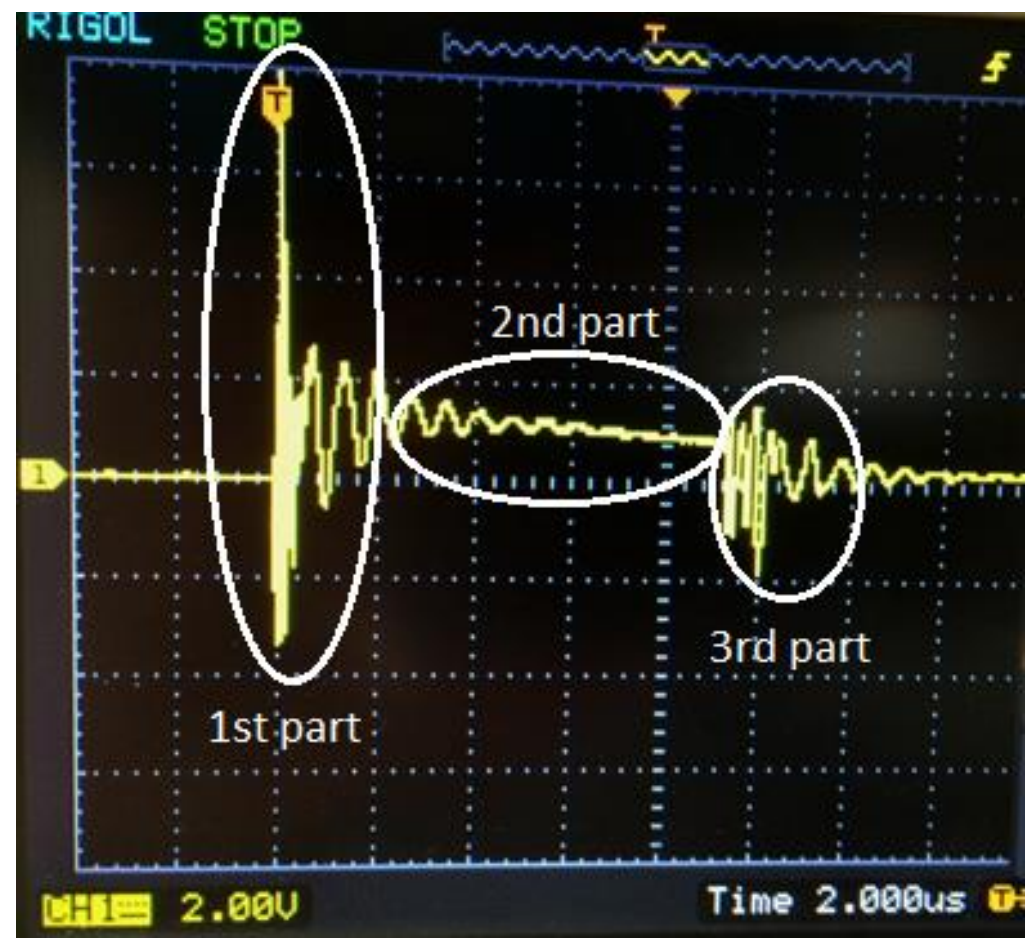

Figure 3-12 Induced voltage on $20 \mathrm{~cm}$ antenna

As the length of antenna is doubled, induced voltage on antenna is doubled to $1.7 \mathrm{~V}$ (which is simulated to be $1.91 \mathrm{~V}$ using Ansys Maxwell) as well. Induced voltage on $40 \mathrm{~cm}$ antenna can be seen from Figure 3-13. In fact, induced voltage is 3.5 times larger (3V) (which is simulated to be $3.19 \mathrm{~V}$ using Ansys Maxwell) when antenna is 3.5 times longer. Induced voltage on $70 \mathrm{~cm}$ antenna can be seen from Figure 3-14. These results show that as antenna length gets larger, induced voltage increases. 


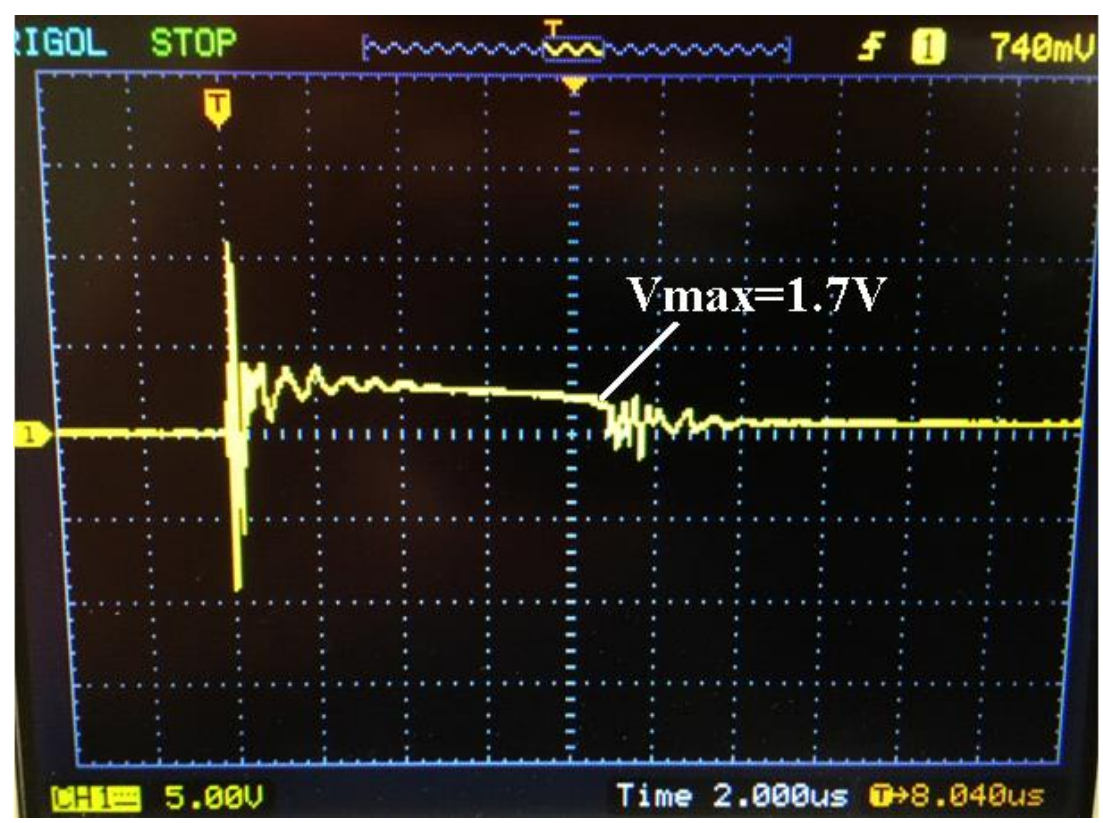

Figure 3-13 Induced voltage on $40 \mathrm{~cm}$ antenna

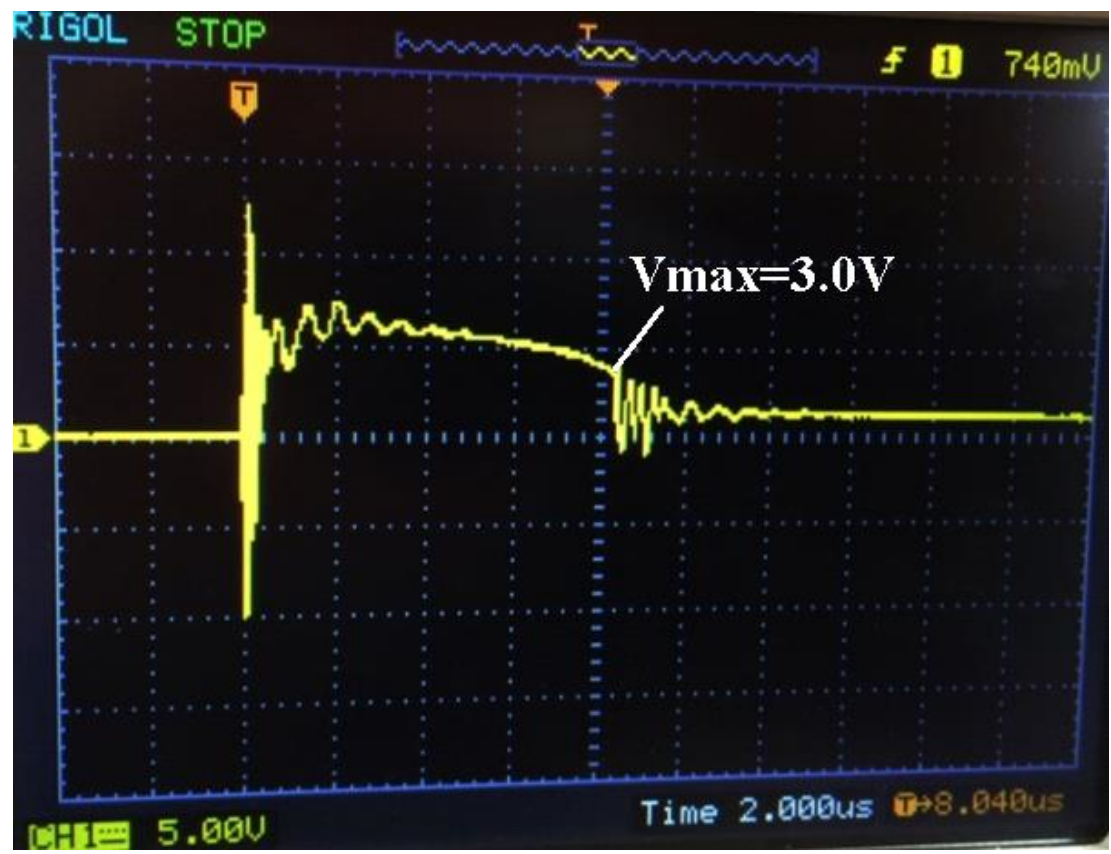

Figure 3-14 Induced voltage on $70 \mathrm{~cm}$ antenna

2) Setup: Antenna is $5 \mathrm{~m}$ far from discharge channel

Induced voltage can be seen from Figure $3-15$ as antenna length is $20 \mathrm{~cm} .0 .4 \mathrm{~V}$ (which is simulated to be $0.43 \mathrm{~V}$ using Ansys Maxwell) is induced just before the breakdown of the air between metal rod and grounded metal plate. 


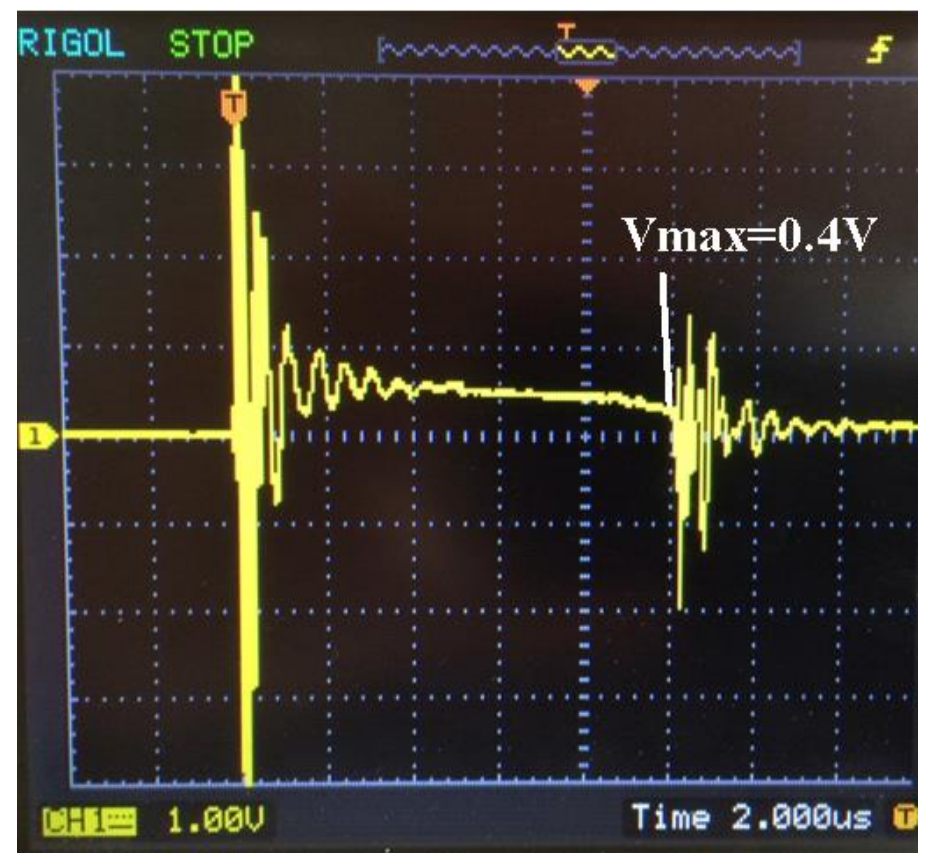

Figure 3-15 Induced voltage on $20 \mathrm{~cm}$ antenna

3) Setup: Antenna is $7.5 \mathrm{~m}$ far from discharge channel

Induced voltage can be seen from Figure 3-16 as antenna length is $20 \mathrm{~cm}$. About $0.15 \mathrm{~V}$ (which is simulated to be $0.13 \mathrm{~V}$ using Ansys Maxwell) is induced just before the breakdown of the air between metal rod and grounded metal plate.

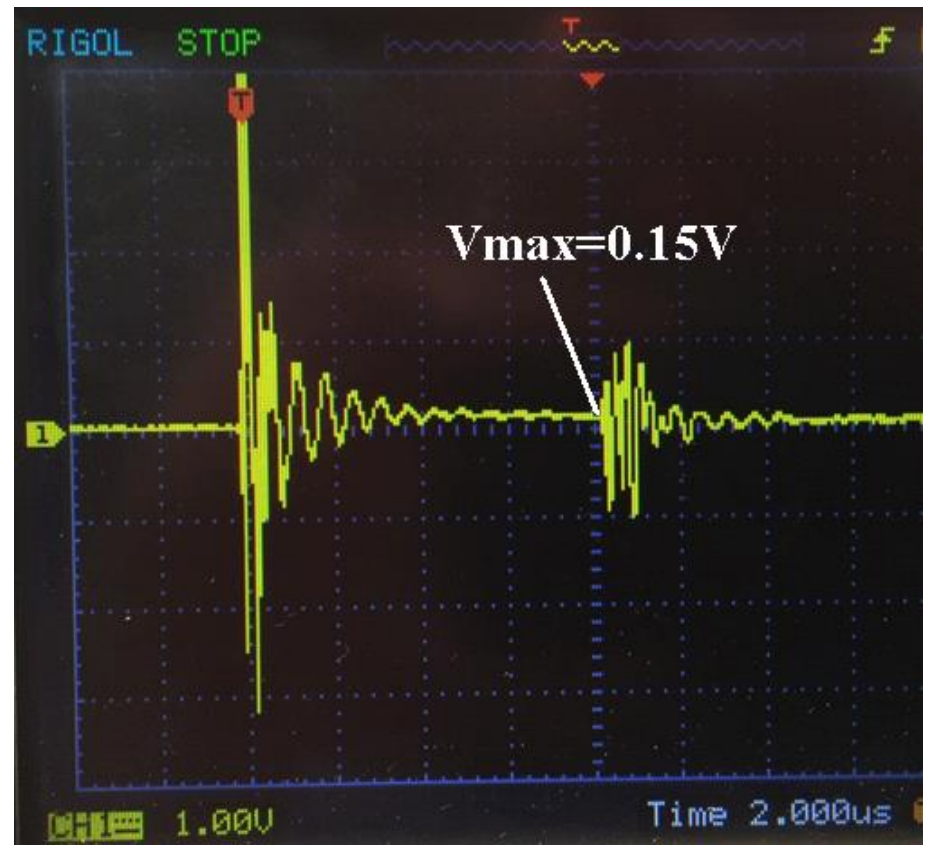

Figure 3-16 Induced voltage on $20 \mathrm{~cm}$ antenna 
For a $20 \mathrm{~cm}\left(\mathrm{~L}_{2}\right)$ antenna, $0.85 \mathrm{~V}\left(\mathrm{~V}_{\text {ind }}\right)$ is induced when discharge channel is $2.5 \mathrm{~m}$ $\left(d_{2}\right)$ far away from it. Discharge current is $90 \mathrm{~A}\left(\mathrm{I}_{2}\right)$ for the high voltage generator used. Since it is charged to $360 \mathrm{kV}(60 \times 6$ levels) and its current is limited by $4 \mathrm{k} \Omega$ resistor. The relationship between induced voltage and distance is discussed in 2.2.1.1. Therefore, induced voltage on a $1.5 \mathrm{~m}\left(\mathrm{~L}_{1}\right), 50 \mathrm{~m}\left(\mathrm{~d}_{1}\right)$ away antenna by a $200 \mathrm{kA}\left(\mathrm{I}_{1}\right), 1.2 / 50 \mu \mathrm{s}$ shaped lightning can be calculated.

$$
\begin{aligned}
& V=V_{\text {ind }} \times\left(\frac{L_{1}}{L_{2}}\right) \times\left(\frac{I_{1}}{I_{2}}\right) \times\left(\frac{d_{2}}{d_{1}}\right) \\
& V=0.85 \times\left(\frac{1.5}{0.2}\right) \times\left(\frac{200000}{90}\right) \times\left(\frac{2.5}{50}\right)=708.3 \mathrm{~V}
\end{aligned}
$$

This voltage is high enough to damage some electronic equipment. It may exceed the breakdown voltage of some semiconductor devices and cause them to burn out.

\subsection{Induced Voltage Protection}

Various protective equipment like varistors and zener diodes are connected between ground signal end of the antenna in order observe the protection performance of them. $70 \mathrm{~cm}$ antenna was $2 \mathrm{~m}$ far away from the generator that is charged to $480 \mathrm{kV}$ (80 x 6 levels).

Induced voltage is $15 \mathrm{~V}$ as can be seen from Figure 3-17 when there is no protection equipment. 


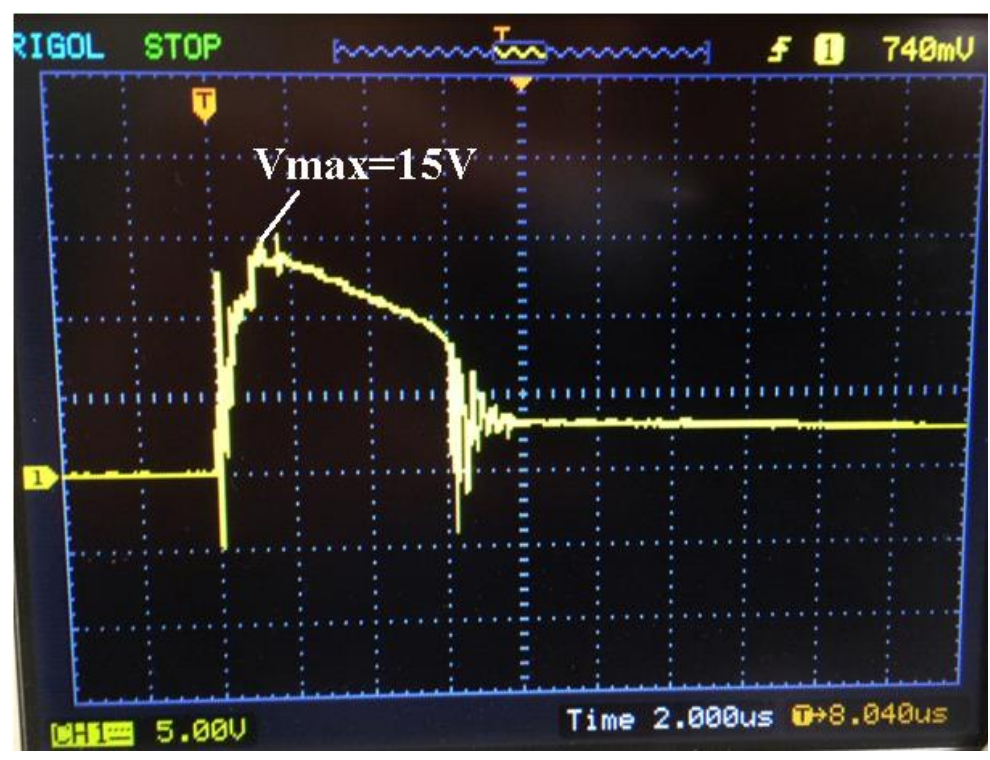

Figure 3-17 Induced voltage when there is no protection

Induced voltage can be seen from Figure 3-18 as a 3.3V zener diode is connected between ground signal end of the antenna. It is observed that zener diode responses immediately and clips off the induced voltage at $3.3 \mathrm{~V}$. Some oscillations are observed at clipping point because of cable inductance and stray capacitance between the antenna and the ground. These oscillations are damped due to resistance of cables. Although zener diode responses very fast, it cannot clip off the high frequency voltage caused by the breakdown of generator's spark gaps.

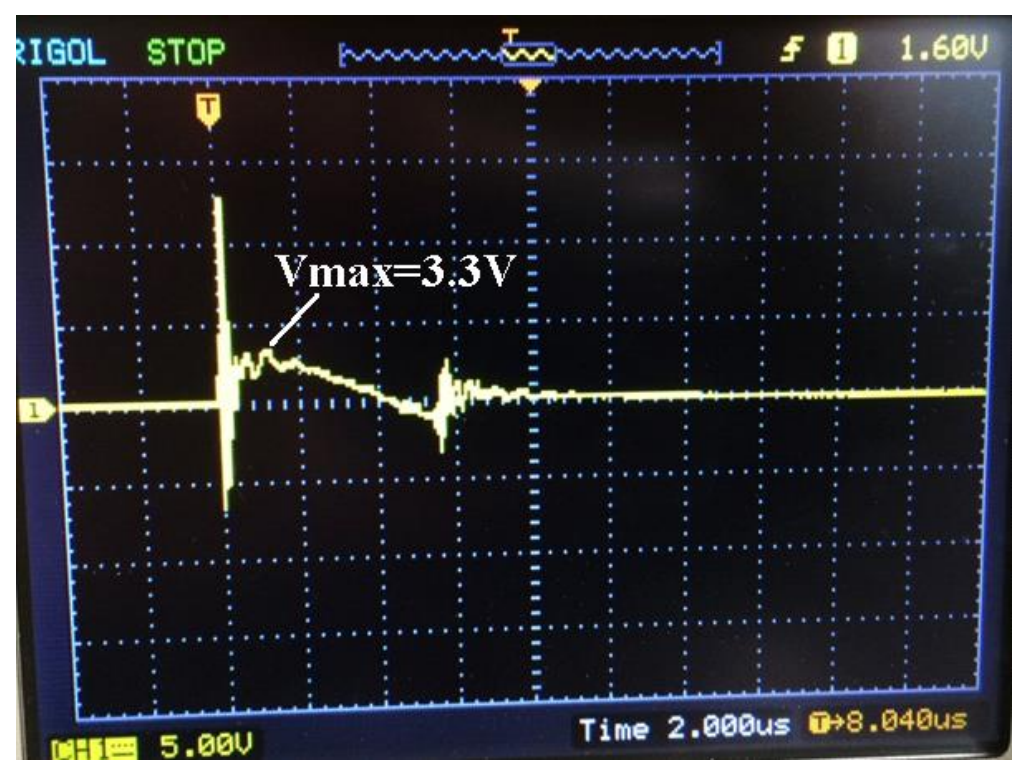

Figure 3-18 Induced voltage with 3.3V zener diode 
Induced voltage can be seen from Figure 3-19 as a 5.6V zener diode is connected between ground signal end of the antenna.

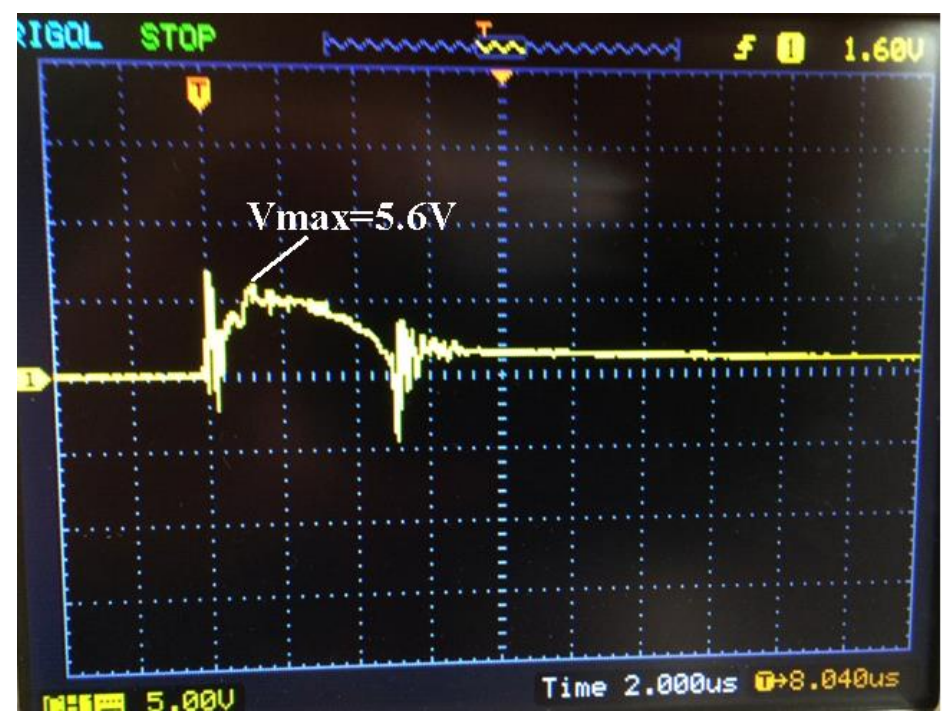

Figure 3-19 Induced voltage with 5.6V zener diode

Induced voltage can be seen from Figure $3-20$ as a $5.6 \mathrm{~V}$ varistor is connected between ground signal end of the antenna. The varistor cannot clip off the voltage at $5.6 \mathrm{~V}$ although its rated voltage is $5.6 \mathrm{~V}$. It is because varistors are not as fast as zener diodes. Induced voltage is present on the antenna for $6 \mu \mathrm{s}$ and the varistor cannot response that fast. Therefore, it is concluded that varistors are not suitable electronic equipment for induced voltage (due to lightning) protections for antennas.

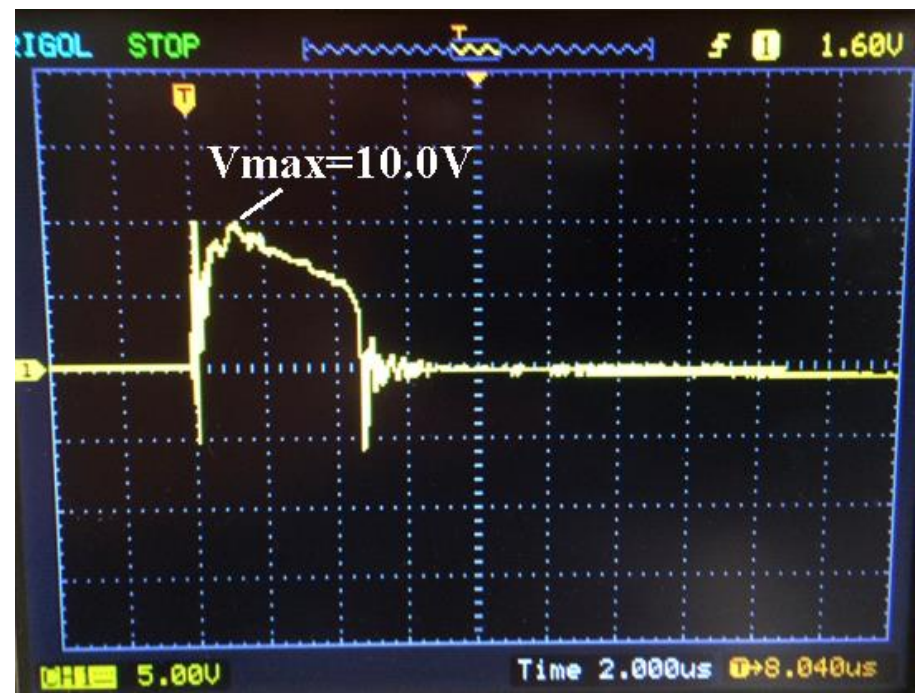

Figure 3-20 Induced voltage with 5.6V varistor 


\section{CHAPTER 4}

\section{CONCLUSION}

Lightning has always aroused the interest of people since it is a powerful, visible and impressive natural phenomenon. First studies about lightning are made by Benjamin Franklin in 1774 [9]. Modern research on lightning physics began in 1916 by C. T. R. Wilson [10], [11]. The pace of the researches about lightning was steady until the 1960s. Solid state electronics devices started to develop in the early 1960s and they were vulnerable to lightning-induced voltages. Consequently, scientist attached importance to studies on lightning [12]. Researchers have made numerous studies on lightning and lightning related topics since then. This thesis is one of those studies which focus on the induced voltages on control \& communication cables and antenna systems caused by lightning discharges.

Lightning is a discharge of atmospheric electricity that causes a sudden release of energy. The mechanism of lightning is a sequence of very complex physical phenomena. Although various scientific researches are made, this mechanism has not fully well-understood yet. Negative electric charges are present in the leader channel just before lightning discharge. Number of charges increases exponentially towards the bottom tip of the leader channel as can be seen from 3.1. Electric field is generated due to these electric charges whose magnitude is increasing towards the bottom tip of the leader channel as well. During return stroke; huge amount of current flows between thunderclouds and the ground. Most of the time more than one flash is observed which is called multiple strokes. Magnetic field is generated because of this huge current. Due to these electric and magnetic fields, induced voltages are generated on the conductors around.

Induced voltages on cables and antennas caused by lightning discharges can be dangerous for the system elements that they are connected to. If a system element is harmed, whole system may shut down. This is an undesired situation which may 
become a very serious problem for some critical systems. First aim is to prevent the cables and antennas from lightning hit by taking some precautions which is detailed below. Despite all precautions, a lightning can hit them directly or indirectly. If the cables or antennas are hit directly by a lightning, there is not much to do to protect the system. Very high voltages exist in the cable or the antenna in this case. If this voltage does not jump to the ground from the cable or the antenna before reaching the system, it will definitely cause damage. If a lightning hit a point which is close to the cables or antennas, it will induce a voltage on them. This induced voltage will directly reach to the system they are connected to. It is not high enough to jump to the ground, but high enough to damage the system.

In order to measure electric and magnetic field created by lightning discharge, high voltage and high current impulse experiments are conducted. High voltage and high current impulses are applied to cables directly or indirectly. High voltage impulse tests led us to measure the electric field created by a lightning discharge. A D-dot probe which is designed to measure electric fields is used in these experiments. High current impulse tests enabled us to measure the magnetic field due to a lightning discharge. An air core coil is designed to sense the current change that led us to measure the magnetic field. The results of these experiments are extrapolated to obtain the values for a real lightning. Then, these values are discussed whether they are harmful for an electrical system, or not. Theoretical values are also compared with the ones we obtained. Similar experiments are conducted for antennas. Only high voltage impulses are applied to them indirectly. Induced voltage is measured and extrapolated as well in this case. The induced voltage values after extrapolation is also analyzed and compared to the results obtained from computer simulations. Experimental results and simulation outputs are close which proves the reliability of the experiments. The simulations are made by software named Ansys Maxwell. It is electromagnetic field simulation software which uses finite element analysis to solve static, frequency-domain, and time-varying electromagnetic and electric fields.

Based on the theoretical analyses, simulations and experiments, it is shown that lightning discharges induce voltages on cables and antennas which are high enough to damage the system they are connected to. Therefore, some precautions must be taken to prevent undesired outcomes. In order to protect the cables from lightning 
discharges, they may be laid down into a metallic channel. This metallic cable channel will distribute the lightning current. By doing so, breakdowns and thermal damages can be prevented. Metallic channel also act as a Faraday cage. Therefore, induced voltage will be reduced. Application examples can be seen from Figure 4-1.
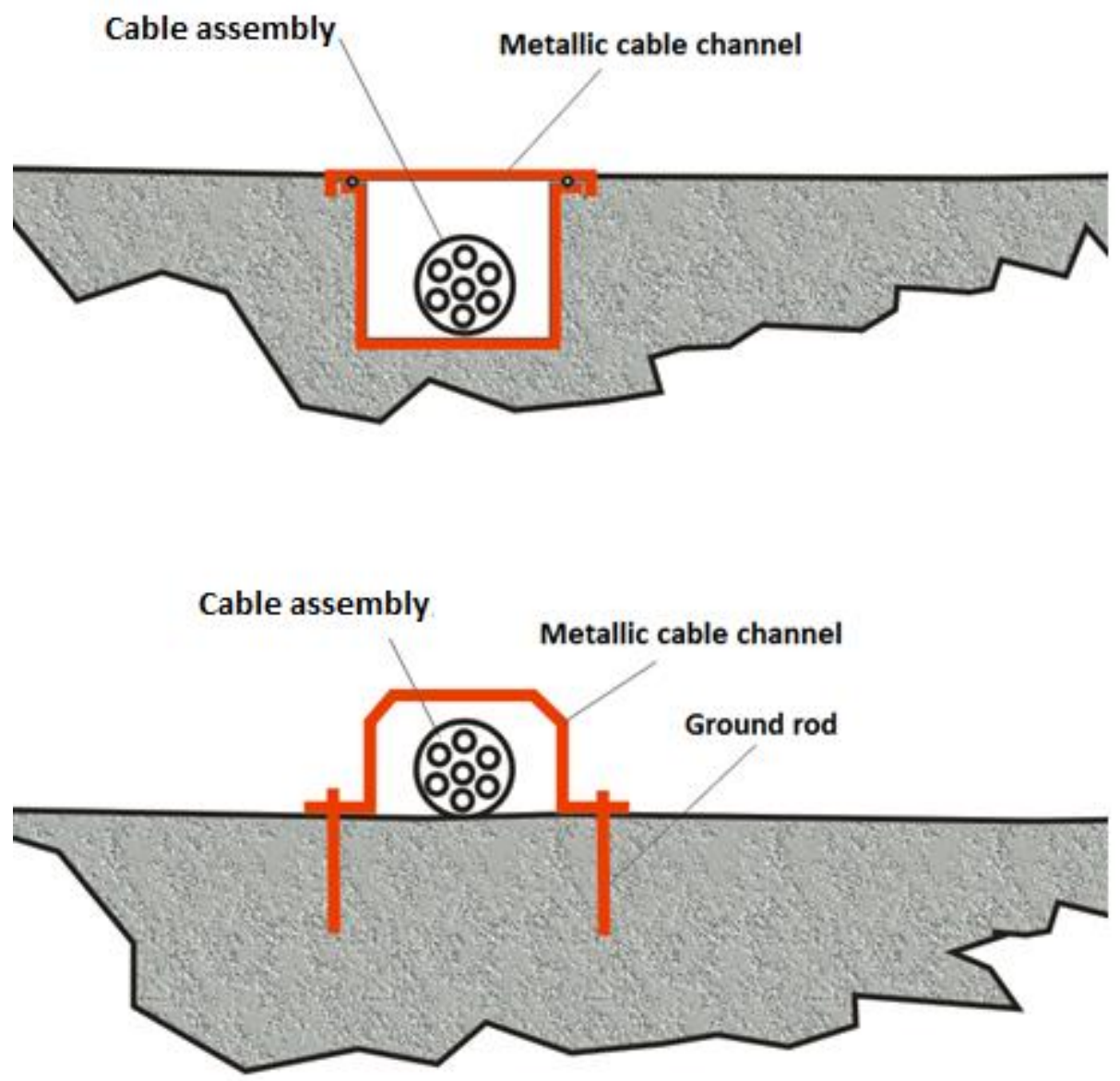

Figure 4-1 Lightning protection examples for control and communication cables

In order to protect the antennas from lightning discharges, power zener diodes can be connected between the ground and the signal end of the antenna. Zener diodes are fast enough to clip off the induced voltages due to lightning on antennas. This is discussed in detail in 3.3. Another precaution may be to shorten the antennas when they are not actively used. Antennas attract lightning less by this way.

To conclude, lightning is a natural phenomenon that happens frequently. Therefore, its effects on control \& communication cables and antennas are worth investigating. In this thesis, these effects are studied in various ways. Computer simulations are made; some experiments are designed and conducted throughout the thesis. In 
addition, academic researches are scanned and compared to simulations and experimental results. After all of these works, it is deduced that direct or indirect lightning hits induce high voltages on control \& communication cables and antennas. These induced voltages are dangerous for systems that the cables or antennas are connected to. Therefore, some precautions are necessary. 


\section{REFERENCES}

[1] Oliver, John E. (2005). Encyclopedia of World Climatology. National Oceanic and Atmospheric Administration.

[2] What causes lightning flash. [Online]. Available:

http://www.nasa.gov/audience/forstudents/k-

4/home/F_What_Causes_Lightning_Flash.html (last accessed on 5 May 2014)

[3] M. A. Uman (1987) The Lightning Discharge. Academic Press, London.

[4] Wilson, G.L. ; Zarakas, P. (1978, February). Anatomy of a blackout: How's and why's the series of events that led to the shutdown of New York's power in July 1977. Spectrum, IEEE. 39-49.

[5] Sugarman, R. (1978, November). Power/energy: New York City’s blackout: A $\$ 350$ million drain. Spectrum, IEEE. 44-46.

[6] M. A. Uman, "A Review of Natural Lightning: Experimental Data and Modeling” IEEE Transactions on Electromagnetic Compatibility, vol. EMC-24, May 1982.

[7] Graf, Rudolf F. (1999) Modern Dictionary of Electronics. Newnes. p. 29.

[8] V.A. Rakov, A. Borghetti, C. Bouquegneau, W.A. Chisholm, V. Cooray, K. Cummins, G. Diendorfer, F. Heidler, A. Hussein, M. Ishii, C.A. Nucci, A. Piantini, O. Pinto, Jr., X. Qie, F. Rachidi, M.M.F. Saba, T. Shindo, W. Schulz, R. Thottappillil, S. Visacro, W. Zischank (2013) CIGRE Technical Brochure on Lightning Parameters for Engineering Applications. P. 2.

[9] B. Franklin, Experiments and Observations on Electricity Made at Philadelphia. London, Great Britain: E. Cave, 1774. 
[10] C. T. R. Wilson, "On some determinations of the sign and magnitude of electric discharges in lightning flashes," Proc. Roy. Soc., vol. A92, pp. 555-574, 1916.

[11] C. T. R. Wilson, "Investigations on lightning discharges and on the electric field of thunderstorms,” Phil. Trans. R. Soc., vol. A221, p. 73, 1920.

[12] M. A. Uman, "Natural Lightning” IEEE Transactions on Industry Applications, vol. 30, no. 3, May/June 1994.

[13] Hizal, M. (2012). Electrostatic Field At Earth As A Function of Leader Stroke Charge [Class Handout]. Department of Electrical and Electronics Engineering, METU, Ankara, Turkey.

[14] Hizal, M. (2012). Mechanism of lightning discharge [Class Handout]. Department of Electrical and Electronics Engineering, METU, Ankara, Turkey.

[15] Standards define impulse tests, mostly. [Online]. Available:

http://www.edn.com/design/test-and-measurement/4389367/Standards-define-testimpulses-mostly (last accessed on 1 November 2014)

[16] F. Napolitano, "An analytical formulation of the electromagnetic field generated by lightning return strokes" IEEE Trans. Electromagn. Compat., vol. 53, no. 1, pp. 108-113, 2011.

[17] M. Rubinstein and M. A. Uman, "Methods for calculating the electromagnetic fields from a known source distribution: Application to lightning," IEEE Trans. Electromagn. Compat., vol. 31, no. 2, pp. 183-189, May 1989.

[18] B. J. Mason, "Mechanism of the lightning flash" in Electronics and Power, vol. 12, IET, May1966, pp. 147-151.

[19] High-voltage test techniques - Part 1: General definitions and test requirements, IEC 60060-1, 1989.

[20] High-voltage test techniques - Part 4: Application guides for measuring devices, IEC 60060-4, 1977. 
[21] Electromagnetic environmental effects requirements for systems, MIL-STD464C, 2010.

[22] B. Daout, "Electric and magnetic field sensor and integrator equations," Montena Technology, Rossens, Switzerland, Tech. Note.

[23] Electromagnetic Free Field Sensors. [Online]. Available:

http://www.montena.com/system/pulse-measurement/field-sensors/ (last accessed on 3 November 2014) 


\section{Electromagnetic Free Field Sensors}

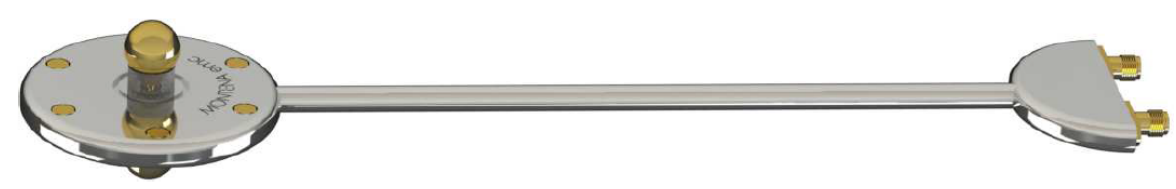

Our range of derivative electromagnetic free field sensors is designed for the measurement of fast pulsed fields. Different models are available: for electric field (D-dot), for magnetic fields (Bdot). Because the sensors are passive, no external or internal power source is required. Baluns and passive integrators are proposed as accessories. Free field sensors might be connected through a fibre optic link to the measurement equipment.

\section{SPECIFICATIONS}

Sensors:

\begin{tabular}{|c|c|c|c|c|c|}
\hline Reference & SFE1G & SFE3-5G & SFE10G & SFM2G & SFM8-5G \\
\hline Type & $\begin{array}{l}\text { D-Dot } \\
\text { (electric) }\end{array}$ & $\begin{array}{l}\text { D-Dot } \\
\text { (electric) }\end{array}$ & $\begin{array}{l}\text { D-Dot } \\
\text { (electric) }\end{array}$ & $\begin{array}{l}\text { B-Dot } \\
\text { (magnetic) }\end{array}$ & $\begin{array}{l}\text { B-Dot } \\
\text { (magnetic) }\end{array}$ \\
\hline Total equ. area $A_{\text {eq,tot }}$ & $2 \times 10^{-2} \mathrm{~m}^{2}$ & $2 \times 10^{-3} \mathrm{~m}^{2}$ & $2 \times 10^{-4} \mathrm{~m}^{2}$ & $2.65 \times 10^{-4} \mathrm{~m}^{2}$ & $1.8 \times 10^{-5} \mathrm{~m}^{2}$ \\
\hline $\begin{array}{l}\text { Frequency response } \\
(-3 \mathrm{~dB})\end{array}$ & $1 \mathrm{GHz}$ & $3.5 \mathrm{GHz}$ & $10 \mathrm{GHz}$ & $2 \mathrm{GHz}$ & $8.5 \mathrm{GHz}$ \\
\hline Risetime (10 - $90 \%)$ & 320 ps & $110 \mathrm{ps}$ & $32 \mathrm{ps}$ & $160 \mathrm{ps}$ & $41 \mathrm{ps}$ \\
\hline Peak max. output & $1 \mathrm{kV}$ & $1 \mathrm{kV}$ & $1 \mathrm{kV}$ & $1 \mathrm{kV}$ & $500 \mathrm{~V}$ \\
\hline Connector type & $\mathrm{SMA}(\mathrm{m})$ & $\mathrm{SMA}(\mathrm{m})$ & $\mathrm{SMA}(\mathrm{m})$ & $\mathrm{SMA}(\mathrm{m})$ & SMA (m) \\
\hline Weight & $800 \mathrm{~g}$ & $350 \mathrm{~g}$ & $200 \mathrm{~g}$ & $375 \mathrm{~g}$ & $150 \mathrm{~g}$ \\
\hline $\begin{array}{l}\text { Dimensions } \\
(L \times W \times H) \text { in } c m\end{array}$ & $40 \times 6 \times 10$ & $40 \times 6 \times 3.5$ & $40 \times 6 \times 1.8$ & $40 \times 6 \times 4$ & $40 \times 0.6 \times 0.5$ \\
\hline Recommended balun & BL3-5G & BL3-5G & BL10G & BL3-5G & BL10G \\
\hline
\end{tabular}


APPENDIX B

\section{CABLE ASSEMBLY DATASHEET}

Manufacturer

Manufacturer's specification

Manufacturer's type number

Description

Outer diameter

Jacket material
: TYCO-RAYCHEM USA

: Specification sheet of Raychem Engineering Product Design, EPD-RWC-17787 dated 6/5/02, 2 pages, and Electronics Product Catalogue 7/97.

\section{: EPD-RWC-17787}

: Overall shielded and jacketed cable with 8 shielded twisted pair (AWG24), 5 twisted pair (AWG24), 3 primary wires (AWG24), 1 FIL-40-0.055

: $\varnothing 13.82 \pm 0.69 \mathrm{~mm}$

: FDR25
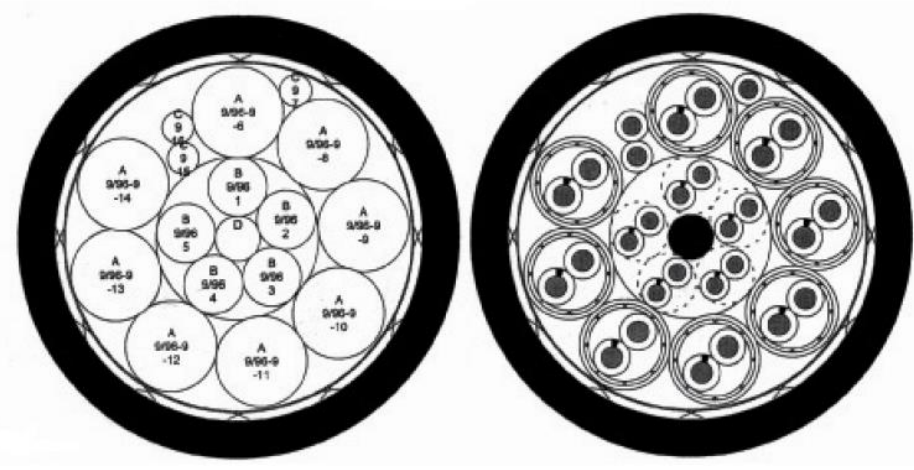